NASACONTRACTOR REPORT

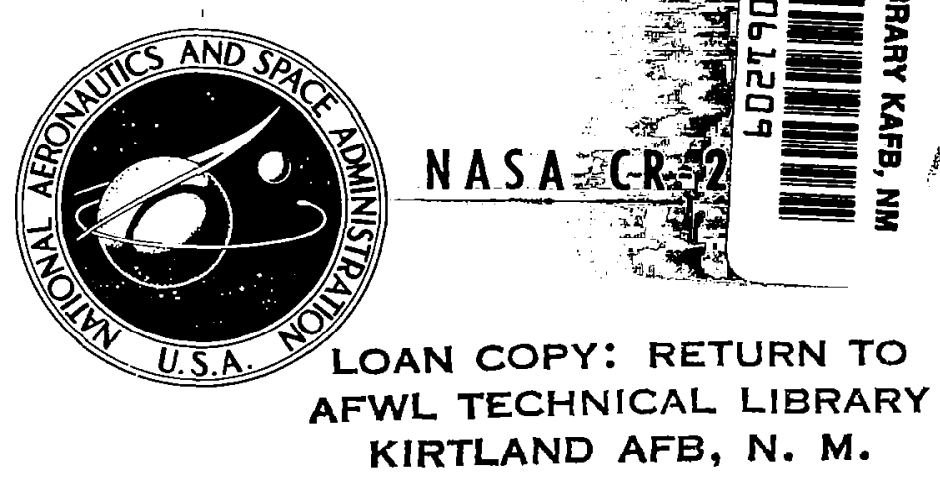

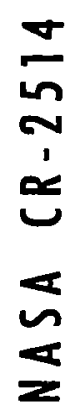

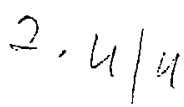

AFWL TECHNICAL LIBRARY KIRTLAND AFB, N. M.

\title{
ADVANCED BEADED AND TUBULAR STRUCTURAL PANELS
}

Max D. Musgrove and Bruce E. Greene

Prepared by

IHE BOEING COMPANYY

Seattle W Wash.

for Langley Research Center

NATIONAL AERONAUTICS AND SPACE ADMINISTRATION - WASHINGTON, D. C. - SEPfEMBER 7975 


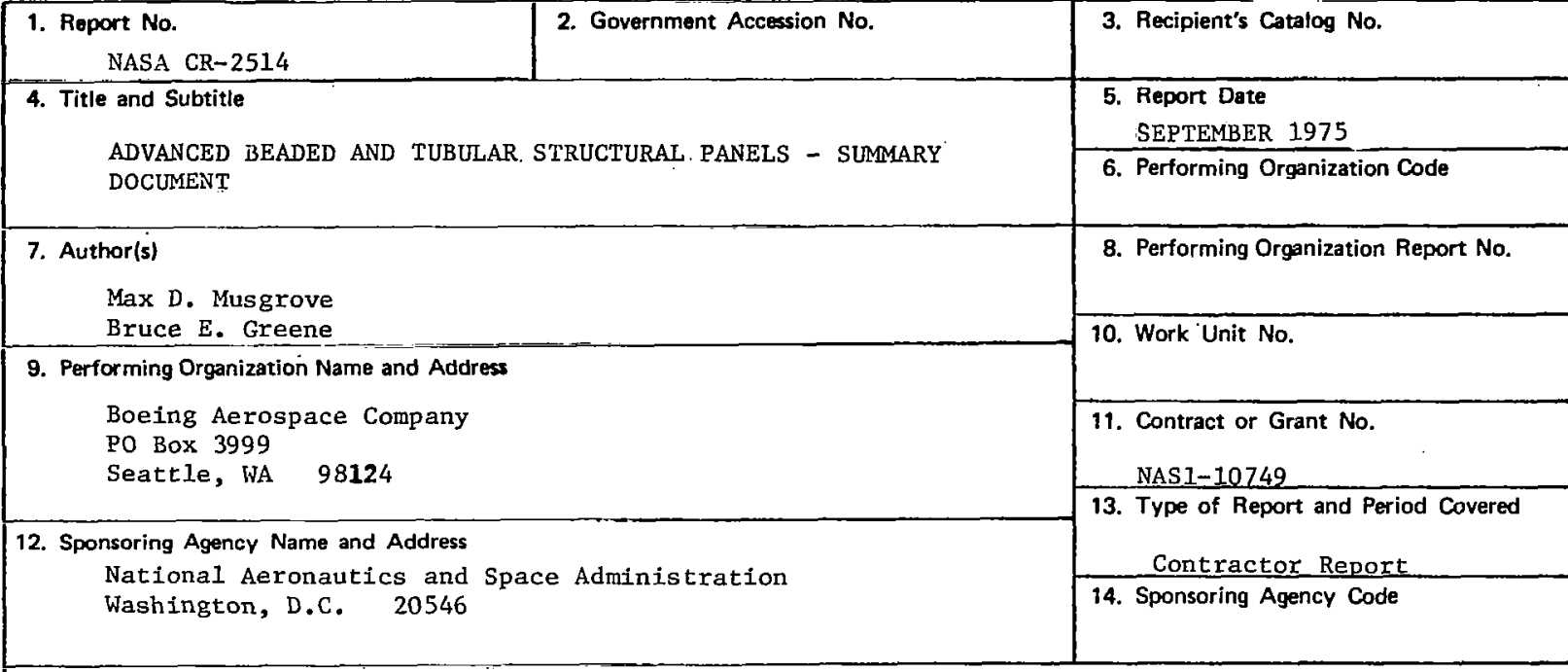

\section{Supplementary Notes}

FINAL REPORT

16. Abstract

A NASA program to develop 1ightweight beaded and tubular structural panels is described. Applications include external surfaces, where aerodynamically acceptable, and primary structure protected by heat shields. The design configurations were optimized and selected with a computer code which iterates geometric parameters to satisfy strength, stability and weight constraints. Methods of fabricating these new configurations are discussed. Nondestructive testing produced extensive combined compression, shear and bending test data on local buckling specimens and large panels. The optimized design concepts offer 25 to $30 \%$ weight savings compared to conventional stiffened sheet construction.

17. Key Words (Suggested by Author(s))

Tubular panels Stiffened panels Orthotropic

Minimum weight Plasticity
Combined loads Brake-forming Buckling Nondestructive testing Moire grid
18. Distribution Statement

Unclassified - unlimited
19. Security Classif. (of this report)
20. Security Classif. (of this page)
Unclassified
Unclassified
21. No. of Pages
101
22. Price*
$\$ 5.25$ 

This report was prepared by the Boeing Aerospace Company, a division of The Boeing Company, Seattle, Washington, for the Langley Research Center of the National Aeronautics and Space Administration. The strength analysis, design, fabrication and testing of advanced beaded and tubular structural panel test specimens are presented. The work is part of a comprehensive program to develop advanced beaded and tubular structural panel designs and static strength prediction methods under contract NAS1-10749, "Design and Testing of Advanced Structural Panels".

The primary investigator was Bruce E. Greene and the technical leader was Max D. Musgrove, reporting to the program manager, John L. Arnquist, Chief of the Structural Allowable and Military Structures organization.

Manufacturing activities in support of this program were under the direction of Russell Northrop. Testing was under the direction of Philip Hedges. Burke Dykes provided the grid shadow moire support.

This report was prepared by Max. D. Musgrove and Bruce E. Greene.

The art work and drafts for this report were prepared by Gary Jensen . 

SUMMARY . . . . . . . . . . . . . . . . . . . . . 1

INTRODUCTION. • . . . . . . . . . . . . . . . . . . 2

SYMBOLS . . . . . . . . . . . . . . . . . . . . 3

PROBLEM STATEMENT •. . . . . . . . . . . . . . . . 6

CONFIGURATION OPTIMIZATION. . . . . . . . . . . . . . . . 8

General Instability. . . . . . . . . . . . . . . . 8

Local Instability. . . . . . . . . . . . . . . . . 11

Material Yield . . . . . . . . . . . . . . . . . 11

OPTRAN Code. . . . . . . . . . . . . . . . . . . . 11

FABRICATION DEVELOPMENT • . . . . . . . . . . . . . . . 13

Uniform Section Brake Forming. . . . . . . . . . . . . 13

End Closure Forming. . . . . . . . . . . . . . . . . 13

High Energy Rate Reforming . . . . . . . . . . . . . . 13

Panel Assembly and Machining . . . . . . . . . . . . . 16

DESIGN EVOLUTION. • . . . . . . . . . . . . . . . . . 18

Screening Test Specimens . . . . . . . . . . . . . . . 18

End Closure Evolution. . . . . . . . . . . . . . . 18

Panels . . . . . . . . . . . . . . . . . 26

TEST SPECIMENS. . . . . . . . . . . . . . . . . . 33

Local Buckling Test Specimens. . . . . . . . . . . . 33

Panel Test Specimens. . . . . . . . . . . . . . . . 33

INSTRUMENTATION . . . . . . . . . . . . . . . . . . . 37

Strain Gages . . . . . . . . . . . . . . . . . . 37

Grid Shadow Moire. . . . . . . . . . . . . . . 37

TEST TECHNIQUE. . . . . . . . . . . . . . . . . . . . . 40

Force/Stiffness Nondestructive Test Technique. . . . . . . . 40

Test Procedure . . . . . . . . . . . . . . . . . 43 
CONTENTS (Continued)

TEST RESULTS. . . . . . . . . . . . . . . . . . . 47

Circular Tube Specimen Results . . . . . . . . . . 47

Fluted Single Sheet Specimen Results . . . . . . . . . . 55

Low Load Fluted Tube Specimen Results. . . . . . . . . . 65

High Load Fluted Tube Panels . . . . . . . . . . . . 74

FAILURE CRITERIA AND DESIGN DATA. . . . . . . . . . . . . . 83

CONCLUDING REMARKS. . . . . . . . . . . . . . . . . . 85

APPENDIX. . . . . . . . . . . . . . . . . . . . . 86

REFERENCES. . . . . . . . . . . . . . . . . . . . . 90 


\section{LIST OF FIGURES}

Compression Panel Mass vs. End Load . . . . . . . . . 7

Preliminary Mass Comparison of Beaded and Tubular Panel

Configurations. . . . . . . . . . . . . . . . 9

Optimized Developmental Configurations. . . . . . . 10

Typical Variable Geometric Parameters . . . . . . . 12

Brake Forming in Standard Brake Machine . . . . . . . 14

Uniform Section Brake Forming - Die Open. . . . . . . . . 14

Uniform Section Brake Forming - Die Closed. . . . . . . 14

Formed Uniform Section with Increased Bend Radius Near

Ends. . . . . . . . . . . . . . . . 15

Reforming Secondary Bead in Panel End . . . . . . . 15

Reforming Bead End Closure in Panel End . . . . . . . 15

11 Circular Tube Panel Being Prepared For Bonding. . . . .

Circular Tube Panel With Bondilig Fixture. . . . . . 17

Circular Tube Buffer Bay Panel With Prepared Edges. . . 17

First End Closure Configuration . . . . . . . . . 20

First Beaded Specimen with Curved Elements. . . . . . 20

First Tube Specimen . . . . . . . . . . . . 20

Failed End Closure Axial Compression Test Specimen. . . 20 


\section{LIST OF FIGURES (Con't )}

No.

Title

Page

Single Sheet End Closure Shear Test Specimen. . . . .

24 Moire Photograph of Single Sheet End Closure Loaded in Shear . . . . . . . . . . . . . . . . . .

Moire Photograph of Stiffened Single Sheet End Closure

Loaded in Shear.................... 22

Single Sheet End Closure Development Specimen . . . .

Single Sheet End Closure Development Specimen . . . .

Single Sheet End Closure Shear Test Specimen. . . . .

Moire Photograph of Single Sheet End Closure Loaded in

Fluted Single Sheet End Attachment Shear Test Specimen. •

Moire Photograph of Circular Tube End Closure After Shear Load Induced Bond Failure . . . . . . . . . . . .

Circular Tube After Shear Load Induced Failure. . . .

Tubular Specimen Failed in Shear. . . . . . . . .

Final Circular Tube End Closure . . . . . . . . .

Alternate Circular Tube End Closure . . . . . . .

Intermediate Stage $2 \mathrm{~A}-2$ End Closure Showing Forming

Final Fluted Tube End Closure . . . . . . . . . .

End Closure Specimen Failed in Combined Axial Compression and Shear . . . . . . . . . . . . . . . . .

Failed Low Load Fluted Tube Compression Specimen. . . • 
Pane1 2A-2-P-2M Inserts . . . . . . . . . 32

Fluted Single Sheet Local Buckling Test Specimen. . . . 34

Test Pane1 2A-2-P-2M. ............. 34

Strain Gage Installation-Panel No. 2-2-P-1. . . . . 38

Schematic of Panel and Grid-Shadow Moire Coverage . . . 39

Panel Test Fixture. . . . . . . . . . .

Panel Test Fixture Showing Pressure Bag and Lateral

Support .................. 42

Force/Stiffness Plot for General Instability. . . . . 44

Falled Pane1 2-2-P-1.............. 54

Failed Panel 2-2-P-2. ........... 54

Falled Edge of Panel 2-2-P-3............ 54

Local Buckling Test/Analysis Correlation -

Panel Type 1A ............... 58

Force/Stiffness Nondestructive Testing of 1A-2-U-5

Specimen. . . . . . . . . . . . . .

Theoretical Failure Load Interaction Surface Showing Correlation With Test Data - Panel Type 1A. 


\section{LIST OF FIGURES (Con't)}

No.

Title

$\underline{\text { Page }}$

64

Pane1 1A-1-P-2 Loaded to $89 \%$ of Design Load . . . . .

63

65

Pane1 1A-1-P-2 Failed at $89 \%$ of Design Load . . . . .

64

66

Local Buckling Test/Analysis Correlation -

Pane1 Type 2A-1

Panel 2A-1-P-1 at $60 \% \mathrm{~N}_{\mathrm{XY}} \cdot$. . . . . . . . .

68

Theoretical Failure Load Interaction Surface Showing

Correlation With Test Data - Panel Type 2A-1. . . . .

69

Pane1 2A-1-P-1M at $60 \% \mathrm{~N}_{\mathrm{XY}}$. . . . . . . . . . . 72

70

Pane1 2A-1-P-1 at 1 psi and $50 \%$ of $\mathrm{N}_{\mathrm{X}}$ and $\mathrm{N}_{\mathrm{XY}} \cdot$. . . . 73

71

Pane1 2A-1-P-1M at 1 psi and $50 \%$ of $\mathrm{N}_{\mathrm{X}}$ and $\mathrm{N}_{\mathrm{XY}} \cdot \boldsymbol{C} \cdot$.

Loca1 Buckling Test/Analysis Correlation -

Pane1 Type 2A-2

Pane1 2A-2-P-2M at $88 \%$

$\mathrm{N}_{\mathrm{XY}}$

80

74

Panel 2A-2-P-2M Failed

at $92 \%$

$\mathrm{N}_{\mathrm{XY}}$

80

75

Modified Theoretical Failure Load Interaction Surface Showing Correlation With Test Data - Panel 2A-2-P-3M. . 


\section{LIST OF TABLES}

No.

Title

$\underline{\text { Page }}$

Mass of 40 Inch $\times 40$ Inch $(1 \mathrm{~m} \times 1 \mathrm{~m})$ Panels. . . . . . . 36

2(a) Test Load Conditions for Design Load Condition

2(b) Test Load Conditions for Design Load Condition

2 Panels. . . . . . . . . . . . . . . . 45

3 Circular Tube Local Buckling Test Data Summary. . . . . 48

4 Circular Tube Panel Test Data Summary (F/S Data). . . . 52

$5 \quad$ Fluted Single Sheet Local Buckling Test Results . . . . 57

6 Fluted Single Sheet Panel Test Results Summary

(F/S Data Except Where Noted) . . . . . . . . 61

7 Correlation of Local Buckling Test Results With AnalysisPanel Type 2A-1 . . . . . . . . . . . . . . . 66

8 Low Load Fluted Tube Pane1 Test Results Summary

(F/S Data). . . . . . . . . . . . . . . 70

9 Correlation of Local Buckling Test Results With AnalysisPane1 Type 2A-2.................... 75

High Load Fluted Tube Panel Test Results Summary. . . . 78 


\title{
ADVANCED BEADED AND \\ TUBULAR STRUCTURAL PANELS \\ By Max D. Musgrove and Bruce E. Greene \\ The Boeing Company \\ Research and Engineering Division
}

\author{
SUMMARY
}

A study was conducted to exploit the efficiency of curved elements in the design of lightweight structural panels under combined loads of axial compression, inplane shear, and bending. Governing geometric constraint equations were incorporated in a random search type optimization computer program to identify minimum mass designs for several potentially efficient concepts. Buckling tests were conducted on subscale panels to identify local failure modes and provide for modification of local buckling theory where required. Full scale 40 × 40 inch ( 1 × 1 meter) panels were tested under combined loading to obtain failure data for correlation with theory. Modifications to faflure theory were made as required. A nondestructive force-stiffness test technique was used in conjunction with a Moire' grid monitoring technique to provide extensive test data from a comparatively few test panels.

Test data produced under combined loading on local buckling specimens and on large panels of a circular tube configuration show excellent agreement with theory and show 25 to 30 percent mass reduction over optimized stringerstiffened panels. The consistent structural performance of the circular tube panel has indicated a level of confidence which warrants the use of this concept in the design load range investigated.

A fluted single sheet beaded panel concept offers a highly efficient design in the very low load range although significant out of plane deflections occur in the end closures when the panel is loaded in shear. It appears that these out of plane deflections can be avoided by an attachment method which does not reduce the panel cross section shape to a flat sheet at the panel ends.

Tests of fluted panels revealed unanticipated tube flattening under bending load and tube distortions under shear. As a result, the panels demonstrated lower strengths than those predicted from local buckling tests. The use of internal stiffening appeared to control tube flattening and raised panel strengths significantly, but at a loss in mass efficiency. However, large deformations which were not completely suppressed prevented reliable correlation of test data with theory.

Because of the potential mass savings demonstrated in this program, application of the tubular panel concept should result in increased structural efficiency in many types of future aerospace structures such as advance space vehicles, missile interstages, and high speed cruise vehicles. 


\section{INTRODUCTION}

For several years the Langley Research Center has been investigating structural concepts which use elements with curved cross sections to develop beaded or corrugated skin panel structure as indicated in Reference 1 through 6 . The curved sections exhibit high local buckling strengths which lead to highly efficient structural concepts. These concepts can be applied where a lightly beaded external surface is aerodynamically acceptable or where the primary structure is protected by heat shields. The corrugated nature of the panels makes them especially attractive for high temperature applications because controlled thermal growth is permitted which minimizes thermal stress. The technology resulting from this program is applicable to various formable materials and to many product areas such as launch vehicles, space vehicles and hypersonic aircraft.

A study was conducted to develop lightweight structural panels designed for combined loads of axial compression, inplane shear, and bending due to lateral pressure. Governing analytical static strength and stability equations for panels under combined load, and material and geometric constraint equations were incorporated in a random search type optimization computer program described in Reference 7 to identify minimum mass designs for several potentially efficient concepts. However in order for these concepts to realize their analytical potential, all of the significant fallure modes had to be properly recognized and accounted for. Consequently, a major fabrication and test development effort was conducted. Buckling tests were made on sub-scale panels to identify local failure modes and provide for modification of local buckling theory where required. Ful1 scale 40 × 40 inch ( 1 x 1 meter) panels were tested under combined loading to obtain large panel failure data for correlation with theory. A nondestructive force-stiffness test technique described in Reference 8, was used in conjunction with the Moire grid monitoring technique to provide extensive test data including identification of buckling modes from a comparatively few panels.

The fabrication effort was directed toward the development of new fabrication concepts and techniques to provide maximum versatility in terms of ayailable bead configuration while providing improved configuration tolerance control and minimizing fabrication costs.

This document presents a summary of the structural panel development program including $40 \times 40$ inch ( 1 x 1 meter) panel test results, correlation with theory and an improved design and strength prediction method substantiated by these tests. Details of the design, fabrication and test efforts are presented in References 9, 10 , and 11 respectively, which are substantiating data documents for the advanced structural panel program. 


\section{SYMBOLS}

AFH

a

B

b

BBW

BFW

c

C.F.

D

$\mathrm{D}_{\mathrm{cr}}$

$\mathrm{D}_{\mathrm{O}}$

$\mathrm{D}_{1}, \mathrm{D}_{2}, \mathrm{D}_{3}$

$\mathrm{D}_{1}^{\prime}, \mathrm{D}_{2}^{\prime}, \mathrm{D}_{3}^{\prime}$

d

E

$\mathrm{E}_{\mathrm{A}}$

e

F

$F_{B}, F_{C}, F_{S}$

$F_{c b}, F_{c c}, F_{c s}$

$F_{\text {cr }}$

F

$F_{f c}, F_{f s}$ depth of bead flute

length of panel element

width of panel

width of panel element; bead spacing

width of bead

width of bead flute

height of bead above neutral axis plane

correlation factor

generalized displacement or strain

limiting strain value

initial imperfection

orthotropic plate stiffness coefficients in panel

stability equations

orthotropic plate stiffness coefficients in diagonal

buckling equations

diagonal width

modulus of elasticity

elastic modulus of aluminum

Moiré grid line spacing

generalized force

bending, compression, shear stresses at failure

bending, compression, shear local buckling critical

stresses for circular arc elements

critical stress

compression yield stress

compression, shear local buckling critical stresses

of flat elements 
SYMBOLS (Continued)

FW

f

$f_{b}, f_{c}, f_{s}$

$f_{1}$

G

$k, k_{s}$

L

$\mathbf{M}_{\mathbf{X}}$

$\mathbf{N}_{\mathbf{x}}$

$\mathrm{N}_{\mathrm{xcr}}$

N xder

$\mathrm{N}_{\text {xy }}$

$N_{\text {xycr }}$

N xyder

$\mathrm{P}, \mathrm{p}$

Q

R

$R_{b}, R_{c}, R_{s}$

SH

$\mathbf{S}$

s.

s d

$\mathrm{T}, \mathrm{t}$

$\bar{t}$

$\mathrm{y}_{\mathrm{o}}$

Z

width of flat

width of flat

bending, compression, shear stresses

stress intensity, octrahedral shear theory

shear modulus

buckling coefficients

length of panel

panel center bending moment per unit width

panel axial compression load per unit width

critical axial compression load for panel instability

critical axial compression load for diagonal buckling

panel shear load per unit width

critical shear load for panel instability

critical shear load for diagonal buckling

pressure load, lateral pressure

statical moment of one bead about panel mid plane axis radius

stress ratios of actual stress to critical stress for bending, compression, shear

stiffener (bead) height

developed length of panel cross section associated with

bead spacing width, $b$

arc length of circular arc element of panel cross

section

developed length of panel cross section associated

with diagonal width, d

thickness

equivalent extensional thickness

panel center deflection produced by pressure load only

panel curvature parameter in local shear buckling

analysis 


\section{SYMBOLS (Continued)}

$\alpha$

$\delta$

$n, n_{1}, n_{2}$, etc. $\theta$

v bead semi-arc angle

lateral deflection

plasticity correction factors

light source incidence angle in grid shadow Moiré method; angle defining diagonal width, d

Poisson's ratio 


\section{PROBLEM STATEMENT}

Many recent high performance vehicle designs, such as the space shuttle orbiter, employ large, thick, low aspect ratio wings which are lightly loaded. Figure 1, which shows optimum panel unit mass as a function of compressive load (Reference 4) indicates that lightly loaded tubular panels are 25 to 30 percent lighter than conventional stiffened panels.

Plans to exploit the potential of curved elements by the use of beaded and tubular panels included the following major steps: (1) identification of optimum design shapes for single sheet and double sheet panels recognizing manufacturing limits and available analytical data; (2) development of fabrication techniques to provide the maximum versatility in bead geometry and geometry contro1; (3) fabrication and test of specimens to determine local failure loads and correlation results with the theory; (4) fabrication and test of panel specimens to define the failure interaction surfaces due to combined loads; and (5) modification of the design and analysis equations to reflect the observed test result.

It was necessary to select a structural material, a panel size and specific load combinations for use in comparing the different panel configurations. The 7075-T6 aluminum was selected to provide a high proportional limit and ease of fabrication. The high proportional limit is desirable for developmental testing as described in Reference 12, otherwise test failures occur well into the inelastic range and specimen stability characteristics are obscured by material behavior. A panel size of $40 \times 40$ inches ( 1 x 1 meter) with the beads terminated at the supports and two specific design loading conditions were selected as typical of advanced space shuttle orbiter wing designs.

The selected loading conditions were: (1) $600 \mathrm{lb} / \mathrm{in}$. (105 kN/m) axial compression, $200 \mathrm{lb} / \mathrm{in}$. (35 kN/m) inplane shear and $1 \mathrm{psi}\left(6.9 \mathrm{kN} / \mathrm{m}^{2}\right)$ lateral pressure, and (2) $2000 \mathrm{lb} / \mathrm{in}$. ( $350 \mathrm{kN} / \mathrm{m})$ compression, $400 \mathrm{lb} / \mathrm{in} .(70 \mathrm{kN} / \mathrm{m})$ shear and $2 \mathrm{psi}\left(13.8 \mathrm{kN} / \mathrm{m}^{2}\right)$ pressure. These are referred to as design load conditions (1) and (2), respectively.

Special attention was given to the problem of getting loads in and out of the panels, however, joint designs (panel end closures) were not analyzed or optimized in detail. The depth of the end closure development and analysis was sufficient to assure that the validity of the test data would not be jeopardized by premature end closure failures and that the indicated panel structural efficiencies could be realized in actual hardware applications. 


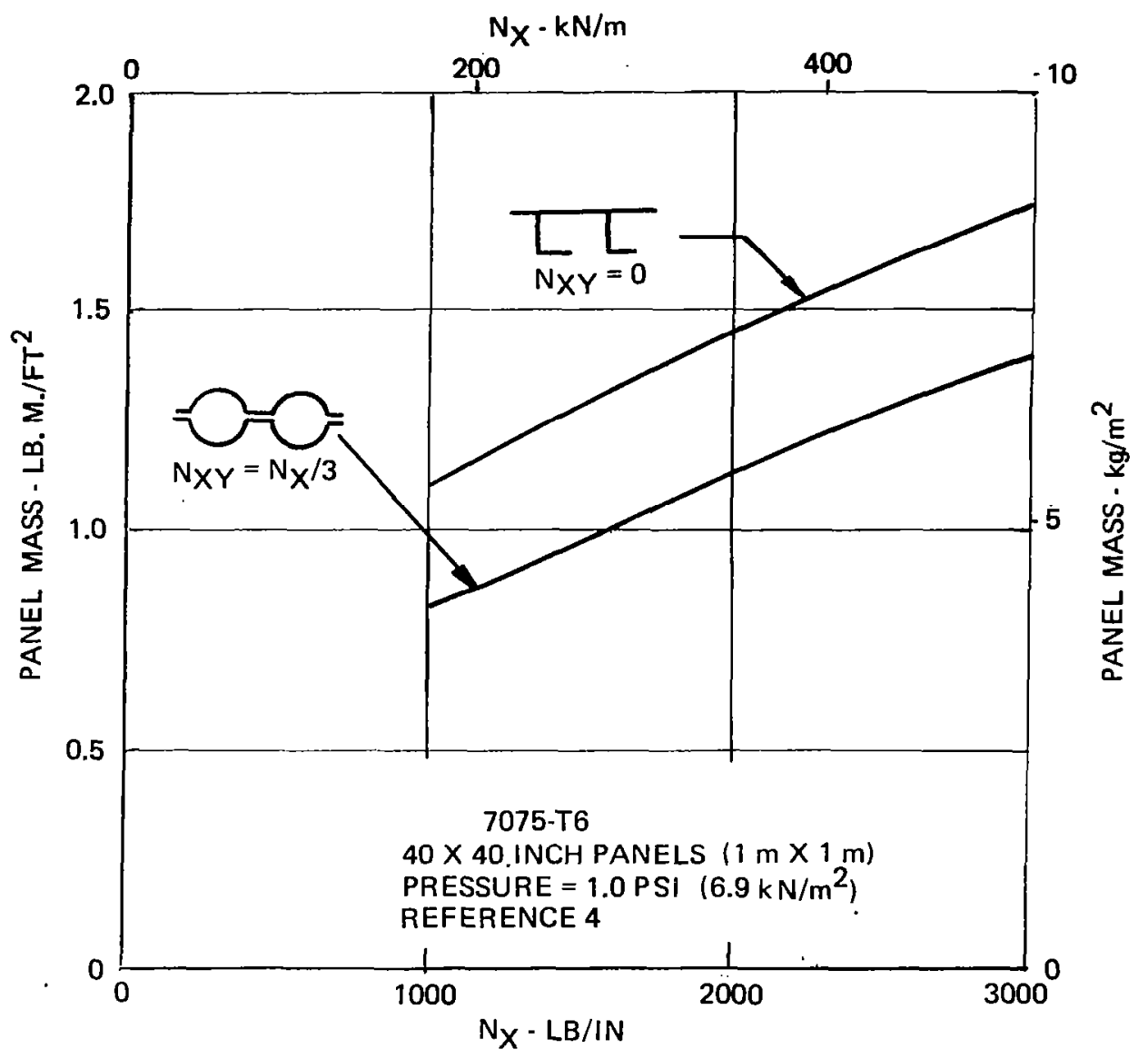

Figure 1: COMPRESSION PANEL MASS VS. END LOAD 


\section{CONFIGURATION OPTIMIZATION}

Static strength and stability analyses are the foundations upon which the panel design optimization is based. To obtain a valid optimum panel design, all possible failure modes had to be recognized and included in the analysis. Three categories of failure modes were considered: (1) general instability; (2) local instabllity; (3) material yield. Only failures involving the uniform section, or central region, of the panel were considered here. Panel end closure, joint and attachment details were assumed adequate to transmit loads necessary to develop full panel strength. The specific equations used in the initial static strength analyses are presented in Reference 9.

The relative mass for a number of design concepts, determined by these equations, are shown in Figure 2 as a function design axial load. The curves represent mass at the center of the panel. The failure analysis that formed the basis for these curves had been verified by initial screening tests of specimens of both of the type 1 and the type 2 configurations. The curves shown in Figure 2 provided the basis for selecting four specific designs for detailed investigation including fabrication and testing.

The basic configurations that were selected for detailed investigation are shown in Figure 3. Note that the first number in the configuration designation indicates the number of sheets of material required to form the cross section and the second number corresponds to the design load condition. In identifying the test specimens a third term was used to indicate the type of test specimen and a fourth term was used to indicate the number of the specimen in the test sequence. The fluted single sheet design (configuration IA-1) was selected as the lightest design concept in the low load range. The circular tubular design (configuration 2-2) was selected because of the confidence gained with respect to fabricability and structural perfomance during the initial screening tests. The high load fluted tube design (configuration $2 \mathrm{~A}-2$ ) was selected as the lightest design at the higher loads as indicated in Figure 2. The low load fluted tube design (configuration 2A-1) was selected to provide a second design of the $2 \mathrm{~A}$ concept to improve the data base for extrapolation to other load conditions. The geometry of the fluted single sheet $(1 \mathrm{~A}-1)$ and the fluted tube (2A-1) corresponds to optimum designs for load condition 1 , and the geometry of configurations (2-2) and (2A-2) correspond to optimum designs for load condition 2 .

\section{Genera1 Instability}

General instability is considered to be buckling in which the significant deflections are of the entire panel without local distortion of the bead cross section. Available classical solutions for rectangular, simply supported, orthotropic plates are used for elastic shear buckling criteria. However, for compression buckling of highly orthotropic panels of the types considered here, the rectangular plate solution degenerates to the wide-column Euler load. 


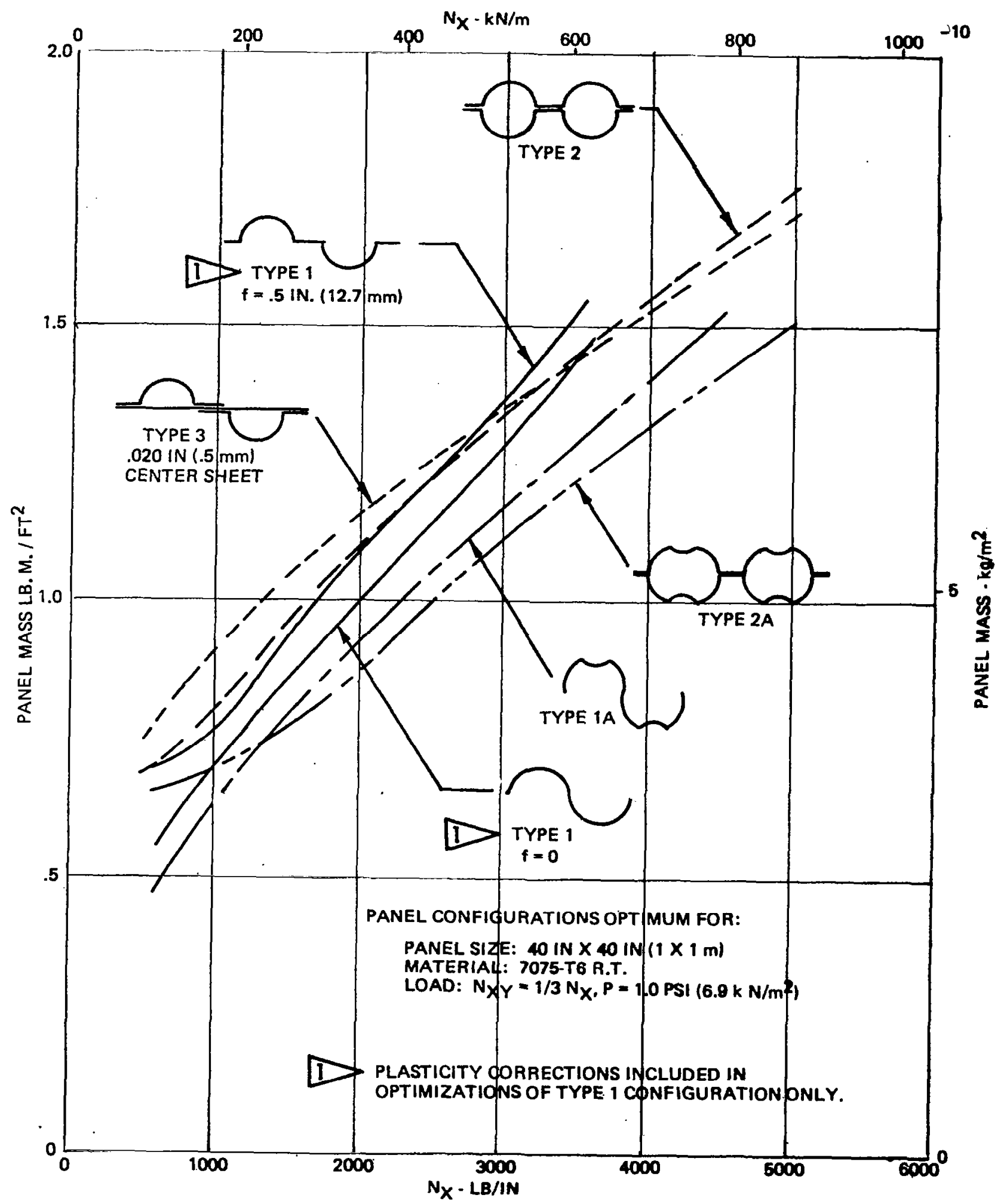

FIgUTE 2: PRELIMINARY MASS COMPARISON OF BEADED AND TUBULAR PANEL CONFYGURATIONS 


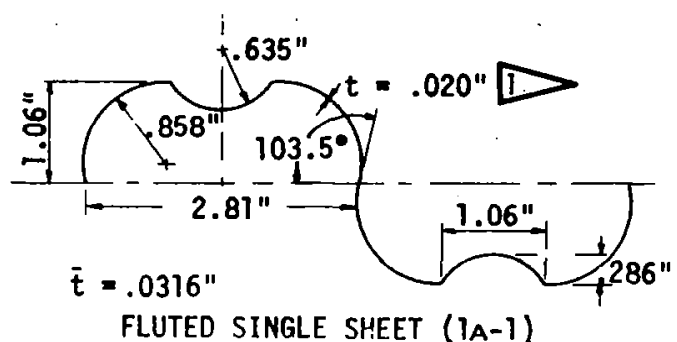

FLUTED SINGLE SHEET (1A-1)

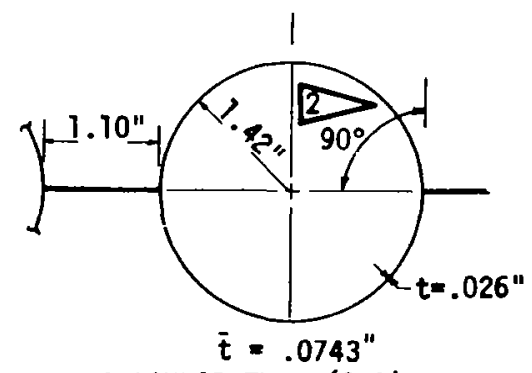

CIRCULAR TUBE $(2-2)$

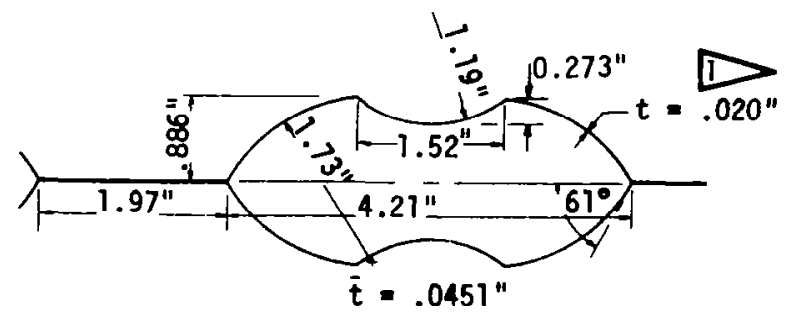

FLUTED TUBE $(2 A-1)$

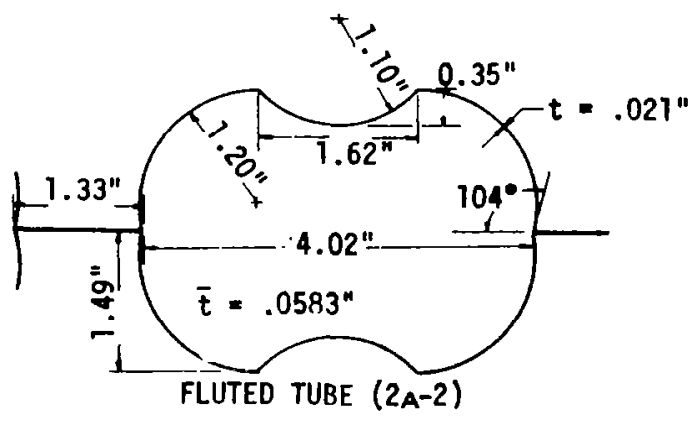

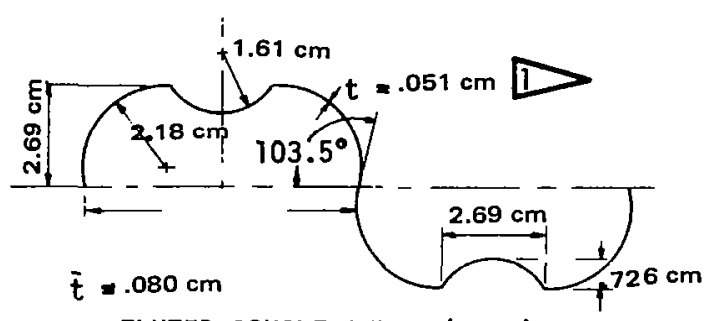

FLUTED SINGLE SHEET (1A-1)

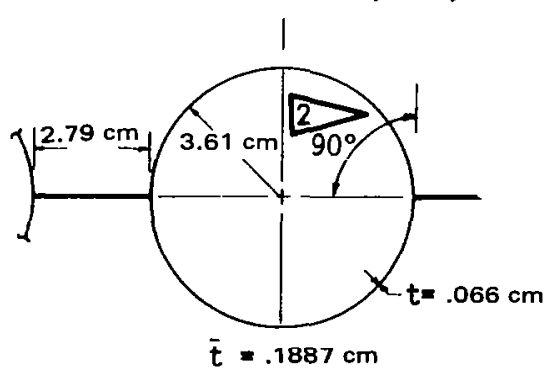

CIRCULAR TUBE $(2-2)$

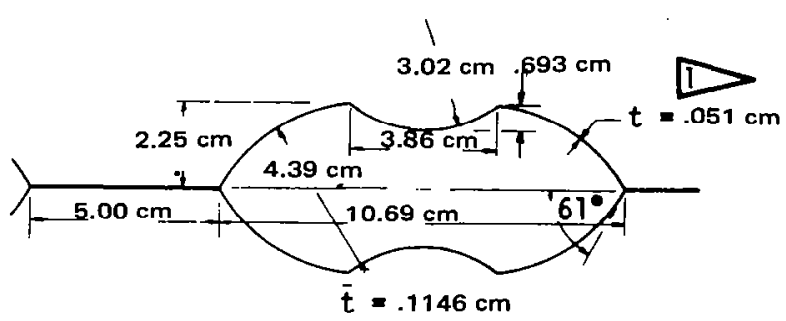

FLUTED TUBE $(2 \mathrm{~A}-1)$

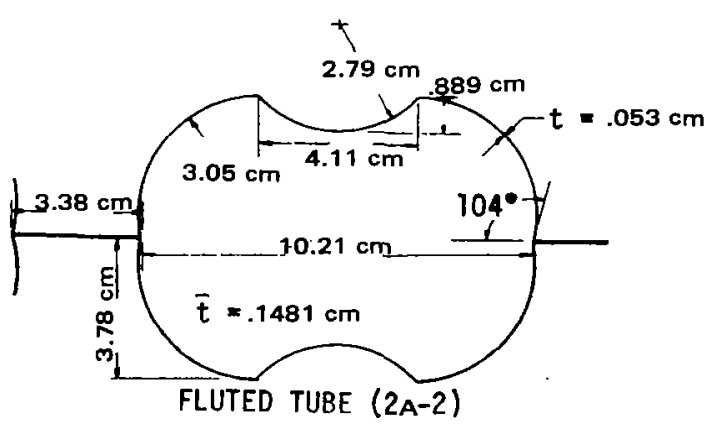

1 Minimum GAGE DESIGN CONSTRAINT

2 BEAD ANGLE CONSTRAINT BASED ON PRELIMINARY STUDIES

Figure 3: OPTIMIZED DEVELOPMENTAL CONFIGURATION 
Because of its simpler form the wide-column analysis was used for compression buckling. General instability under combined loading in compression and shear was determined by the standard interaction equation,

$$
\mathrm{R}_{c}+\mathrm{R}_{\mathrm{s}}^{2}=1
$$

where $R_{c}$ and $R_{S}$ are ratios of applied compression and shear stress to the critical stresses for panel general instability in compression alone and in shear alone, respectively. The lateral pressure is not reflected in the general instability analysis since the bending stresses produced by lateral pressure contribute only to local instability.

\section{Local Instability}

Local instability is defined here as buckling of one or more elements of the panel cross section with buckle deflections primarily involving distortions of the bead cross section rather than the whole panel cross section. Flat elements of the panel cross section were analyzed for local instability in compression and shear as long, simply supported, isotropic plates using classical solutions available in Reference 13. Circular portions of the panel cross section were analyzed for local instability in axial compression and bending using Reference 14, and using Reference 15 for shear. Local instabilities under combined compression, shear and lateral bending loads were determined by interaction equations of the same form used in the general instability analysis but including a bending term as follows,

$$
R_{b}+R_{c}+R_{s}^{2}=1
$$

\section{Material Yield}

Material yield was determined from combined axial compression, bending, and shear stresses at the panel center, using the effective stress intensity according to the Hencky-von Mises yield criterion presented in Reference 16. The stress intensity was also used in determining plasticity correction factors for buckling stresses greater than the proportional limit of the material.

\section{OPTRAN Code}

The various beaded and tubular panel cross sections were optimized using the general design computer code OPTRAN (OPTimization by RANdom search algorithm) described in Reference 7. OPTRAN establishes designs by randomly selecting values of the dimensional parameters within specified search ranges. Minimum gage design constraints are imposed by proper specification of the search ranges. The OPTRAN code makes it possible to investigate effects of various design constraints that would otherwise be quite difficult when large numbers of variables are involved. Figure 4 shows one configuration and the seven variable dimensional parameters which specify the geometry. The number of variables is limited only by computer time. 


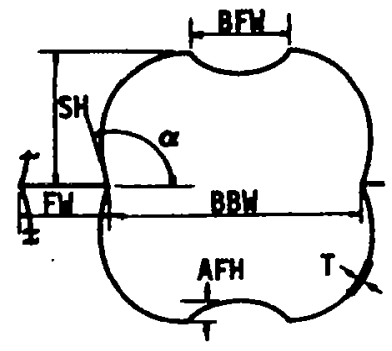

Figure 4 Typical Variable Geometric Parameters

Designs optimized for load conditions (1) and (2) were critical in local instability over most of the combined load failure surface. If the panel cross section was retained but the panel length was increased, general instability began to dominate more of this failure surface; but the panel design was no longer optimum. When the panel design was reoptimized for the increased length it was found that the local instability modes again predominated. Also, when individual parameter changes were arbitrarily made to an optimized design, the efficiency was decreased; but when the individual parameters were constrained and the design was reoptimized, relatively little loss in efficiency occurred. Thus, nominal gage material or standardized bead pitch can be used with minimum loss in efficiency. 


\section{FABRICATION DEVELOPMENT}

Conventional methods of fabricating panels with stretch formed beads have been by hydropress or matched die processes where all bead elements for the full panel are formed in a single operation. Some associated disadvantages are: (1) separate full size dies are required for each panel; (2) material elongation limits seriously restrict the depth of beads that can be formed; and (3) material thinning is greatest at the crests of the beads where stresses are highest. Thus, the potential efficiency of the conventional stretch formed panels is degraded. These limitations provided a considerable Incentive for investigating alternate fabrication methods.

\section{Uniform Section Brake Forming}

Studies made to determined methods of producing deep, multiple, large-arc beads in 7075 aluminum resulted in a technique of brake forming corrugations for the ful1 length of the pane1, then reforming the ends to close out the beads and obtain flat edges for attachment of the panel. The initial brake forming of one sheet for the 2-2 panel configuration is shown in Figures 5 through 7 . Figure 5 shows a sheet of material being hand fed through a standard brake forming machine to form the initial corrugations. Figure 6 shows a close up view of the sheet, positioned by an index pin located in the upper die, ready for forming. Figure 7 shows the die closed at the end of the forming stroke. The bends are formed by a wrapping action which minimizes thinning, but which results in considerable spring back necessitating the use of three part dies to obtain 180 degree beads. A rubber strip located under the edge of the lower parts of the die permits the die to close at the end of the stroke but otherwise keeps it open. Figure 8 shows a closeup of the brake formed, corrugated sheet. The $2 t$ bend radius adjacent to the flats has been increased to approximately $10 t$ at the ends to permit reforming of the ends without memory of the initial bend lines.

\section{End Closure Forming}

Small two part dies installed in the brake forming machine are used to reform the end closures. Figure 9 shows secondary beads being formed in the flats between the primary beads and Figure 10 shows the end closures being formed in a similar manner. The compound contours of typical end closures are formed with net-dimensional tooling (no springback). One problem encountered with end closure forming is compressive wrinkling associated with the compound contour in thin gage materials. The secondary bead, being formed in the upper portion of Figure 9 , is benefictal in reducing this compressive wrinkling as well as resisting load-induced local buckling in the large flat areas at the panel ends.

\section{High Energy Rate Reforming}

An additional forming stage is required to form the end closures when $\alpha$ is greater then $90^{\circ}$ as shown for configuration 2A-2 in Figure 4. The end closures are preformed to approximate shape using dies similar to those in Figure 10, and finally the full end closure is sized in a female steel die using a 


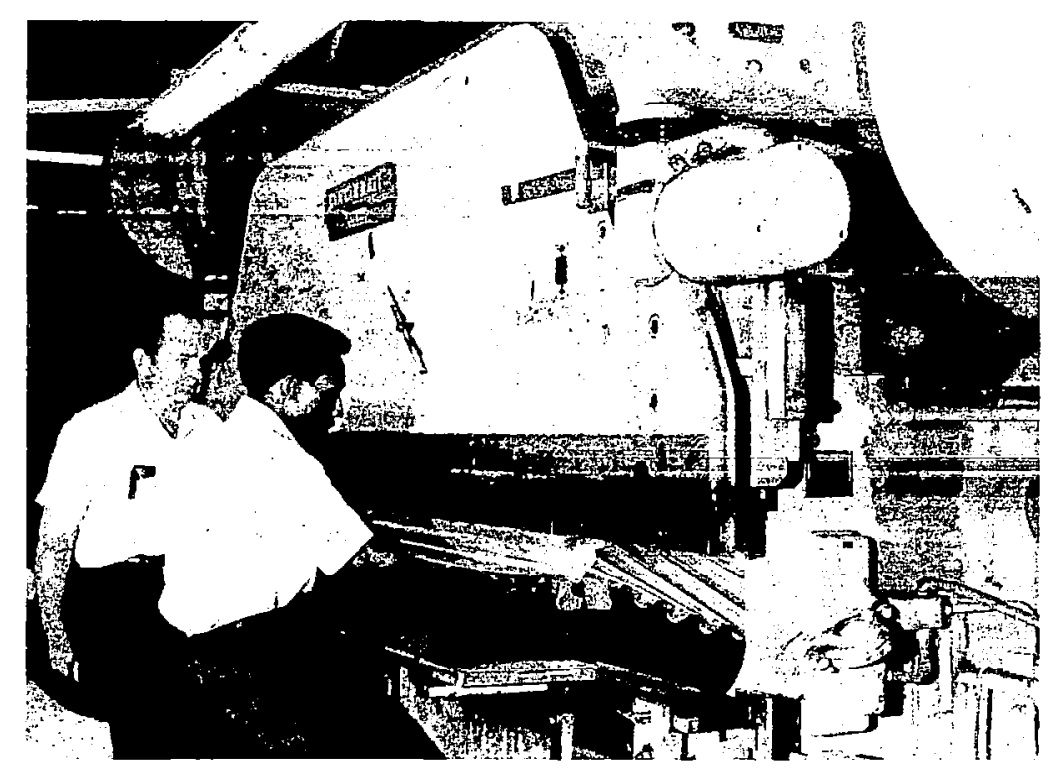

Figure 5: BRAKE FORMING IN STANDARD BRAKE MACHINE

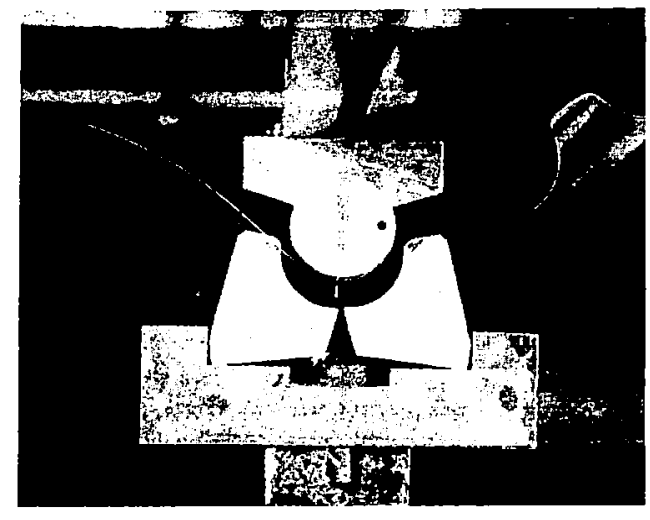

Figure 6: UNIFORM SECTION BRAKE FORMING -DIE OPEN

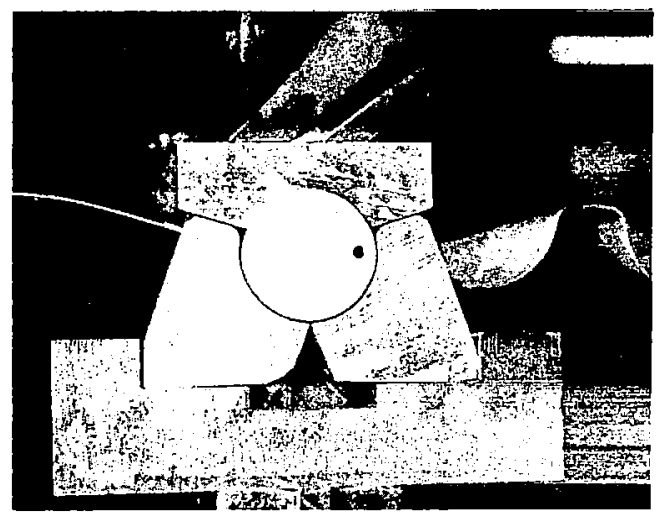

Figure 7: UNIFORM SECTION BRAKE FORMING -DIE CLOSED 


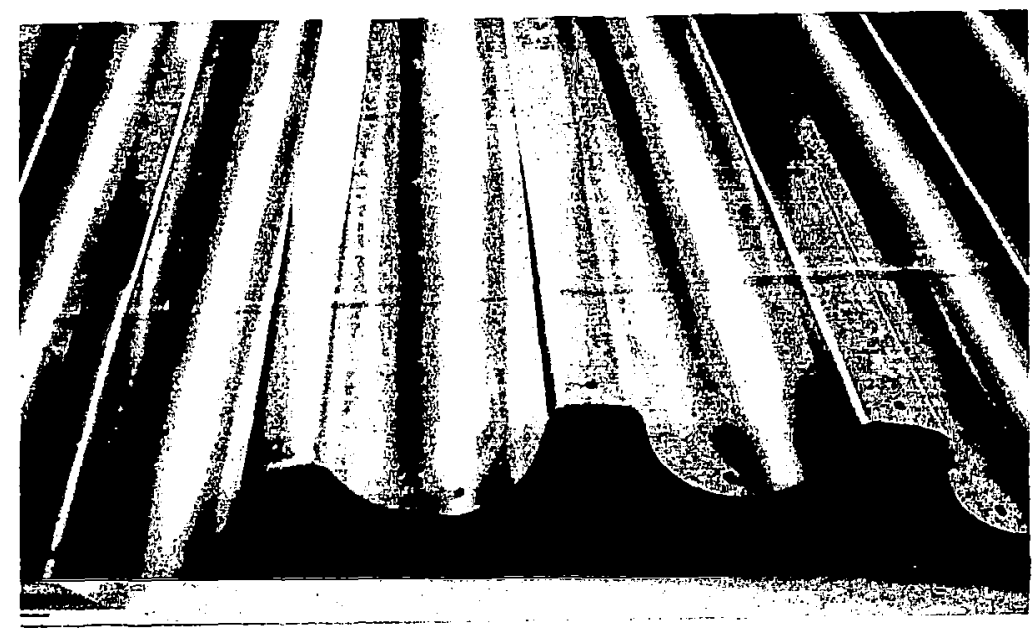

Figure 8: FORMED UNIFORM SECTION WITH INCREASED BEND RADIUS NEAR ENDS

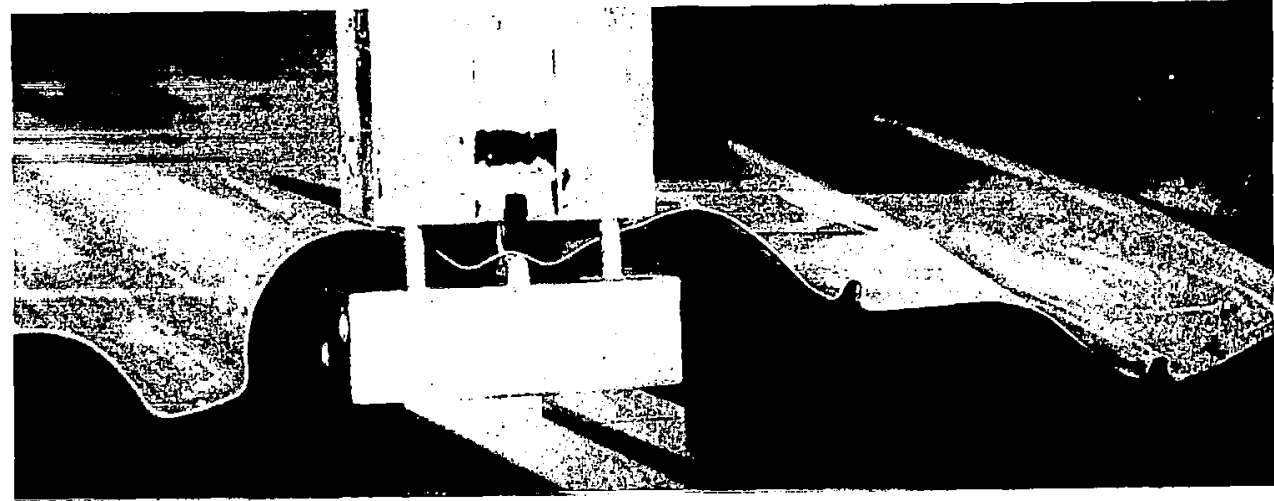

Figure 9: REFORMING SECONDARY BEAD IN PANEL END

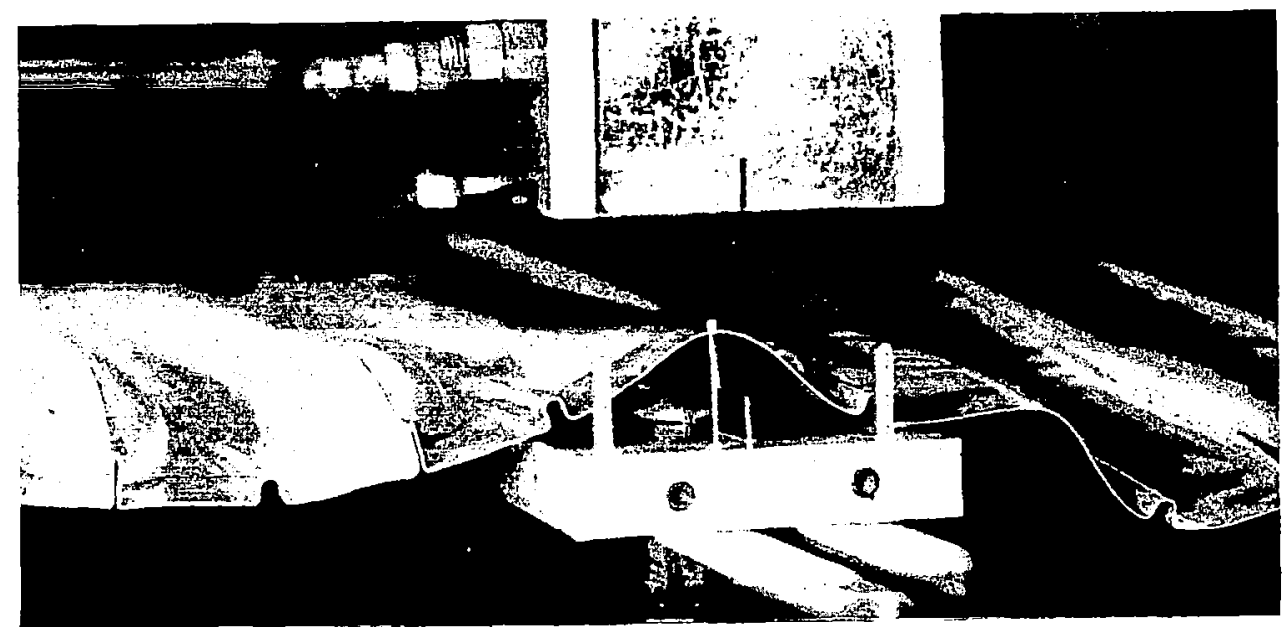

Figure 10: REFORMING BEAD END CLOSURE IN PANEL END 
high-energy rate electro-hydraulic process (capacitor discharge through a spark gap in a water chamber). The electro-hydraulic process is also helpful in Improving configuration control and in reducing local buckles in thin gage parts. The high energy rate forming technique was used for final sizing of the two fluted tube bead end closure designs. It was not used in forming the end closures for the circular tube panels.

\section{Panel Assembly and Machining}

Assembly was accomplished by adhesive bonding of the face sheets and necessary doublers in a single bond cycle. Figure 11 shows two beaded face sheets, a fingered doubler and two edge doublers for a circular tube panel being prepared for final assembly. The fingered doublers were tapered to a thickness of approximately 0.002 inches $(.05 \mathrm{~mm})$ at the tips to permit satisfactory bonding of the face sheets adjacent to the tips. The fingered doublers located between the two beaded sheets reinforce the ends of the panels to provide for redistribution of the internal loads between the flat ends and the beaded uniform section of the panel. Uniform thickness external doublers were used to reinforce the bolted edge attachments.

Figure 12 shows a panel being placed in the bonding fixture. The fixture was made primarily from constant thickness bars and plates that were cut to shape on a band saw. A vacuum was used to apply pressure during the bonding cycle.

Figure 13 shows one of the 30 inch $(760 \mathrm{~mm})$ long circular tube panels prepared for installation in the test fixture. The panel edges were machined and drilled on the same numerical control machine that was used in machining and drilling the corresponding elements of the test fixture. The rivets located in the area of the tube end closures were installed by an automatic riveting machine.

The fabrication techniques described above permitted the desired configurations to be fabricated while essentially avoiding problems of local thinning in critical areas. Neither material forming limits nor configuration control limits were encountered. Additionally, a comparison of brake forming and stretch forming costs indicated that the brake forming approach offers less cost per panel for production to nearly 70 pane1s (Ref. 10). 


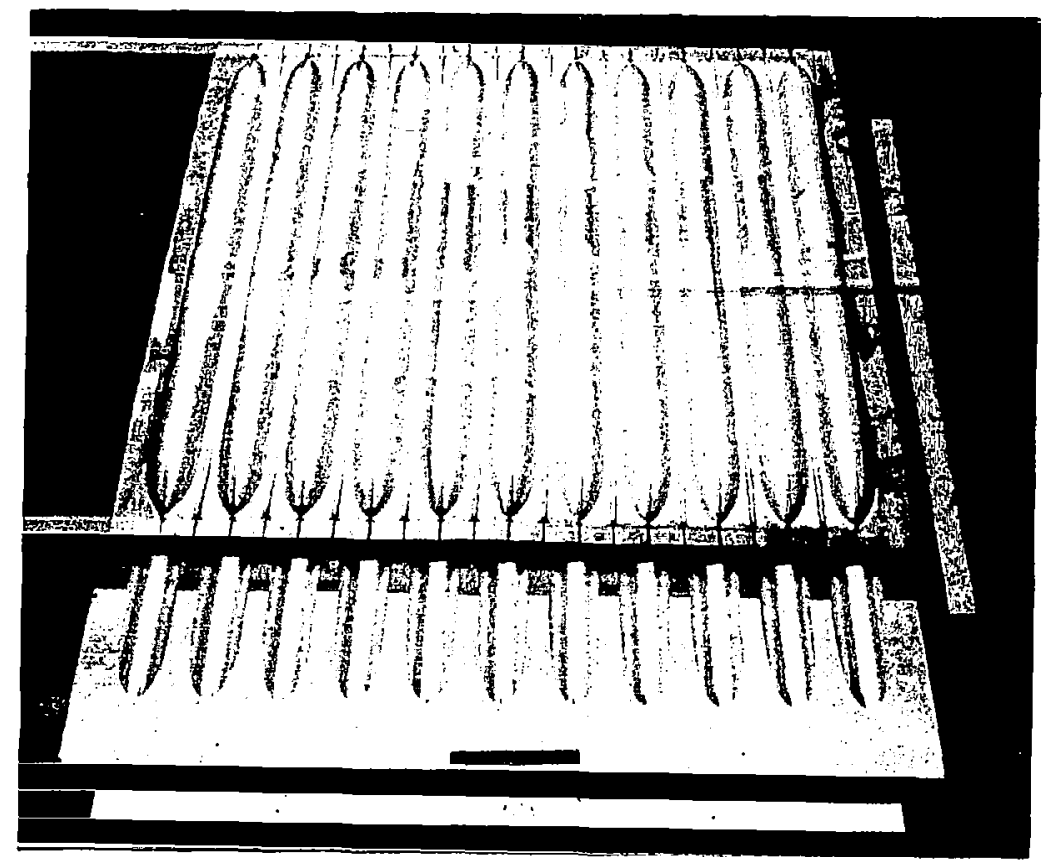

Figure 11: CIRCULAR TUBE PANEL BEING PREPARED FOR BONDING

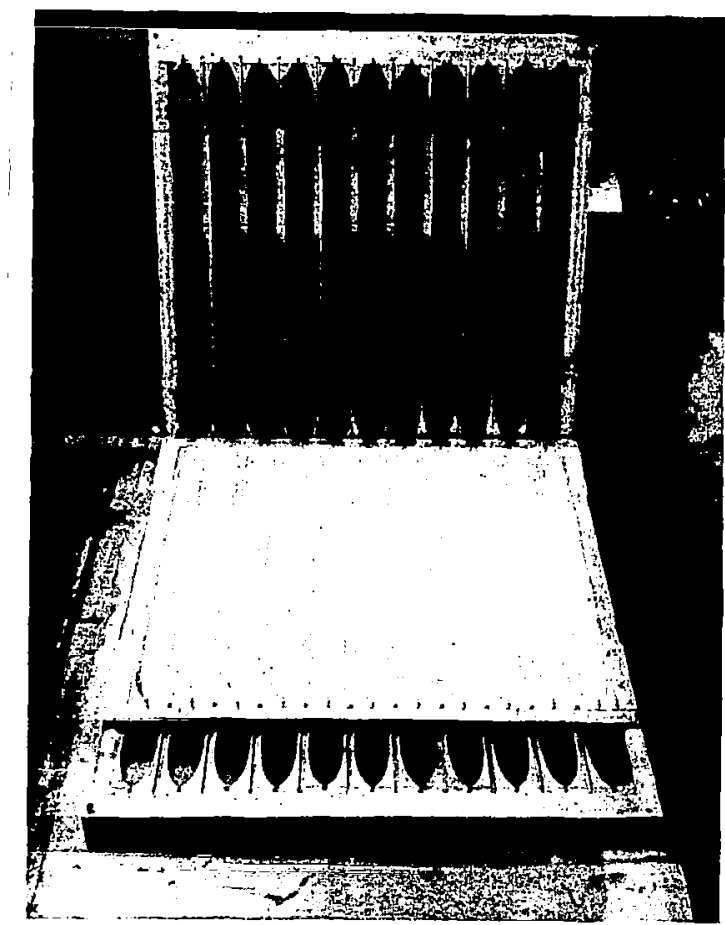

Figure 12: CIRCULAR TUBE PANEL WITH BONDING FIXTURE

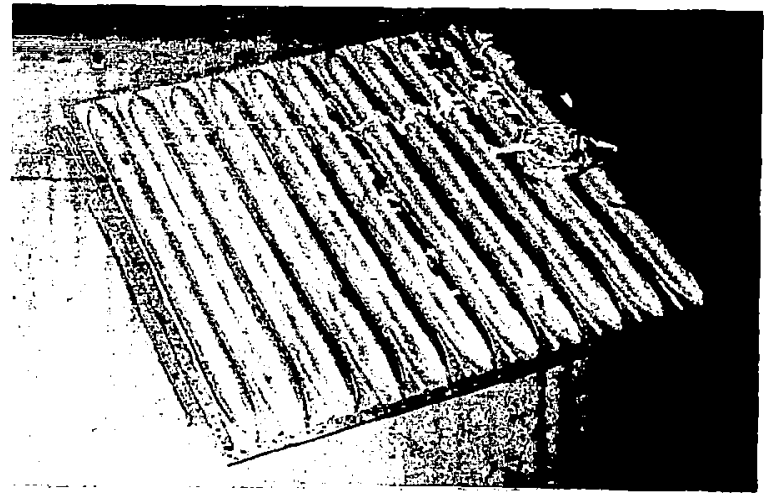

Figure 13: CIRCULAR TUBE BUFFER BAY PANEL WITH PREPARED EDGES 


\section{DESIGN EVOLUTION}

Development of the panel designs that were fabricated and tested for this program was an evolutionary process addressing two portions of the design separately but simultaneously. Selection of the uniform section designs was based on the computerized design optimization process. The end closure development involved many iterations of the design, fabrication, test and evaluation proc-esses in order to obtain end closure designs that were compatible with the strength of the uniform center portion of the panels. The rationale employed was that the end closures should be sufficiently strong to support the panels for the panel design loads and that their strength be verified by experiment. This parallel development of the cross section and end closure proved to be very satisfactory. With good coordination and shop support the fabrication and testing of the end closure concepts was rapid and economical. Furthermore, a precise analysis of end closures was considered beyond the scope of this program.

\section{Screening Test Specimens}

Based upon preliminary analysis and data of the nature shown in Figure 2 three simple circular arc configuration concepts were selected for preliminary development and screening purposes. Those configurations are shown in Figure 14. Specimens having the same bead radii were formed using the same forming dies. These screening test specimens provide preliminary fabrication development experience, allowed development of end closure design and fabrication concepts, checkout of test fixtures and test techniques, and provided preliminary test data within the applicable design ranges to assist in the selection of the four developmental configurations. Test results from these specimens indicated that the circular bead configurations were easily formable and well behaved and ultimately led to the selection of the more complex configurations shown in Figure 3.

\section{End Closure Evolution}

The end closure design evolution included a number of fabrication and evaluation cycles. The first cycles included very simple specimens which served only as models for further design improvements. Later specimens in the evolution process were tested under various load conditions to determine what additional design improvements should be made. A description of that evolutionary process is presented below.

Single sheet end closures. - Figure 15 shows the first specimen that was fabricated to illustrate the concept of a developable bead with the bead flattened at the end. Figure 16 shows the first beaded specimen with curved elements. Figure 17 shows the first tubular specimen which was fabricated using the dies that were used in fabricating the specimen shown in Figure 16. The uniform section of the specimen shown in Figure 17 was chem milled to provide increased thickness in the end closure, Figures 18 and 19 show carly end closure specimens that were formed using the first tapered end closure forming die. The tapered end closures were necessary to provide adequate effective area for transfer of the loads from the end attachments to the 

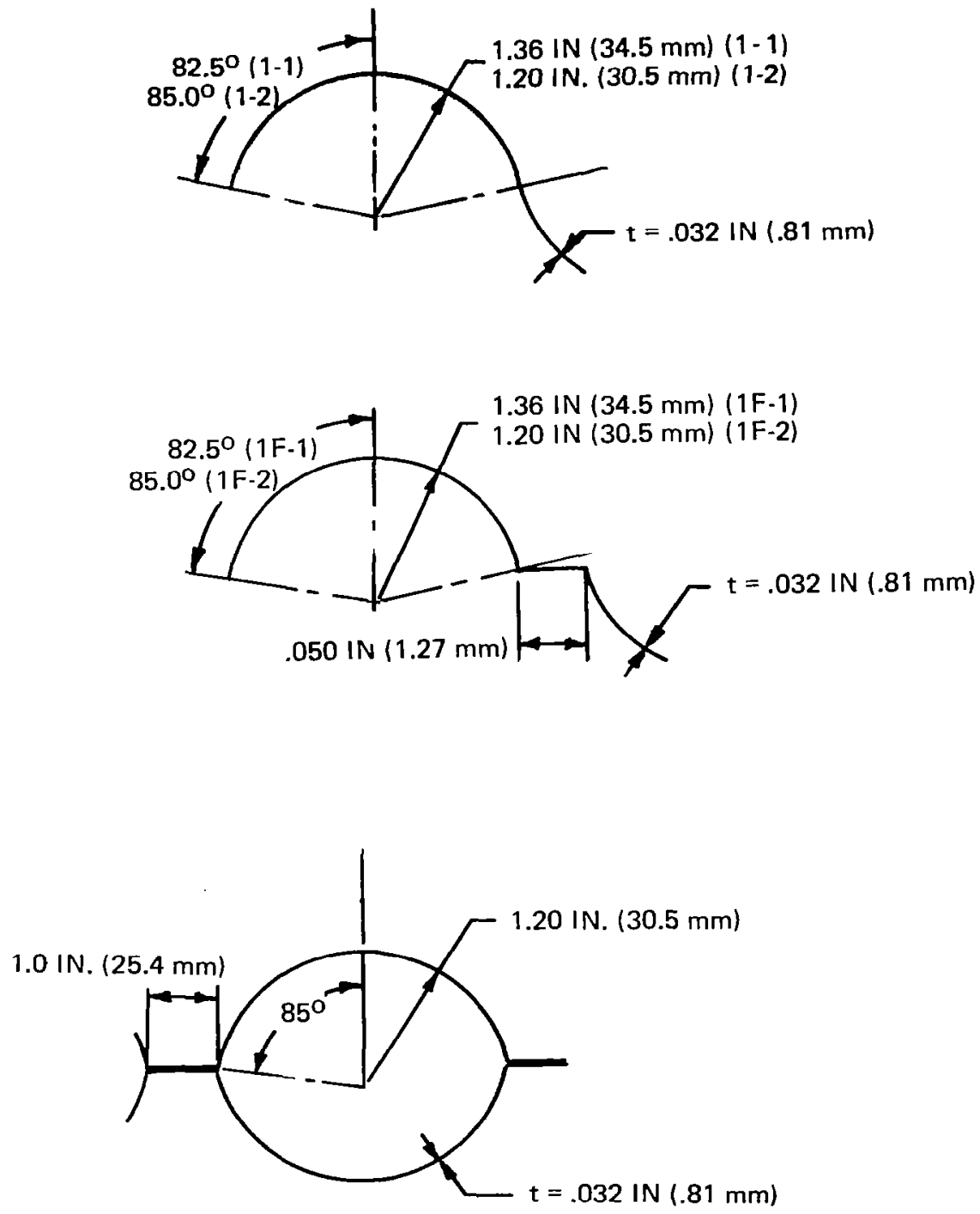

Figure 14: PRELIMINARY SCREENING TEST BEAD CONFIGURATIONS 


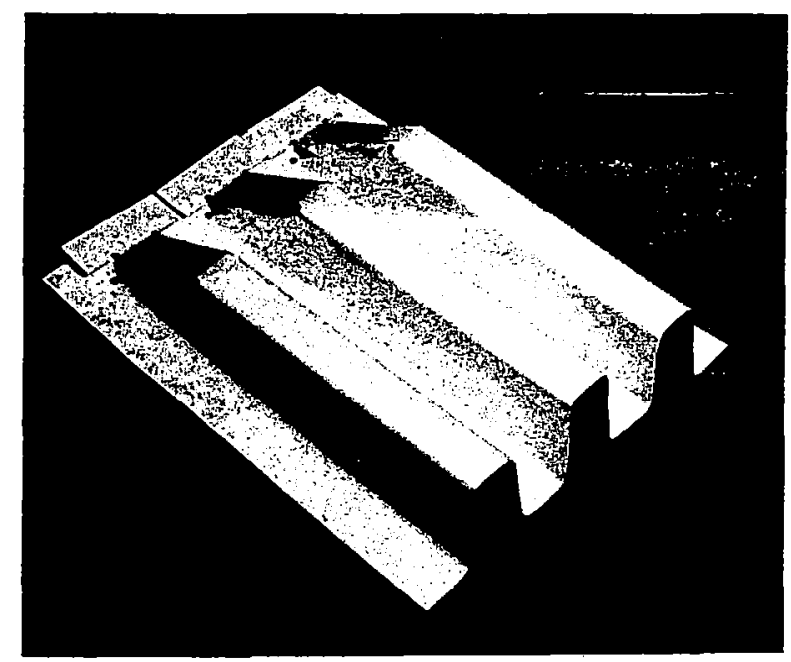

Figure 15: FIRST END CLOSURE CONFIGURATION

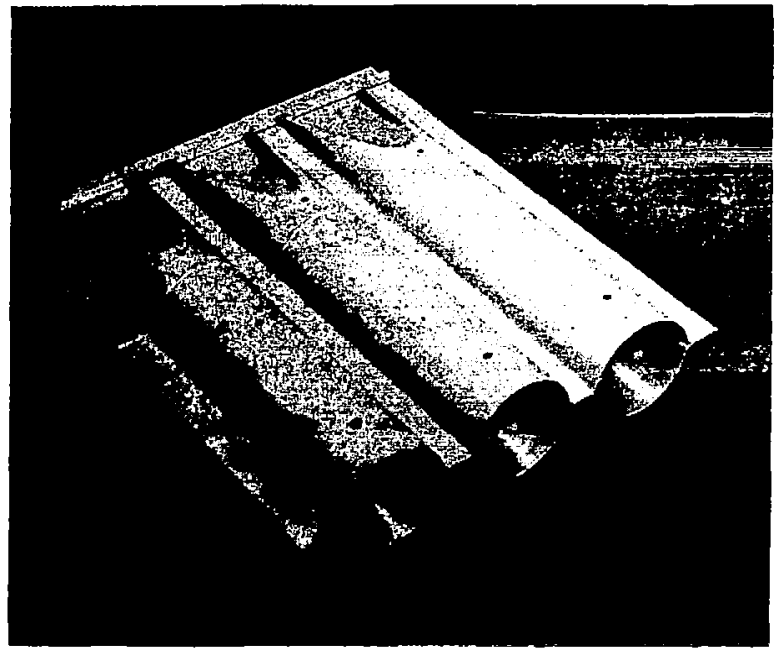

Figure 17: FIRST TUBE SPECIMEN

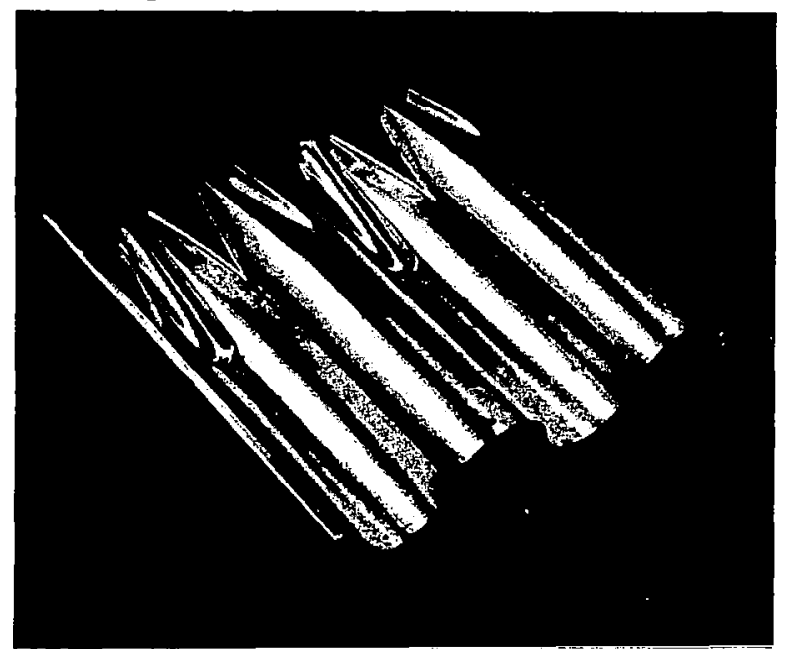

Figure 19: EARLY END CLOSURE WITHOUT FLAT

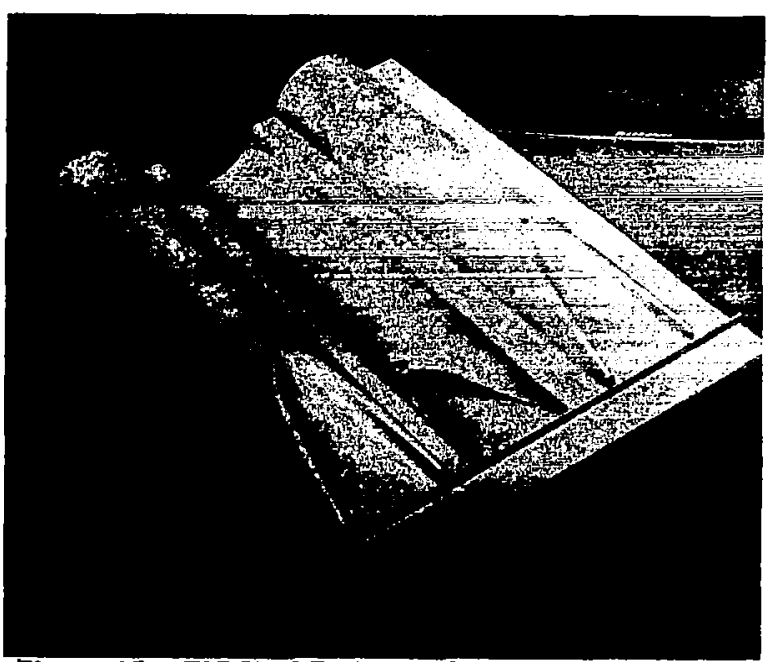

Figure 16: FIRST BEADED SPECIMEN WITH.
CURVED ELEMENTS.

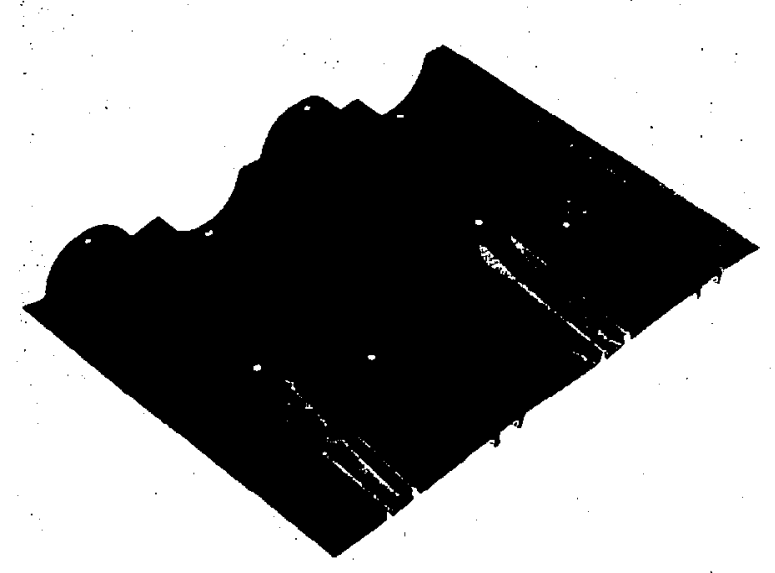

Figure 18: EARLY END CLOSURE WITH FLAT

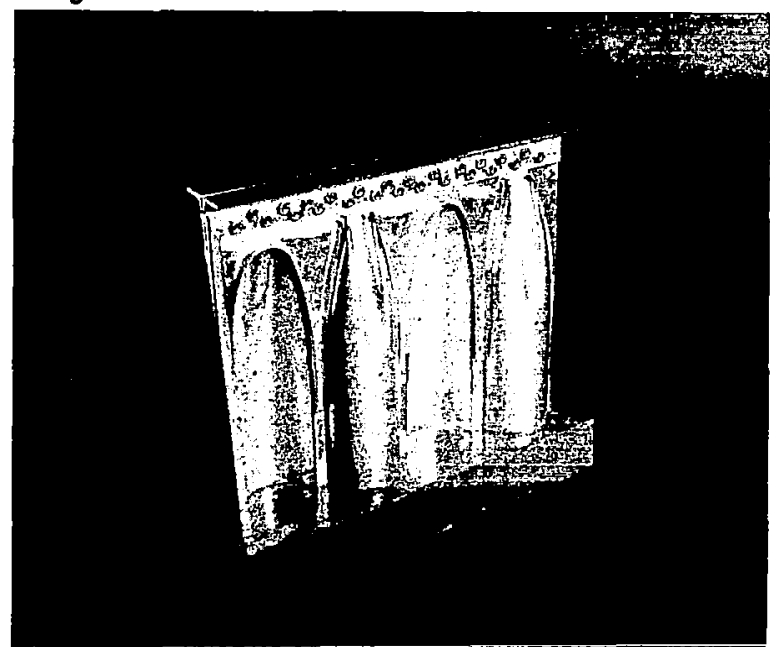

Figure 20: FAILED END CLOSURE AXIAL COMPRESSION TEST SPECIMEN 
uniform section. Figure 20 shows a failed compression test specimen which failed because of inadequate continuity of stiffness between the end closure and the end attachment. Specimens of this type also displayed excessive distortion in the area of the end closure when loaded in shear. Specimens of the type shown in Figures 21 and 22 were then fabricated in an attempt to obtain improved stiffness at the end of the end closure. When prepared with proper end attachments and loaded these specimens developed adequate axial compression strength, but they displayed excessive out-of-plane distortions when loaded in shear. The filler blocks used in the end closures also contituted an undesirable weight penalty.

End closures of the type shown in Figure 23 were formed in an attempt to eliminate the above problems. The specimen shown in Figure 23 is also different than the compression test specimen shown in Figure 20 in that it has relatively heavy " $\mathrm{T}$ " shaped chord members along the sides of the test specimen to transmit shear loads. Compression test specimens with the formed bead end closures of this design carried axial compression loads quite adequately. However, when loaded in shear and monitored with Moire' grid and strain gages, excessive out-of-plane bending strains and deflections were again observed as indicated in Figure 24. In this instance the Molre' IInes, which were obtained by placing cut pleces of grided glass adjacent to the surfaces between the beads, indicate lateral displacements of approximately .006 inches $(.15 \mathrm{~mm})$ per line. The observed out-of-plane deflections result from the local couples which in turn result from the discontinuity in the local shear center for the individual beads. In the area of the bead the local shear center is located outside of the contour of the bead. However, in the end attachment area the shear center is at the center of the sheet. Consequently large out-of-plane deflections occur which reduces shearing stiffness and causes undesirable stress. concentrations.

Figure 25 shows a specimen that is identical to that shown in Figure 24 with the exception that two short "T" sections have been attached to each. side of the specimen. The Moire' grid indicates that the out-of-plane deflection problem was not eliminated. Figures 26 and 27 show two additional specimens which were designed to transmit shear loads more efficiently. However, tests revealed that these designs were unsuccessful in eliminating the out-of-plane deflections associated with the single sheet beaded panels loaded in shear.

Figure 28 shows the last end closure specimen that was fabricated in an attempt to eliminate the out-of-plane deflection problem. For this specimen the shift in the local shear center occurred farther from the end of the bead and it maintained a larger portion of out-of-plane bending stiffness of the bead side wall to the end of the joint splice member. However, the Moire' grid lines seen in Figure 29 indicate that the out-of-plane deflection problem was not eliminated.

The inability to eliminate the single sheet end closure out-of-plane deflection under shear load required some other attachment technique to permit testing the fluted single sheet panels. Figure 30 shows a fluted single sheet shear test specimen with the type of attachment that was used in testing the corresponding panels. An end chord or cap was fabricated from a thick 


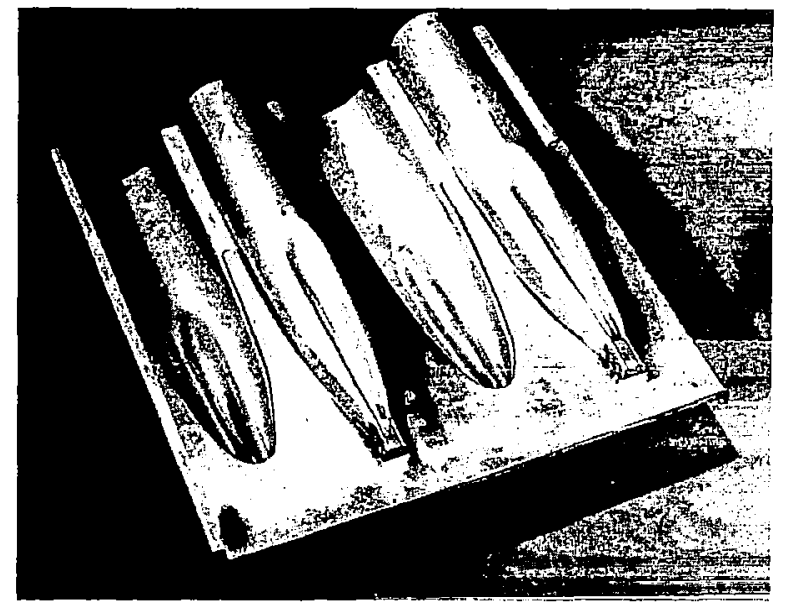

Figure 21: EARLY END CLOSURE WITH FLATS BETWEEN BEADS

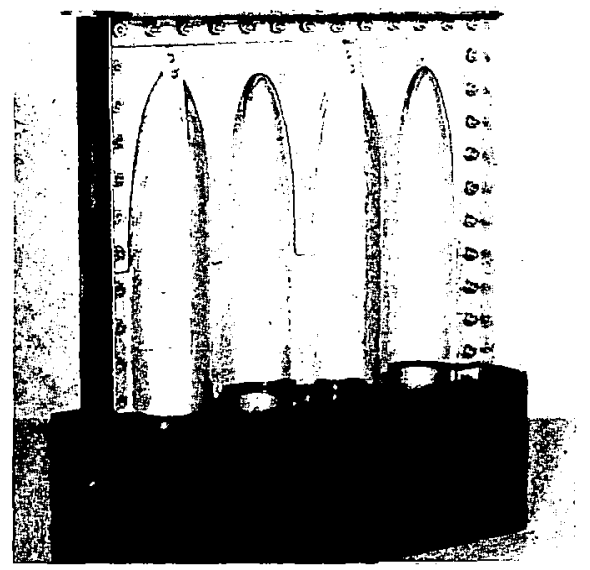

Figure 23: SINGLE SHEET END CLOSURE SHEAR TEST SPECIMEN

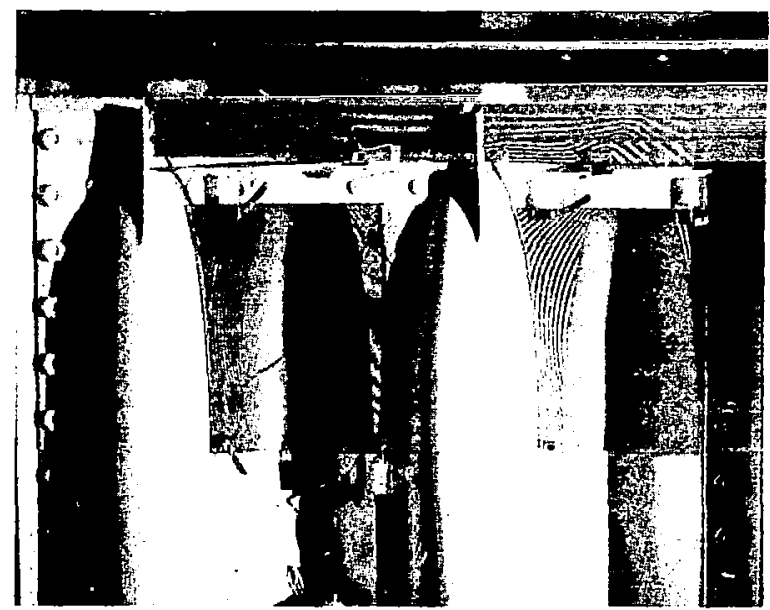

Figure 25: MOIRE PHOTOGRAPH OF STIFFENED SINGLE SHEET END CLOSURE LOADED IN SHEAR

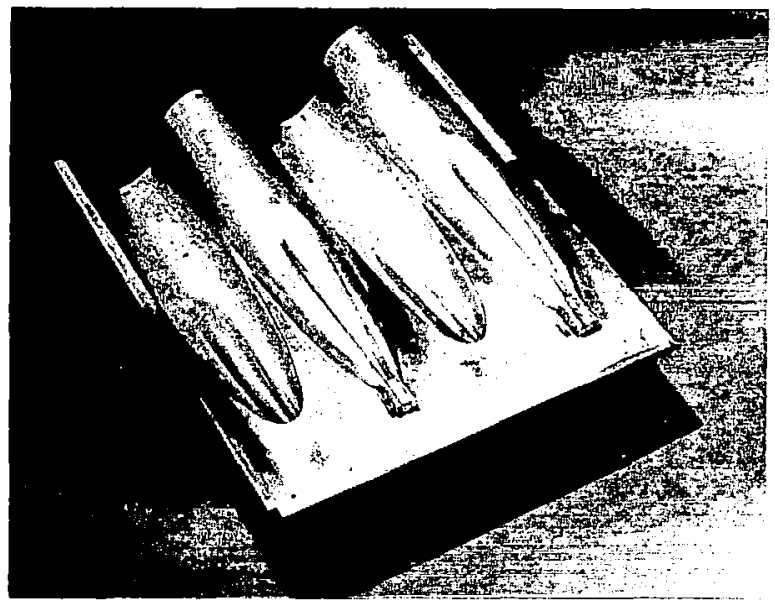

Figure 22: EARLY END CLOSURE WITH NO FLATS BETWEEN BEADS

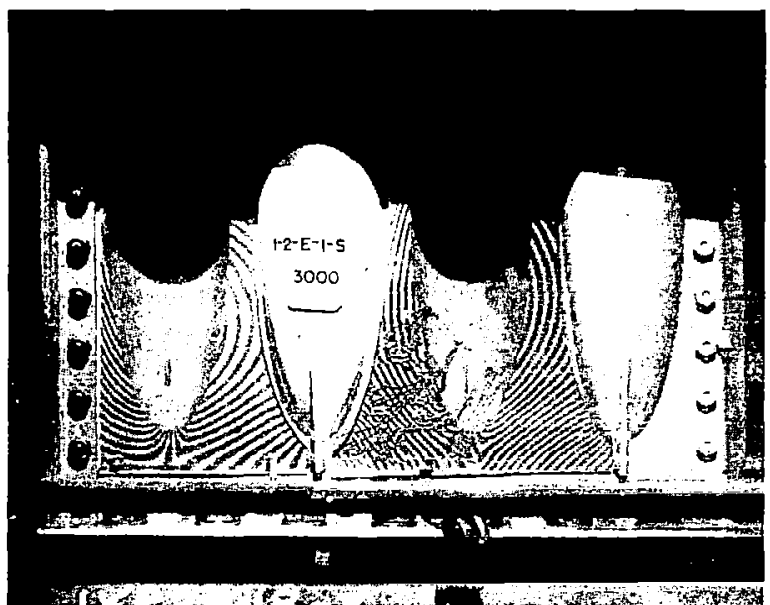

Figure 24: MOIRE PHOTOGRAPH OF SINGLE SHEET END CLOSURE LOADED IN SHEAR

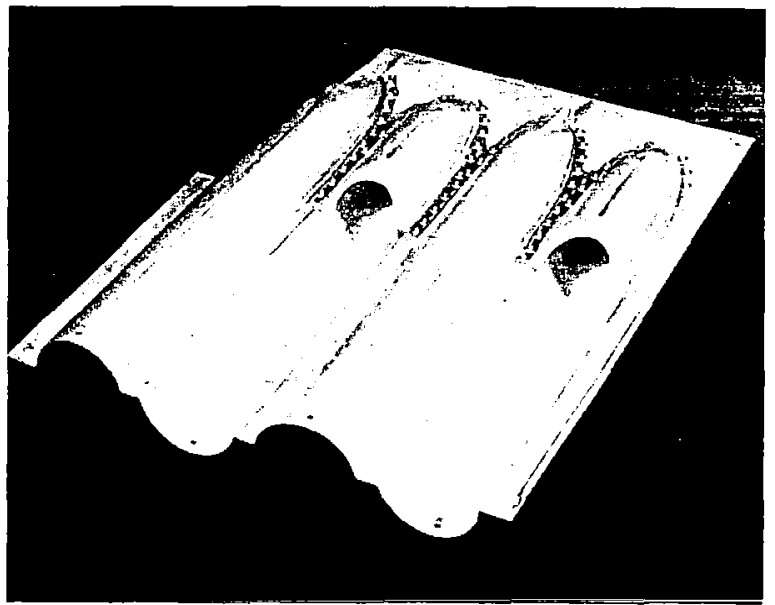

Figure 26: SINGLE SHEET END CLOSURE DEVELOPMENT SPECIMEN 


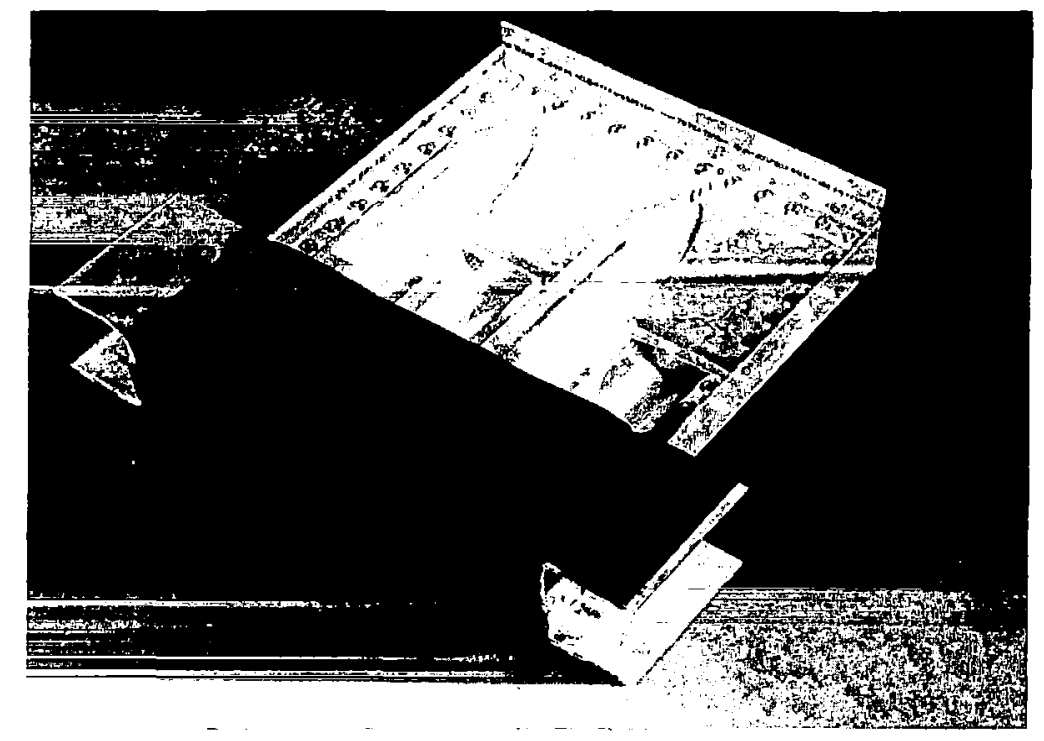

Figure 27: SINGLE SHEET END CLOSURE DEVELOPMENT SPECIMEN

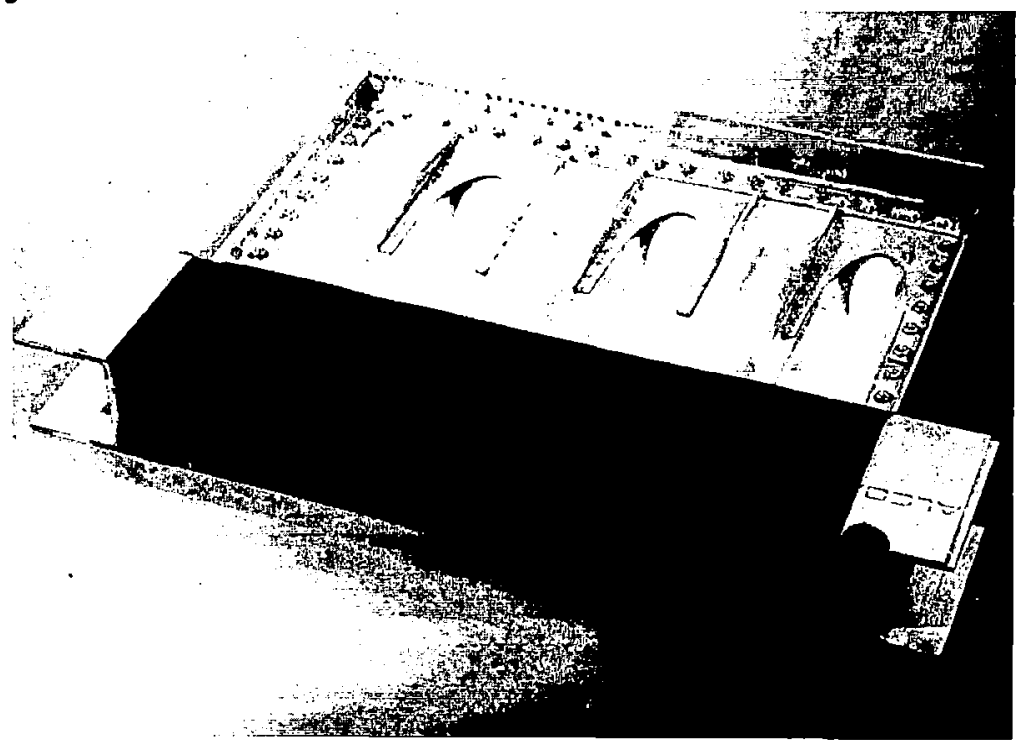

Figure 28: SINGLE SHEET END CLOSURE SHEAR TEST SPECIMEN

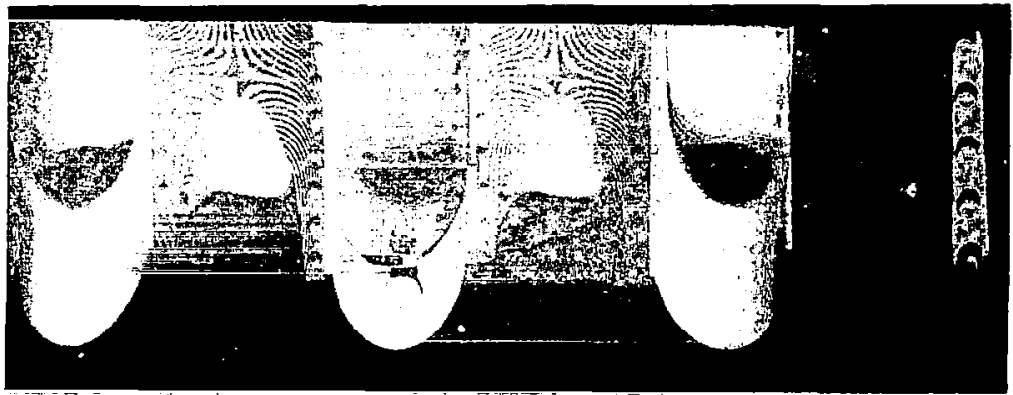

Figure 29: MOIRE PHOTOGRAPH OF SINGLE SHEET END CLOSURE LOADED IN SHEAR 
aluminum plate. First, a strip of copper was formed to the shape of the corrugated sheet and was used as the electrode for electrical discharge machining of a corresponding groove in the aluminum plate. Next, a very short section of corrugated sheet was inserted into the groove and used as a guide for removal of the excess portion of the plate by use of a router. Finally the cap was attached to the corrugated sheet of the test specimen by bonding. The specimen was tested in both compression and shear to loads well in excess of the predicted strengths for the $40 \times 40$ inch ( $1 \times 1 \mathrm{~m}$ ) panels, thus substantiating the design for use with the full size panels.

Two sheet end closures. - The two sheet end closure development proceeded simultaneously with the single sheet development using the same forming dies in many instances. Figure 31 shows a Moire' grid photograph of a two sheet end closure specimen that was fabricated using the same dies used in rorming the single sheet initial screening configuration specimens shown in Figures 23 through 27. The Moire' lines indicate a bond peel failure occurred at a shear load approximately equal to the value which was predicted as the pure shear load strength of the full size panels. The forces driving the bond peel failure in the two sheet specimens were the same as those driving the out-ofplane deflections in the single sheet specimens. The rotations observed in the single sheet specimens did not occur in the two sheet specimens since the couples induced in one of the two sheets oppose those in the other, as is evidenced by the bond failure in Figure 31 .

The shear strength of the circular tube specimens of the initial screening test configuration was increased somewhat by addition of rivets in the area of the end closure. Figure 32 shows a portion of a specimen which was loaded in shear until the rivets failed in tension and tearing of the formed sheet occurred.

Figure 33 shows a specimen which is similar to that shown in Figure 32 except that external doublers were added in the area of the flats where the rivets were installed. As seen in the photograph this specimen failed by buckling of the tube wall in the end closure transition section. The failure load was very nearly equal to the shear strength of the corresponding uniform section tube specimens that were tested. Compression test specimens of the design shown in Figure 33 failed by buckling in the uniform section. These tests indicated that the end closure was at least as strong as the uniform section and thereby verified the end closure design.

The optimized panel cross section for the circular tube panels shown in Figure 3 was different from that shown in Figure 14 for the screening test configurations. Therefore new end closure forming dies had to be made and additional improvements were incorporated in the design. Figure 34 shows a developmental part made from the improved circular tube end closure dies. This photograph shows the addition of a secondary bead in the area of the end closure. The secondary beads serve three basic functions. They stabilize the otherwise unsupported flats, they increase the moment of inertia at the end of the panel and they provide much better local configuration control. The bead end closure shown in Figure 34 was made slightly longer and therefore less abrupt than the previous circular tube end closures in order to reduce the stresses of the 


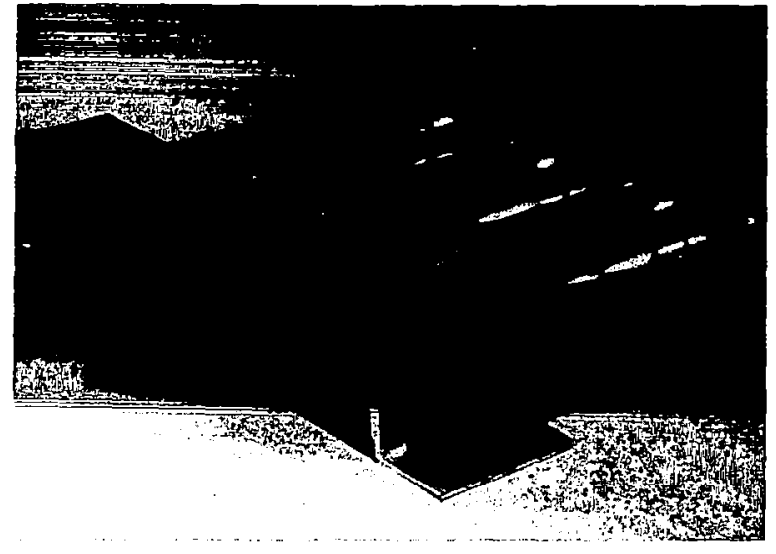

Figure 30: FLUTED SINGLE SHEET END ATTACHMENT SHEAR TEST SPECIMEN

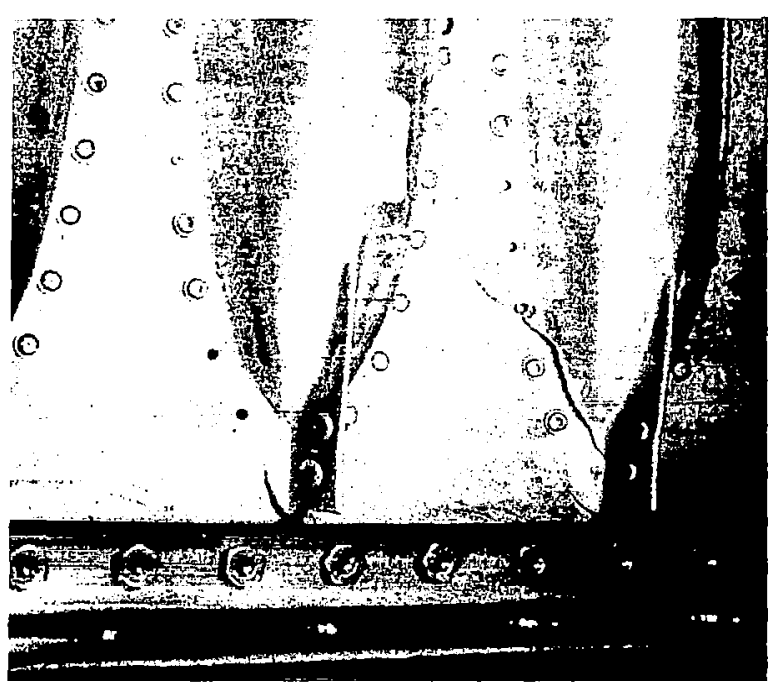

Figure 32: CIRCULAR TUBE AFTER SHEAR LOAD INDUCED FAILURE

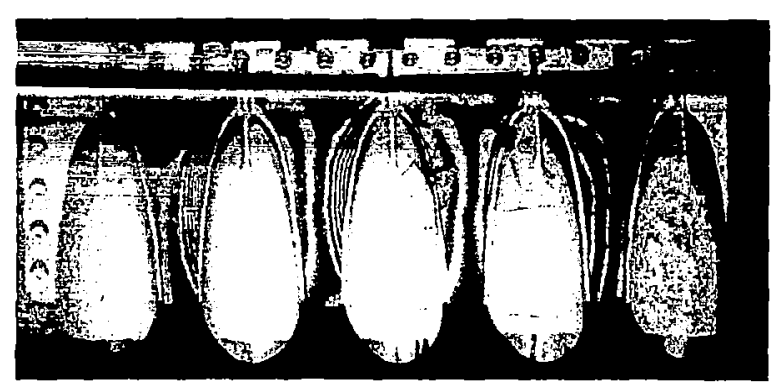

Figure 31: MOIRE PHOTOGRAPH OF CIRCULAR TUBE END CLOSURE AFTER SHEAR LOAD INDUCED BOND FAILURE

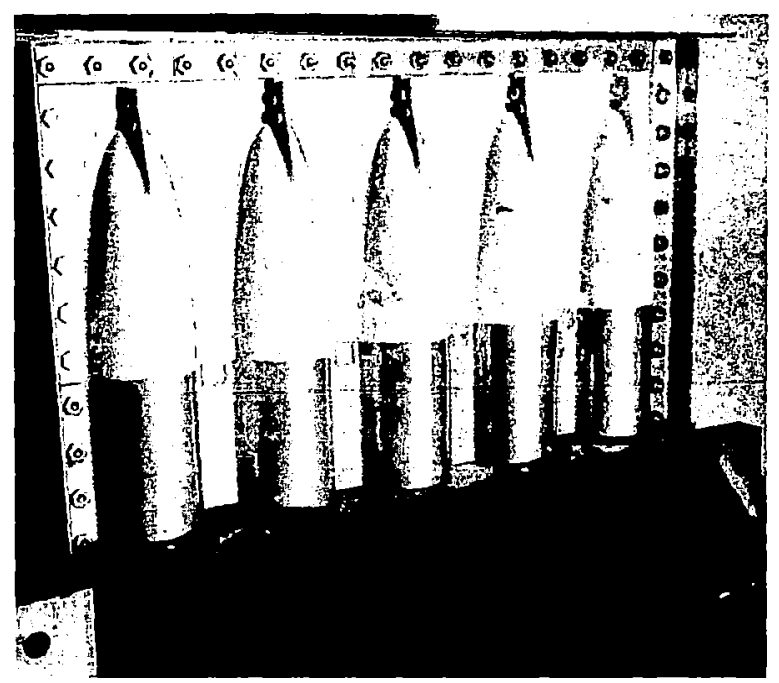

Figure 33: TUBULAR SPECIMEN FAILED IN SHEAR 
type that caused the bond peeling failure under shear load shown in Figure 31 . End closures of the design shown in Figure 34 were used for fabrication of the full sized test panels. However, the external doublers were not included in the end closures for the full size panels since these panels were not designed for shear load alone. No separate end closure specimens of this design were tested. Subsequent to large panel tests (discussed in a later section of this report) an end closure was developed which eliminated the vertical fins along the crest of each bead. This end closure is shown in Figure 35.

Fluted tube end closures. - Designs for the fluted tube end closures were developed subsequent to those for the circular tube end closures. Consequently they duplicate many of the details of the circular tube end closures. One significant difference was that severe forming of the thinner sheets resulted in local wrinkling of the flats. Figure 36 shows one of the high load fluted tube end closure developmental parts with the wrinkles that existed after forming. The wrinkles were eliminated by the final high-energy rate electrohydraulic sizing operation discussed previously. Figure 37 shows a specimen which is relatively free of local wrinkles following final sizing. Figure 38 shows the end closure area of one of the high. load fluted tube panels after bonding and riveting of the fingered external doublers but before preparation of the edges. Figure 39 shows an end closure specimen of the same design that failed by a combination of axial compression and shear at a load level well above the predicted strength for the full size test panels.

Figure 40 shows a low load fluted tube end closure test specimen that failed in axial compression. This end closure configuration was selected to incorporate features similar to those shown in Figures 35 and 37 . Figure 40 shows two small secondary beads that were used to prevent buckling in each of the large flat areas. As seen in Figure 40 the end closure specimen failures occurred in the uniform section rather than the end closure, although no external doublers were used. Only a single fingered doubler of thickness equal to the face sheet thickness was used between the two face sheets. Individual and combined load tests verified the adequacy of the two fluted tube end closure designs.

\section{Panels}

All of the full size panels were designed and fabricated with the uniform sections indicated in Figure 3 and with the end closures described above. The fluted single sheet panels and the circular tube panels were tested without further modification. However, because of degraded panel performance due to cross sectional distortion (described under "Test Results") additional modifications were made to the fluted tube panels. After the initial tests, the first low load fluted tube pane1, 2A-1-P-1, was modified by inserting machined rods as spacers and identified as $2 \mathrm{~A}-1-\mathrm{P}-1 \mathrm{M}$. ("P" in specimen nomenclature represents 40 inch by $40 \mathrm{inch}$ ( $1 \mathrm{~m}$ by $1 \mathrm{~m}$ ) pane1). The purpose of the spacers was to prevent flattening of the beads. Figures 41 and 42 shows views of the modified panel. Figure 42 also shows one of the machined spacers lying in the flute of one of the beads. A mastic material was applied to the rounded end and the shoulder on the spacers to hold the spacers in place until loaded. 


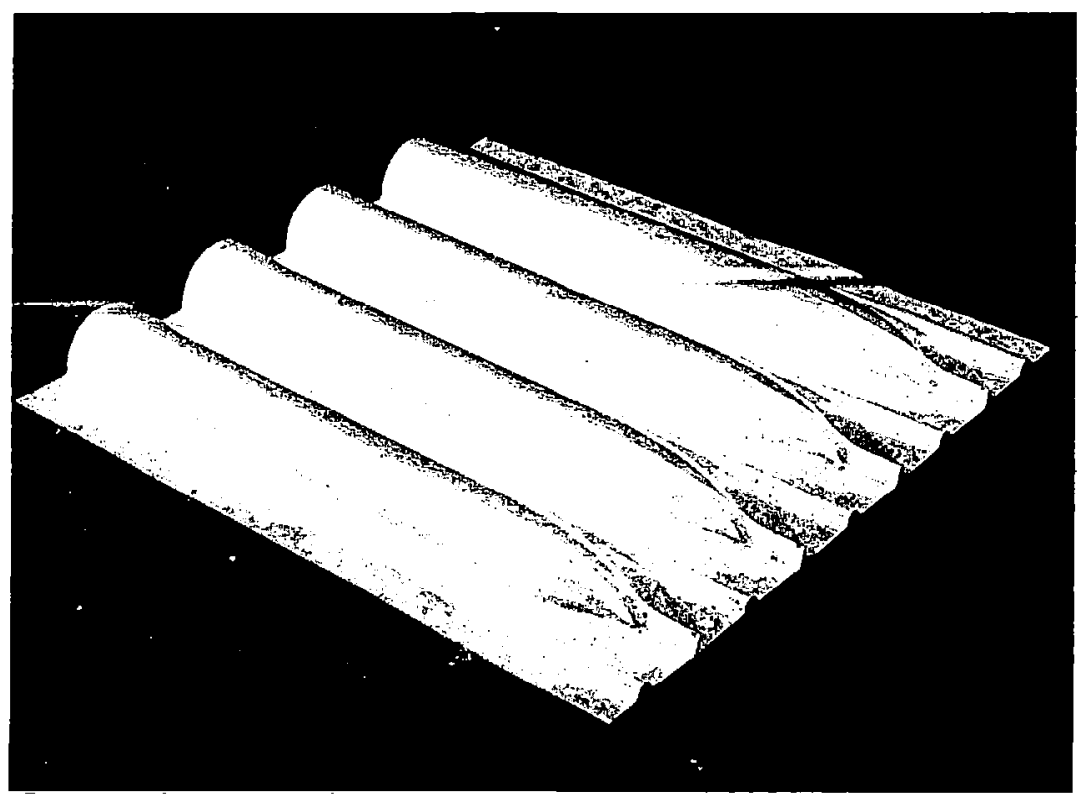

Figure 34: FINAL CIRCULAR TUBE END CLOSURE

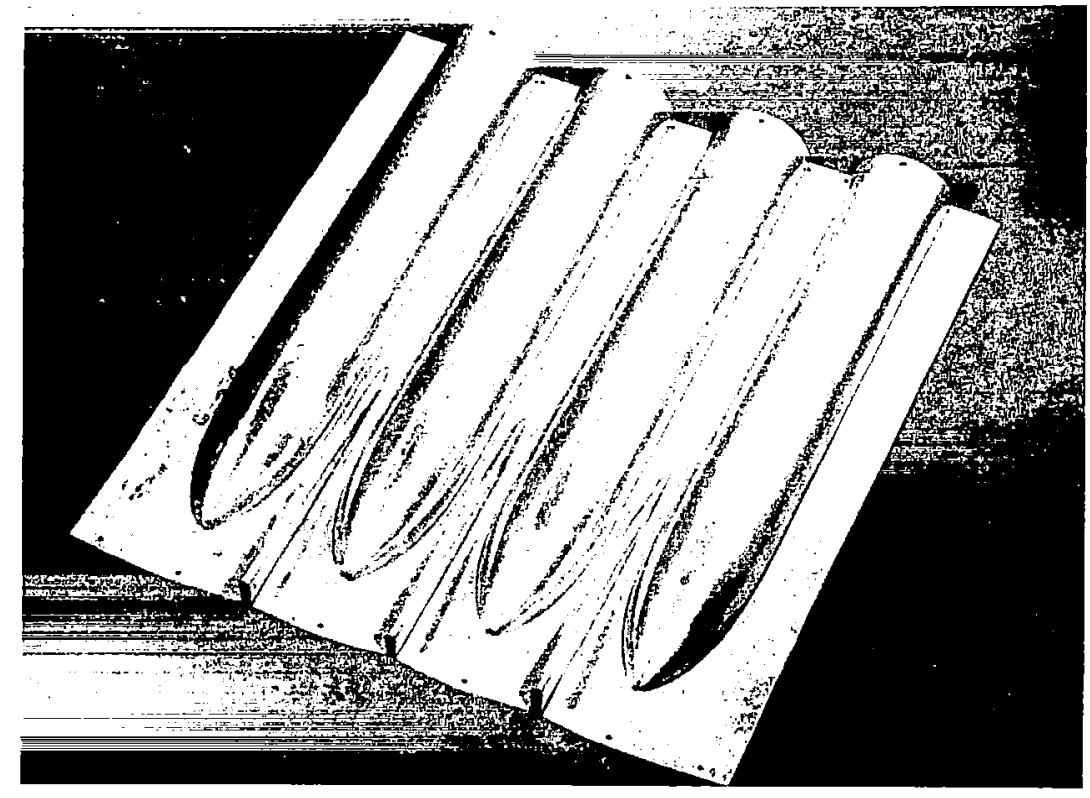

Figure 35: ALTERNATE CIRCULAR TUBE END CLOSURE 


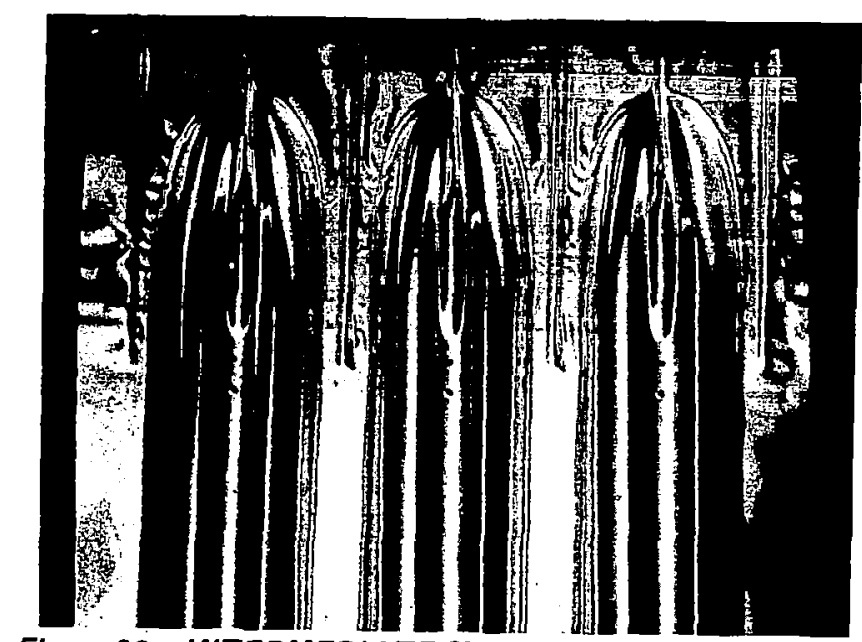

Figure 36: INTERMEDIATE STAGE 2A-2 END CLOSURE SHOWING FORMING WRINKLES

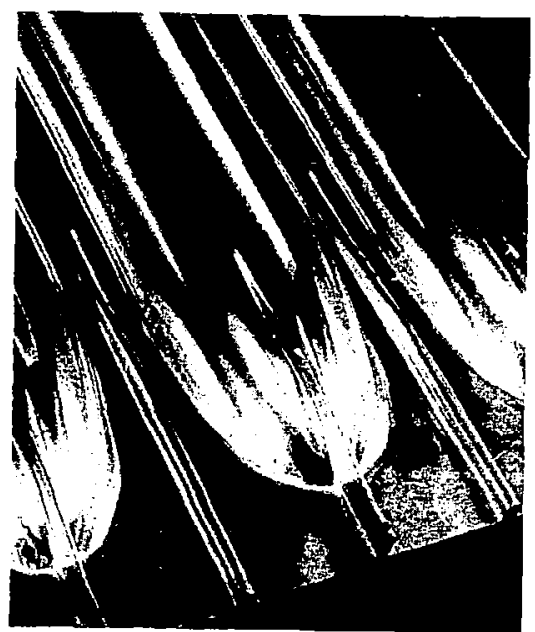

Figure 37: FINAL FLUTED TUBE END CLOSURE

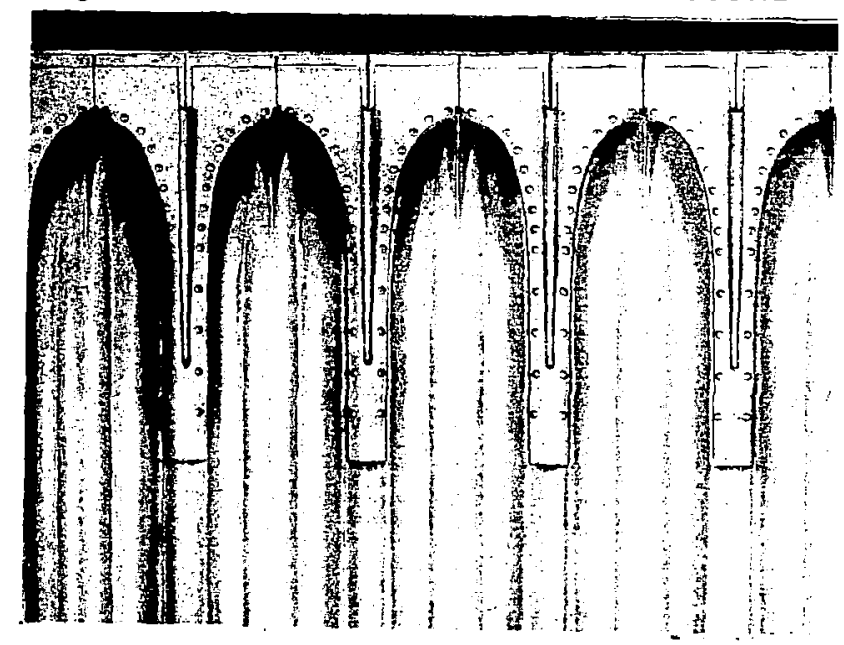

Figure 38: END CLOSURE WITH EXTERNAL DOUBLERS AND RIVETS 


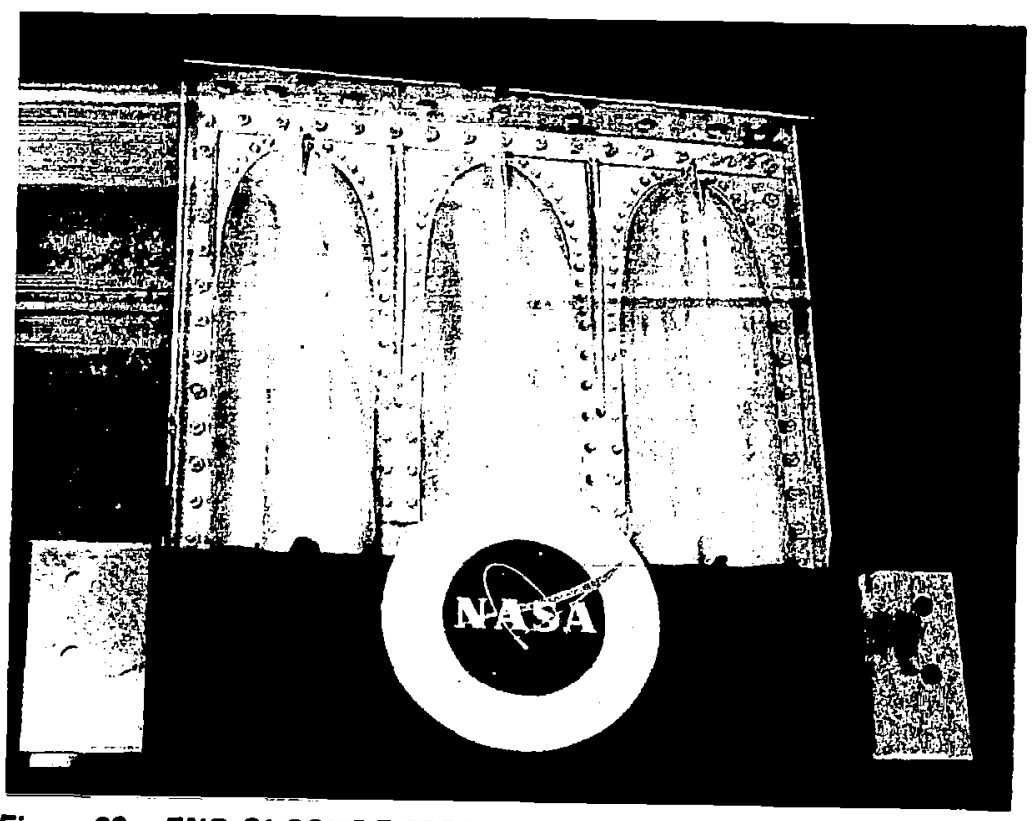

Figure 39: END CLOSURE SPECIMEN FAILED IN COMBINED AXIAL COMPRESSION AND SHEAR

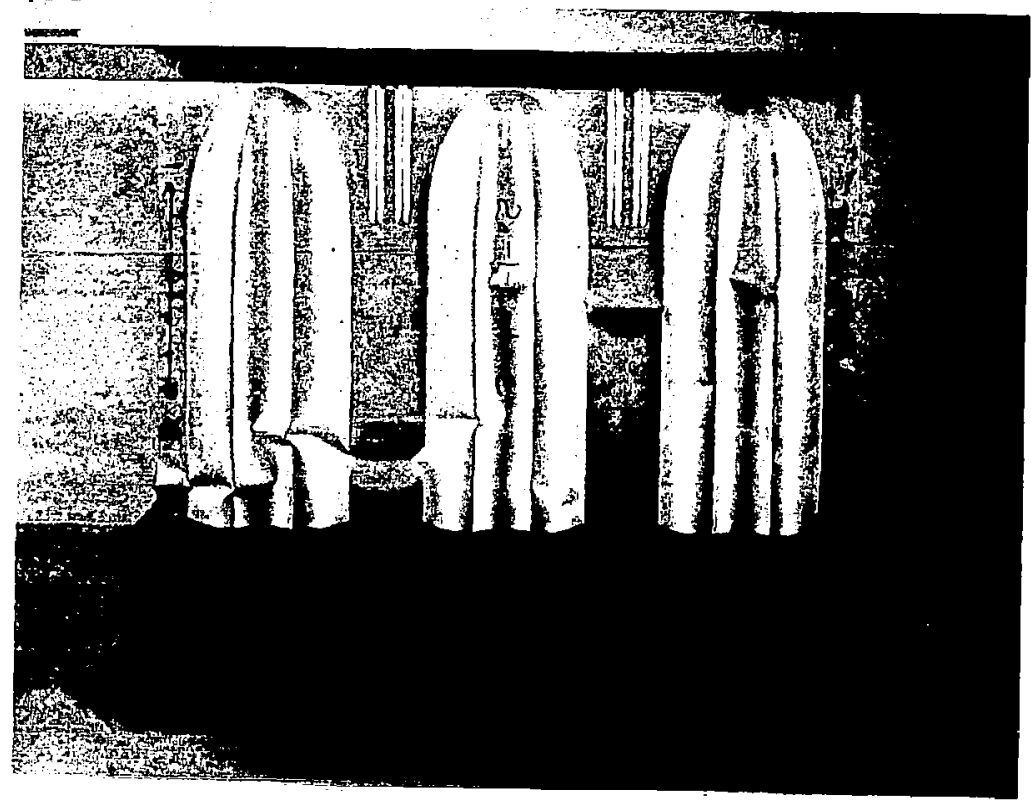

Figure 40: FAILED LOW LOAD FLUTED TUBE COMPRESSION SPECIMEN 


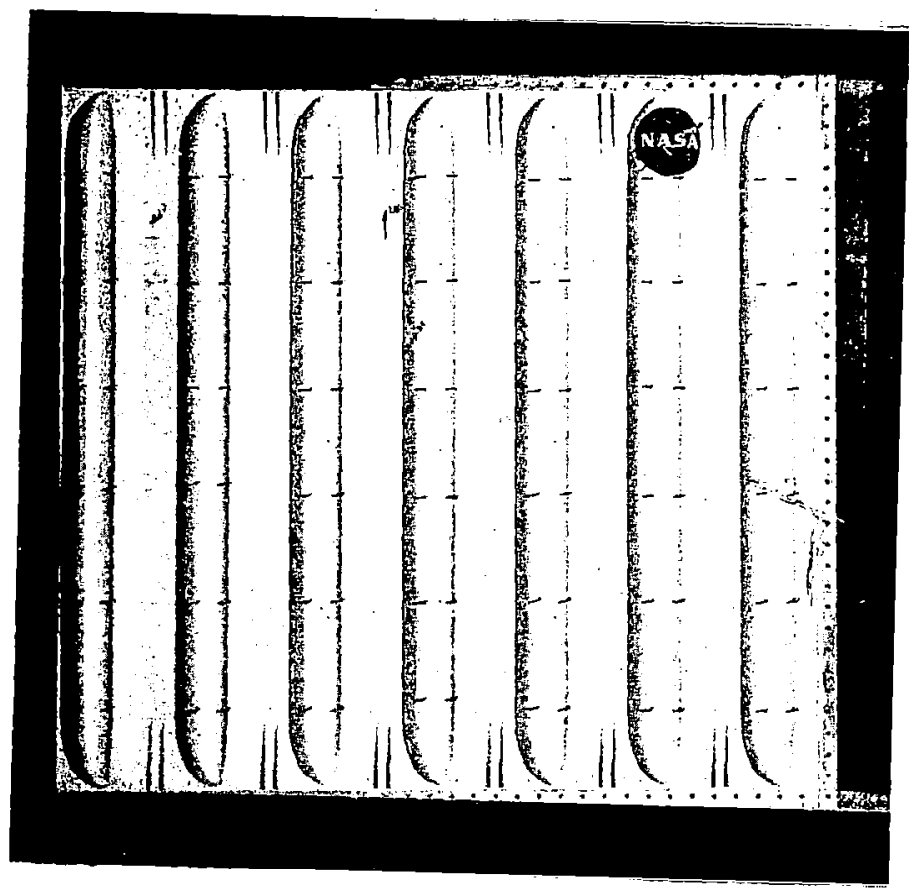

Figure 41: PANEL 2A-1.P-1M

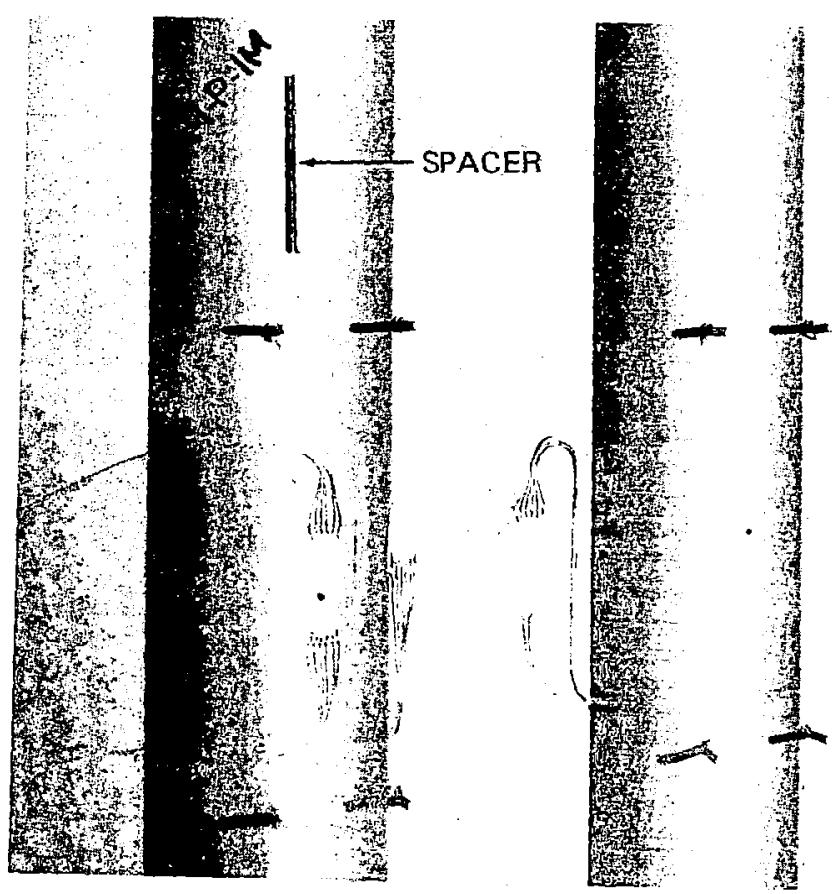

Figure 42: PANEL 2A-1-P-1M AND MACHINED SPACER 
After initial testing, the first of the high load fluted tube panels was modified by inserting rods as spacers in the manner just described. The modified panel was designated 2A-2-P-1M. Further testing of the modified panel indicated that simple spacers did not prevent tube distortional modes from degrading panel performance. The remaining two high load fluted tube specimens were modified by adding tube stabilizer inserts designed to restrain these tube distortional modes.

A portion of the second high load fluted tube panel assembly, $2 A-2-P-2 M$, is shown in Figure 43. The figure shown inserts which were riveted to the first beaded face sheet. After bonding the two face sheets together the inserts were attached to the second face sheet by blind fasteners.

Figure 44 shows a portion of one face sheet of pane1 2A-2-P-3M with inserts bonded in place. The bonding of these inserts was unsuccessful because adequate, uniform bonding pressure could not be maintained. A dense potting material was placed between the formed inserts and the beaded sheet in areas where the applied pressure had not resulted in good contact. Following the potting, four mechanical fasteners were Installed in each insert, locating two in each bead wall. 


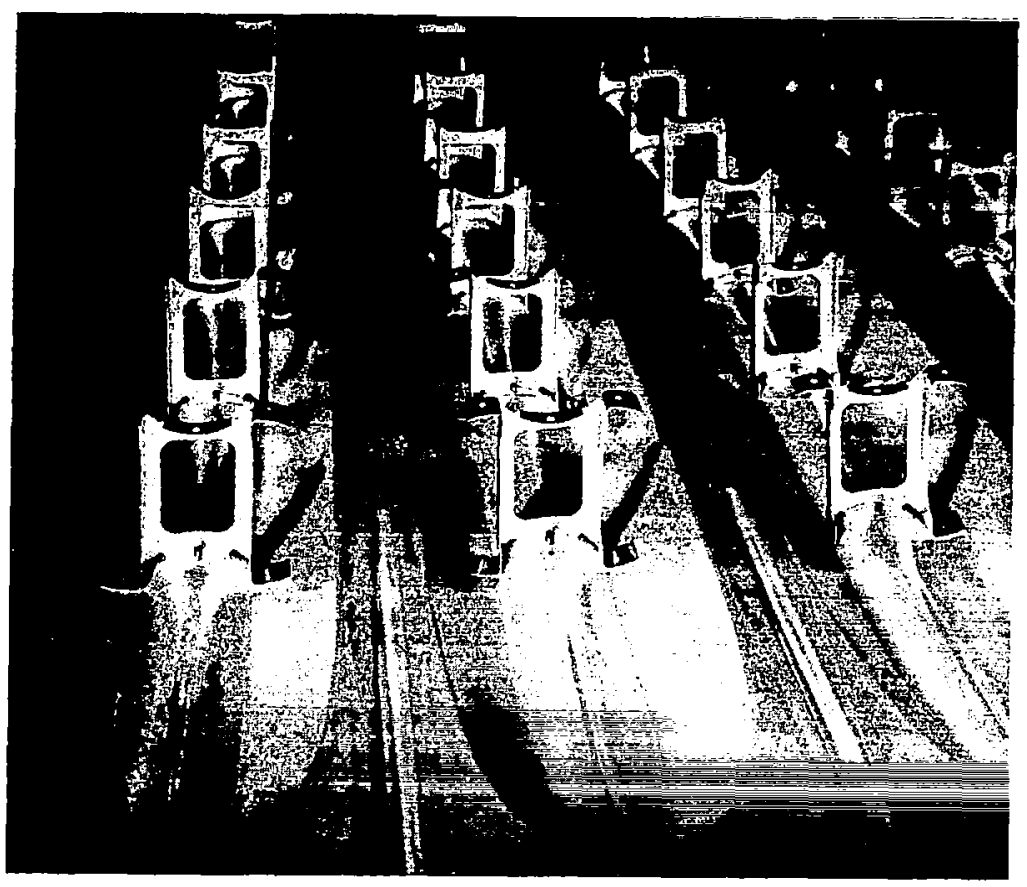

Figure 43: PANEL 2A-2-P-2 MINSERTS

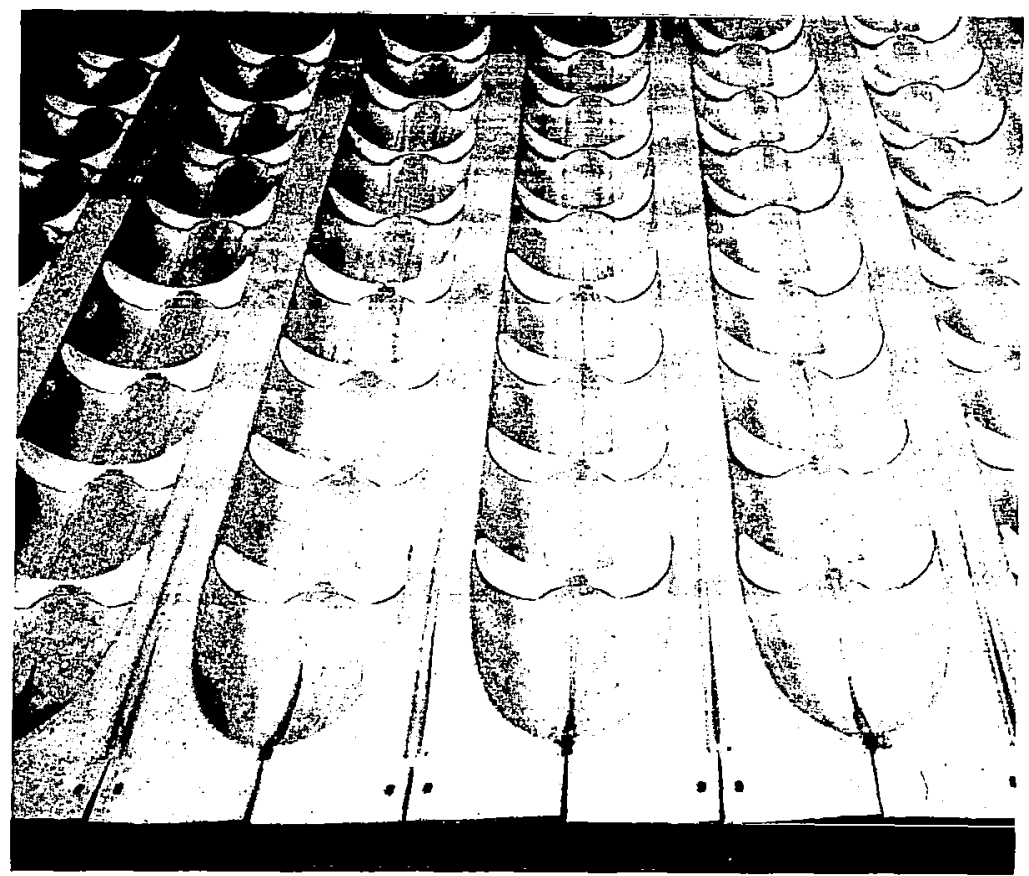

Figure 44: PANEL 2A-2-P-3 M INSERTS 


\section{TEST SPECIMENS}

The beaded and tubular specimens that were fabricated and tested for this program corresponded to nine uniform cross section designs as indicated in Figures 3 and 14. Specimens of the five cross sections shown in Figure 14 were identified as screening test specimens. The various test specimens included the necessary elements and details required to provide the desired boundary condition or interface with the applicable test fixtures. In all cases the internal and external doublers used at the specimen ends and edges were of the same material gage as the beaded sheets.

\section{Local Buckling Test Specimens}

The fluted single sheet test specimen shown in Figure 45 is typical of the local buckling specimens tested in this program. The chords and prepared ends on the specimen shown in Figure 45 are similar to those shown in Figure 39 for the end closure test specimens. The heavy "T" section chords at the edges of the specimen were provided to carry the major portion of the inplane bending moment that resulted from applying inplane shear to the ends of the test specimen. The channel members at the ends of the chords were provided to transmit the chord loads to the test fixture. The high density potting material served both to retain the shape of the end of the specimen and transmit the inplane shear load from the test fixture to the test specimen. The potting material also permitted the local buckling test specimens to be loaded in bending normal to the plane of the specimen by applying equal and opposite couples to the ends of the specimens.

The local buckling specimens were uniform in cross section along the specimen length and were approximately 18 inches $(460 \mathrm{~mm})$ wide. The tubular specimens typically had an unsupported length of 10 inches $(250 \mathrm{~mm})$. The fluted single sheet specimens, which were expected to display longer wave 1ength local buckles were fabricated with a 30 inch $(750 \mathrm{~mm})$ unsupported length.

A limited number of the local buckling specimens were designed specifically to be tested in pure axial compression or bending. They were prepared without the chord and chord attachment members.

Pane1 Test Specimens

Figure 46 shows panel 2A-2-P-2M after fabrication. It is typical of the full size tubular panels in that they have a nominal unsupported length and width of $40 \times 40$ inch $(1 \times 1 \mathrm{~m})$ and one inch $(25 \mathrm{~mm})$ prepared edges with external doublers along all four sides for attachment. Thus the overall panel length is 42 inches $(1.07 \mathrm{~m})$ and the overall width varies from approximately 42 inches $(1.07 \mathrm{~m})$ to 43.7 inches $(1.11 \mathrm{~m})$ as necessary to accommodate an integral number of tubes depending on the configuration. The attachment doublers on the high load fluted tube panels are integral with the external end closure doublers as shown in Figure 36. The attachment doublers for the circular tubular panels and the low load fluted tube panels are separate strips of material bonded in place as shown in Figures 11,12 and 13 . 


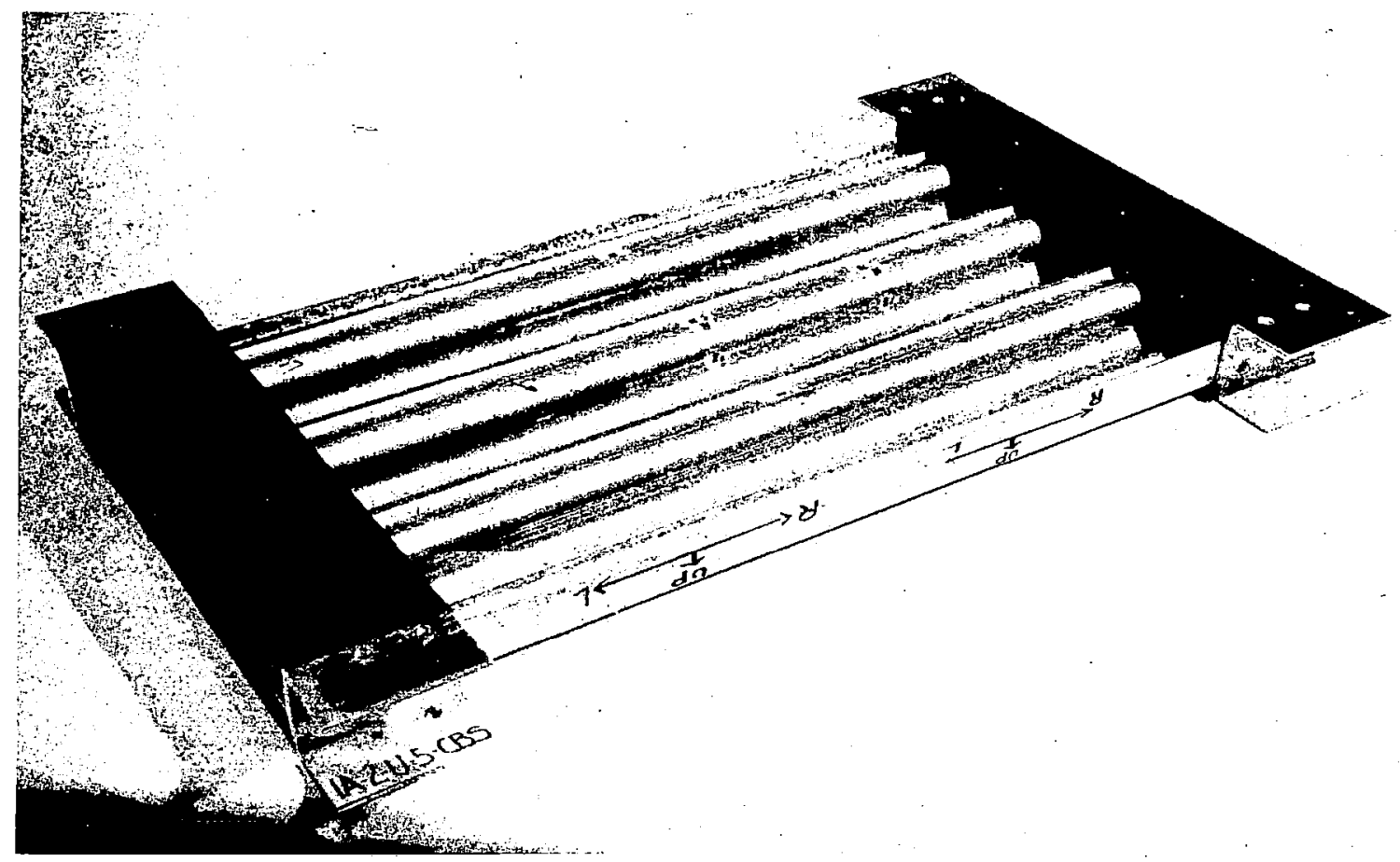

Figure 45: FLUTED SINGLE SHEET LOCAL BUCKLING TEST SPECIMEN

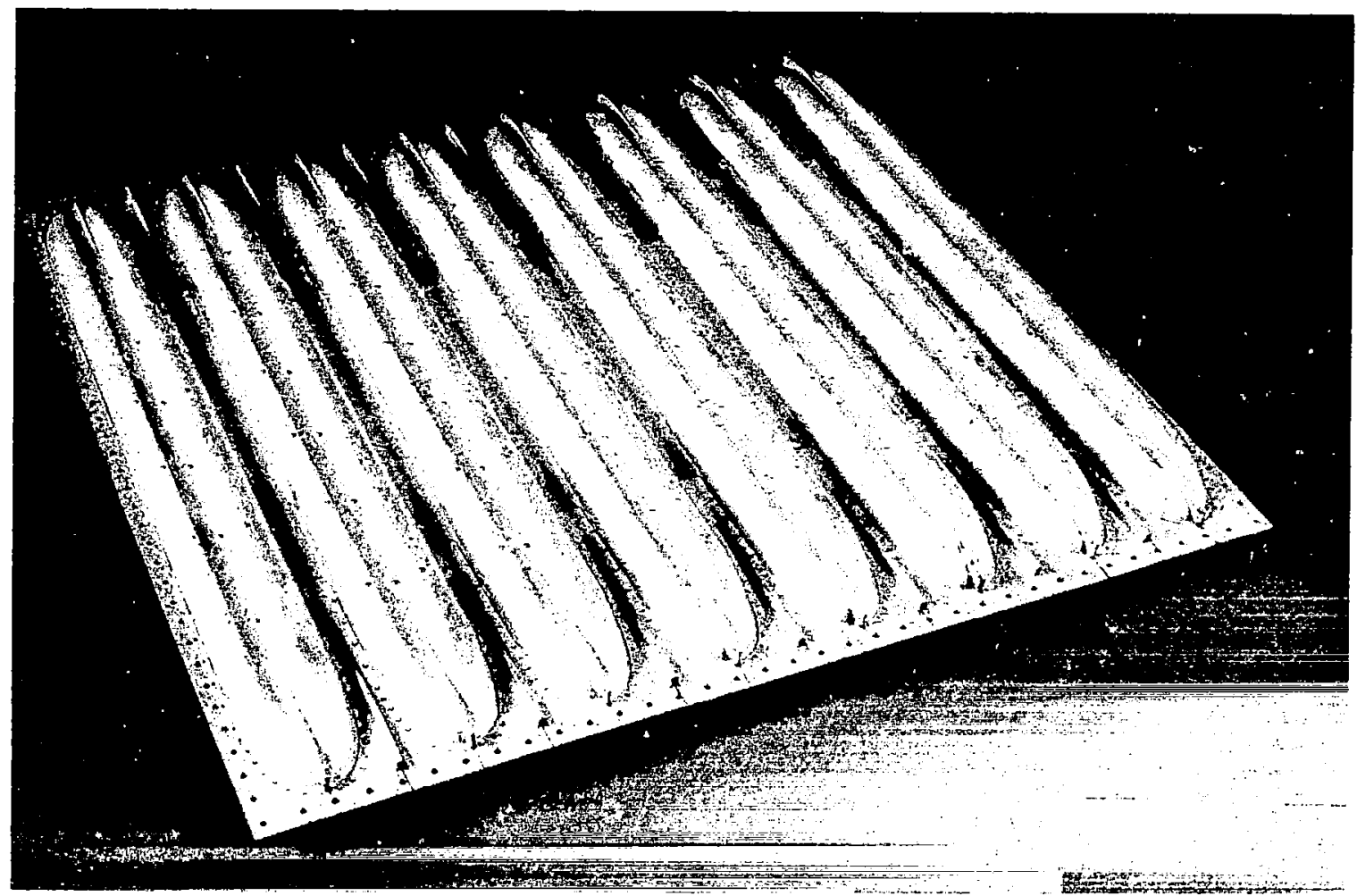

Figure 46: TEST PANEL 2A-2-P-2M 
The fluted single sheet panels employed end attachment plates similar to that shown in Figure 30 with the addition of a flange to permit attachment. The edge doublers were similar to those used on the tubular panels.

A summary of the mass properties of the panel test specimens is given in Table 1. The total masses were obtained by weighing the finished panels after final trimming and drflling of attachment holes. Total mass per unit area was calculated from the total mass and the overall dimensions. The skin mass per unit area was calculated from the panel uniform cross section geometry, and thus represents an ideal panel weight without any penalty for doublers, fasteners, or inserts. The manufactured cross section dimensions for the two high load configurations differ slightly from those indicated in Figure 3 in order to use standard material gages. These differences are discussed in Reference 9. Masses indicated for doublers and fasteners include all internal and external doublers, all bonding material, and all rivets used in reinforcing end closures and attaching inserts, but do not include fasteners for attaching the panels to the test fixture. The total masses given for the fluted single sheet panel specimens are not representative of flight hardware because the excess material in the end attachment plates was not removed by routing, as it was in the end closure specimen seen in Figure 30 . 
Table 1: MASS OF $40 \mathrm{INCH} \times 40 \mathrm{INCH}(1 \mathrm{~m} \times 1 \mathrm{~m})$ PANELS

\begin{tabular}{|c|c|c|c|c|c|c|c|c|c|c|}
\hline \multirow{2}{*}{$\begin{array}{l}\text { PANEL } \\
\text { CONFIGURATION } \\
\text { SPECIMEN } \\
\text { IDENTIFICATION }\end{array}$} & \multicolumn{10}{|c|}{ MASS } \\
\hline & \multicolumn{3}{|c|}{ SKIN } & \multicolumn{3}{|c|}{$\begin{array}{l}\text { DOUBLERS AND } \\
\text { FASTENERS }\end{array}$} & \multicolumn{4}{|c|}{ TOTAL } \\
\hline \multirow{2}{*}{$\begin{array}{l}\text { CIRCULAR } \\
\text { TUBE } \\
\text { 2-2-P-1 }\end{array}$} & \multicolumn{2}{|c|}{$\mathrm{lb} / \mathrm{ft}^{2}$} & $\mathrm{~kg} / \mathrm{m}^{2}$ & \multicolumn{2}{|c|}{ lb } & $(\mathrm{kg})$ & lb & (kg) & $\mathrm{lb} / \mathrm{ft}^{2}$ & $\left(\mathrm{~kg} / \mathrm{m}^{2}\right)$ \\
\hline & \multicolumn{2}{|c|}{1.028} & $(5.019)$ & \multicolumn{2}{|c|}{2.41} & $(1.09)$ & 15.00 & $(6.80)$ & 1.224 & (5.977) \\
\hline $2-2-P-2$ & \multicolumn{2}{|c|}{1.028} & (5.019) & \multicolumn{2}{|c|}{2.26} & $(1.03)$ & 14.85 & $(6.74)$ & 1.212 & $(5.918)$ \\
\hline $2-2-P-3$ & \multicolumn{2}{|c|}{1.028} & (5.019) & \multicolumn{2}{|c|}{2.16} & $(0.98)$ & 14.75 & (6.69) & 1.204 & (5.879) \\
\hline \multicolumn{11}{|l|}{$\begin{array}{l}\text { FLUTED SINGLE } \\
\text { SHEET }\end{array}$} \\
\hline 1A-1-P-1 & \multicolumn{2}{|c|}{0.461} & (2.251) & \multicolumn{2}{|c|}{20.0} & $(9.07)$ & 25.5 & $(11.6)$ & 2.06 & $(10.1)$ \\
\hline $1 A \cdot 1 \cdot P \cdot 2$ & \multicolumn{2}{|c|}{0.461} & & \multicolumn{2}{|c|}{20.0} & (9.07) & 25.5 & (11.6) & 2.06 & (10.1) \\
\hline \multirow[t]{2}{*}{$\begin{array}{l}\text { FLUTED } \\
\text { TUBE }\end{array}$} & \multicolumn{2}{|c|}{ SKIN } & \multicolumn{2}{|c|}{ INSERTS } & \multicolumn{2}{|c|}{$\begin{array}{l}\text { DOUBLERS AND } \\
\text { FASTENERS }\end{array}$} & & & & \\
\hline & $\mathrm{lb} / \mathrm{ft}^{2}$ & $\left(\mathrm{~kg} / \mathrm{m}^{2}\right)$ & lb & (kg) & $\mathrm{lb}$ & (kg) & & & & \\
\hline $2 A-1-P \cdot 1 M$ & 0.657 & (3.208) & 0.25 & $(0.11)$ & 1.92 & $(0.87)$ & 10.22 & $(4.64)$ & 0.802 & (3.916) \\
\hline $2 A-2-P-1 M$ & 0.839 & $(4.097)$ & 0.41 & $(0.19)$ & 2.81 & $(1.27)$ & 13.50 & $(6.12)$ & 1.059 & (5.171) \\
\hline 2A-2-P-2M & 0.839 & $(4.097)$ & 0.57 & $(0.26)$ & 3.18 & (1.44) & 14.03 & $(6.36)$ & 1.101 & $(5.376)$ \\
\hline $2 A-2-P-3 M$ & 0.839 & $(4.097)$ & 1.05 & $(0.48)$ & 4.04 & (1.83) & 15.37 & $(6.97)$ & 1.206 & (5.889) \\
\hline
\end{tabular}




\section{INSTRUMENTATION}

Varying amounts of instrumentation were used with the different test specimens to permit monitoring of stresses, out-of-plane deflections and the associated fallure modes.

\section{Strain Gages}

Strain gages and strain rosettes were installed on each panel to monitor stress distributions and to obtain force/stiffness nondestructive test data. The total number of channels varfed from 40 to 60 , depending on the expected complexity or on the uncertainty of the panel response. Figure 47 shows the arrangement of strain gages used with panel 2-2-P-1 which was the first panel tested. Strain gages were also installed on the chords of the panel test fixture to permit positive identification of the portions of the applied loads that were carried by the chords. This extent of instrumentation was considered necessary to determine stress distributions within the test panels, to simplify the correlation of the test results and to prevent premature failure in the boundary. The failures have generally initiated at the center rather than the edges of the test specimens indicating that satisfactory boundaries were achleved.

End closure specimens were strain gaged only when investigating particular problems. Correspondingly, the number of strain gages used with the local buckling test specimens ranged from none for the initial screening test specimens loaded only in shear to approximately 24 for the final combined load test specimens.

\section{Grid Shadow Moire'}

The grid shadow Moire' monitoring technique described in Reference 17 and depicted in Figure 48 was used in identifying detailed failure modes. The technique permits direct observation of the out-of-plane deflections of initially plane surfaces of the test specimen. The Moire' monitoring technique was used in the initial end closure development to identify the occurrence and nature of deformations associated with the different end closure designs. Moire' was also used in the local buckling tests and the full size panel tests to identify the various buckle modes as they developed.

As indicated in Figure 48 the grid shadow Moire' monitoring technique requires a high intensity point light source, a ruled reference grid and a camera or an observer. The out-of-plane deflections are observed as Moire' fringe lines that result from viewing the shadow of the ruled grid through the grid. The sketch in Figure 48 indicates three viewed surface positions located such that the first and third position will produce dark image bands and the immediate position will result in the maximum light. The sensitivity, which corresponds to the distance between the first and third positions is determined by the grid spacing and the angle to the light source. Examples of grid shadow Moire' photographs are shown in Figures 24, 25, 29 and 31. 


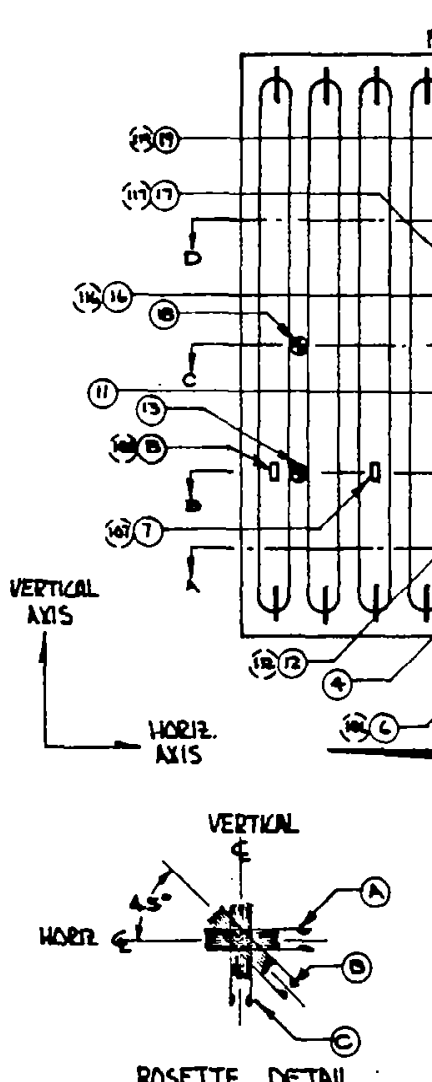

(Lochtous $911,13,1,1,1, L, 18<116)$
TNEL TOP
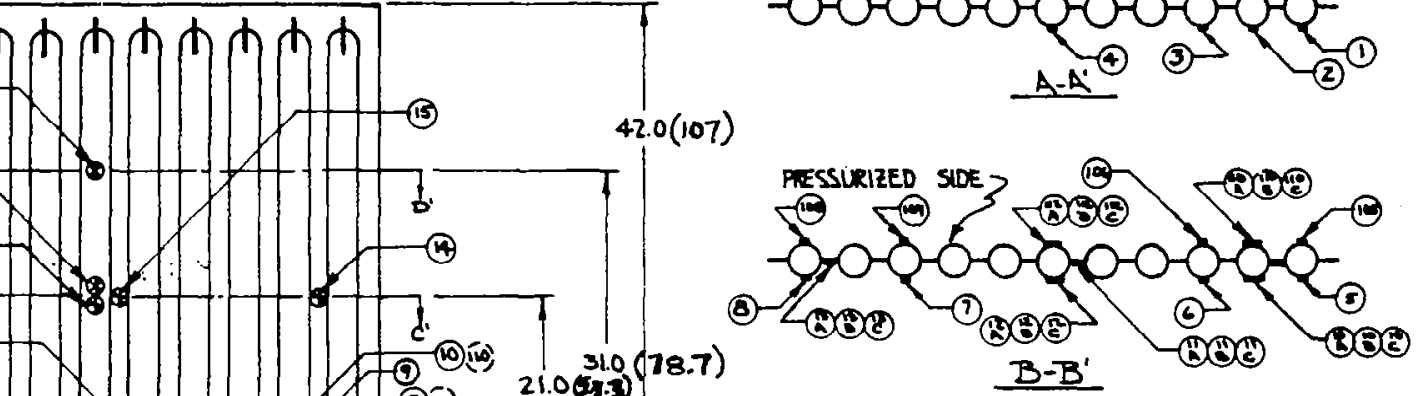

)
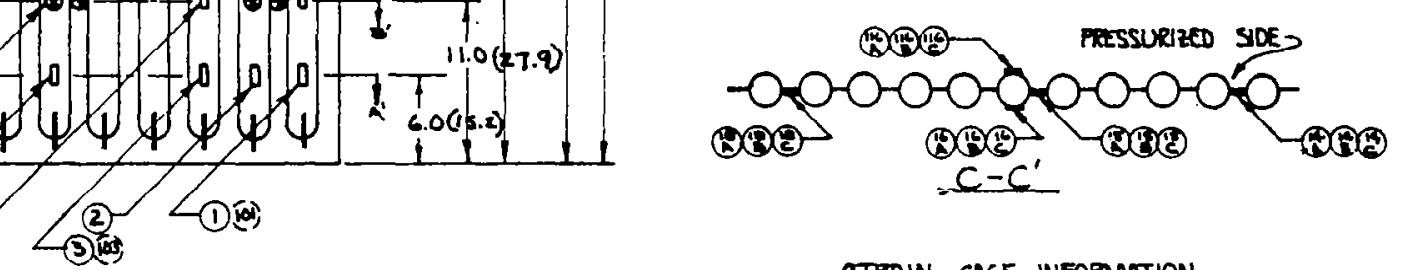

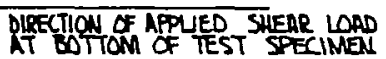
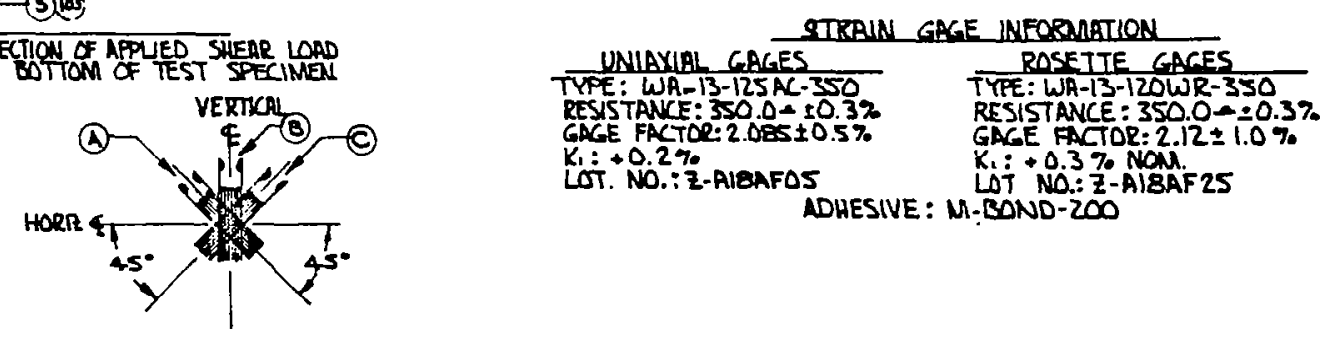

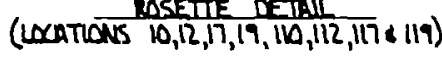

Figure 47: STRAIN GAGE INSTALLATION-PANEL NO. 2-2-P.1

DIMENSIONS IN INCHES (CM) 


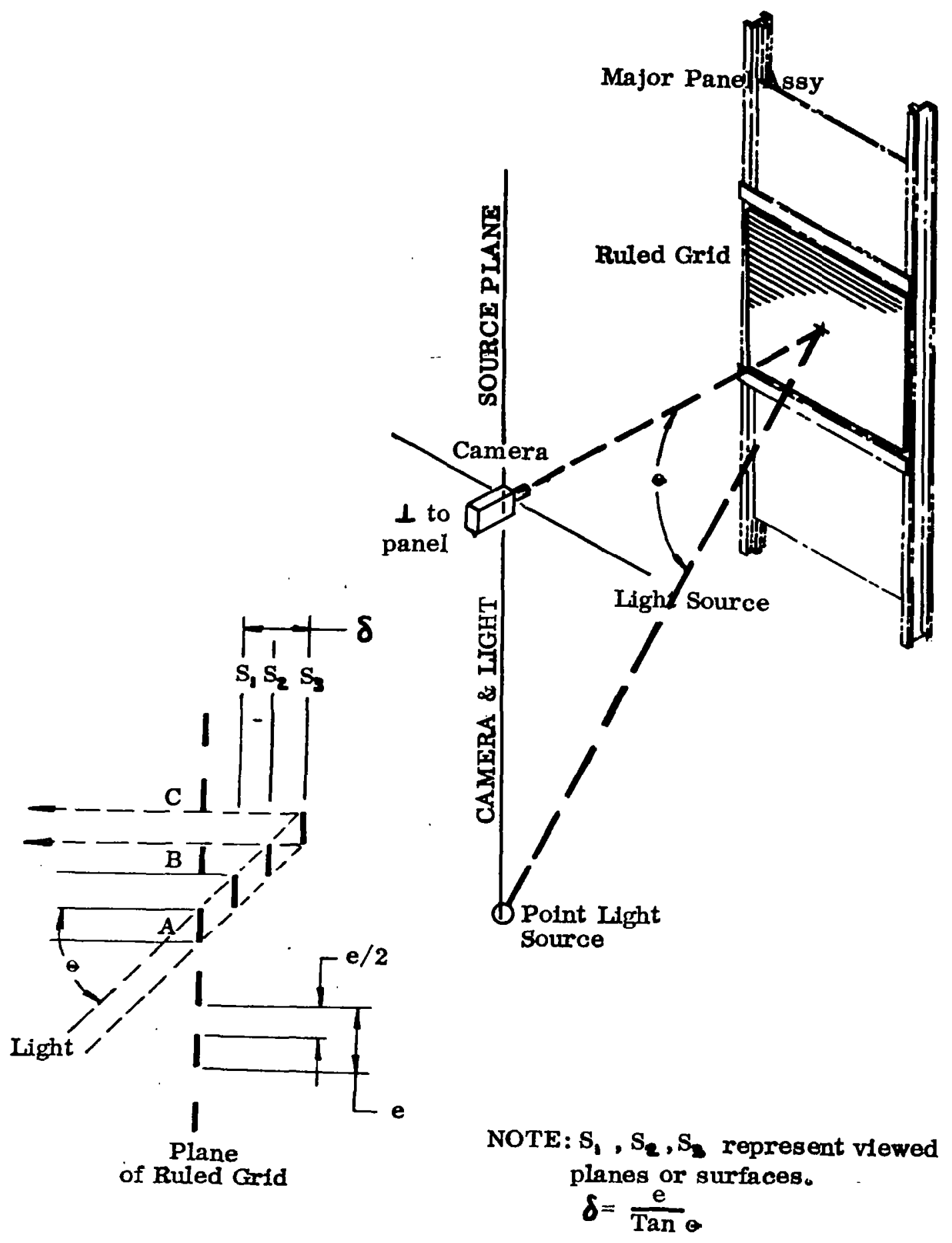

Figure 48: SCHEMATIC OF PANEL AND GRID-SHADOW MOIRE COVERAGE 


\section{TEST TECHNIQUE}

Ful1 size $40 \times 40$ inch ( $1 \times 1$ meter) panels of each of the designs were fabricated and tested under combined loads in the fixture shown in Figure 49. The combined load test technique was an extension of a system developed to test shear beams in support of the Boeing SST development program described in Reference 18. Compression was applied to the panel by the two vertical actuators, and shear was applied by the horizontal actuator shown to the left of the center of the test panel. An air bag system, shown in Figure 50, is located behind the test panel to produce bending in the test panel. Figures 49 and 50 also show the rigid truss system and the pivoted links that were used to restrict motion of the panels to prevent general instability of the three panel system.

Extensive finite element analyses were conducted to support the design of the test beam and its chords, joints, buffer bays and loading plates, to minimize the undesirable influences of the boundary members upon the stress distributions within the test panel. The inplane moments of inertia of the joint members and the chords of the test beam were minimized to reduce the Vierendeel truss effect. It was necessary to provide enough lateral and torsional stiffness in the chord and joint members to prevent local instability in the boundary members.

\section{Force/Stiffness Nondestructive Test Technique}

Both the quantity and quality of the test data available from this program were enhanced by the Force/Stiffness (F/S) nondestructive buckling test technique described in Reference 8 . The F/S technique permits monitoring during a test to observe proximity to and magnitude of the critical buckling load without failing the test specimen. Thus, the F/S technique permitted identification of the critical buckling load for each of several different load conditions for each of the test panels. The ability to define numerous failure loads on a single specimen eliminated the effects of data scatter which normally result from specimen-to-specimen differences. Consequent1y, major improvements were realized in the quality of the test data and in the ability to correlate the test results with the analytical predictions.

The methodology of the F/S technique is based on two simple facts: (1) for classical buckling, data in the F/S format forms a straight line which intersects the load axis at the critical buckling load; (2) a limiting strain level (yield strain or a strain which defines local crippling) plots as a straight line, the intersection of which by an F/S plot signifies local failure. The characteristics of the method in these two situations are discussed briefly below.

The classical buckling deformations of an initially, imperfect structure can usually be represented quite accurately by the well known equation

$$
D=\frac{D_{0}}{F_{c r} / F-1}
$$




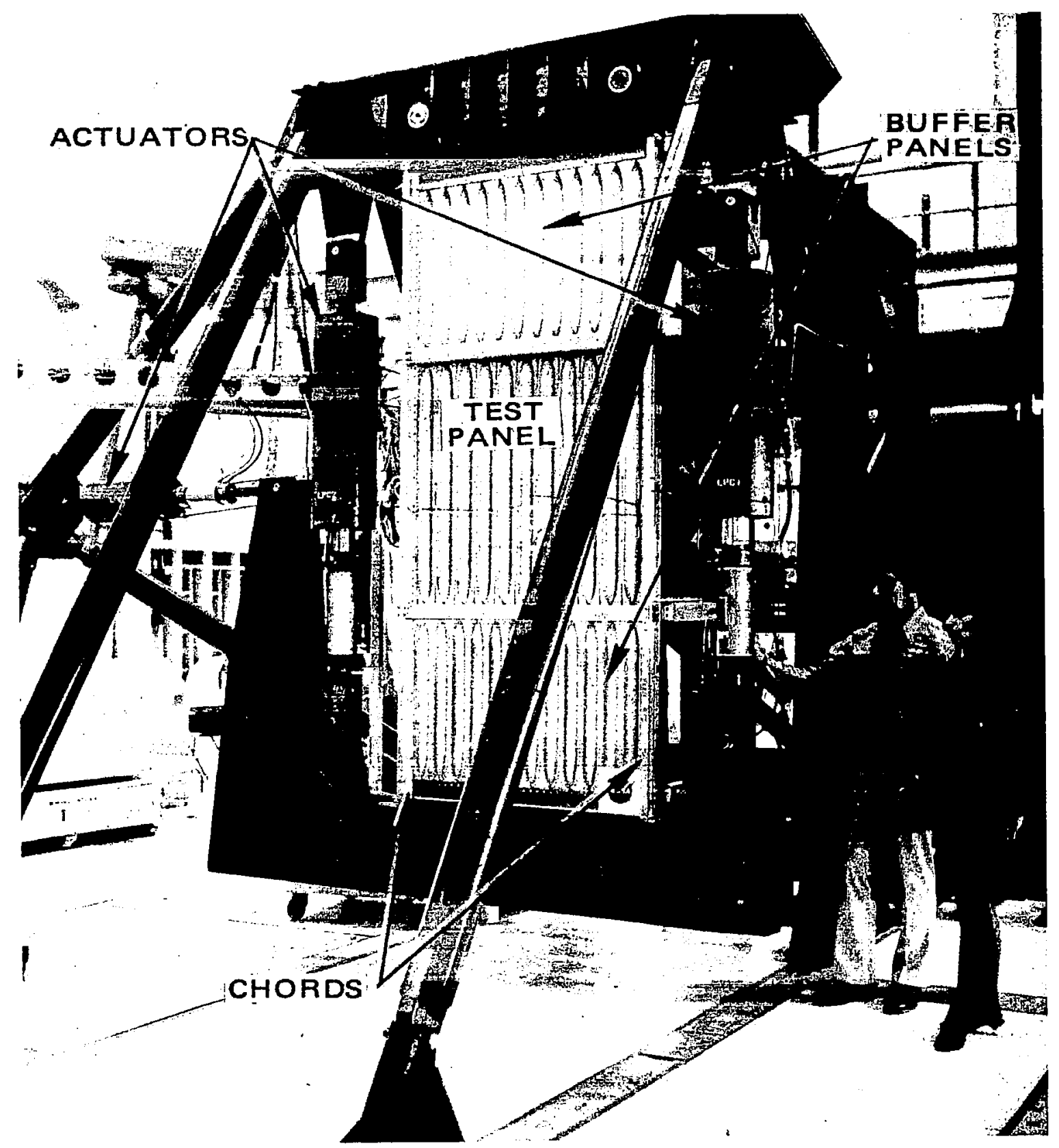

Figure 49: PANEL TEST FIXTURE 


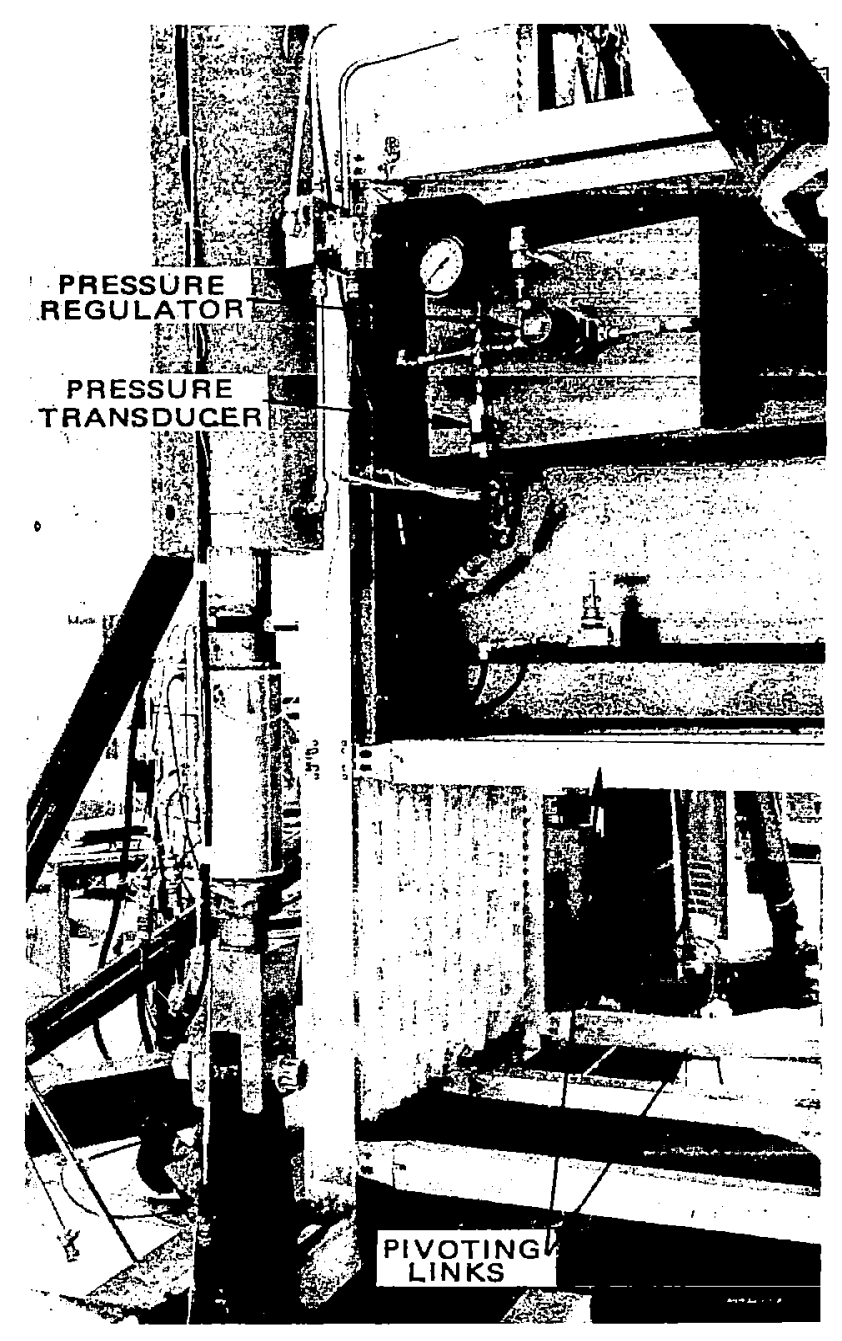

FigUre 50: PANEL TEST FIXTURE SHOWING PRESSURE BAG AND LATERAL SUPPORT 
where $D$ and $F$ are, respectively, displacement or strain, and force or pressure quantities. $D_{\mathrm{O}}$ is an initial imperfection and $F_{\mathrm{cr}}$ is a general instability classical buckling load. The equation is easily put in the form of a stiffness,

$$
\frac{F}{D}=\frac{F_{c r}-F}{D_{0}}
$$

From the equation it is seen that a plot of F/D vs. F (the F/S plot) is a straight line intersecting the F-axis at the critical general instability load, $F_{c r}$. This behavior is illustrated in Figure 51. This simple consideration suggests that, even for complex buckling problems, an F/S plot which is inclined downward to the right, as shown in the figure, is a clear indication of approaching buckling. For buckling which is classical, or is classical in its early stages, the intersection of this line with the horizontal axis, obtained by extrapolation during testing, is an estimate of the general instability load.

The buckling failure of a test specimen is ultimately caused by material failure and/or by a local crippling instability which renders the specimen incapable of supporting load. Suppose that either analytically or by tests of coupon specimens, a strain level is determined at which local failure will occur. This limiting strain value can be represented conveniently on an $\mathrm{F} / \mathrm{S}$ plot as shown in Figure 52. The limiting strain, denoted by $D$, is represented by a straight line passing through the origin, whose (scraled) inverse slope is $\mathrm{D}_{\mathrm{cr}}$. In a test of a structure which incorporates parts whose local strength is represented by $D_{c r}$, failure is indicated by the intersection of the F/S plot with the limiting strain line. Figure 52 illustrates such indicated failure for two types of pre-failure behavior: 1inear elastic behavior, which plots as a straight horizontal line; and a buckling behavior, which shows a downward-to-the-right slope. This approach has proved very valuable for nondestructive monitoring for local buckling or crippling failure while conducting the panel tests.

\section{Test Procedure}

The F/S technique was used to identify failure loads for many load conditions applied to the individual test panels. In general, the matrix of load conditions shown in Table 2 were applied to the panels. A maximum pressure of 1 psi $\left(6.9 \mathrm{kN} / \mathrm{m}^{2}\right)$ was used in testing the panels designed for load condition 1 , and a maximum pressure of $2 \mathrm{psi}\left(13.8 \mathrm{kN} / \mathrm{m}^{2}\right)$ was used in testing the panels designed for load condition 2.

To obtain the best possible accuracy, the test load conditions were applied in sequence to a given percentage of the predicted strength. F/S predictions were made from these data. The percentage was then increased and the load conditions were repeated. Improved $F / S$ predictions were made from the higher load data and the panels were finally tested to failure in a selected load condition. The failure loads provided a check on the F/S strength predictions. 


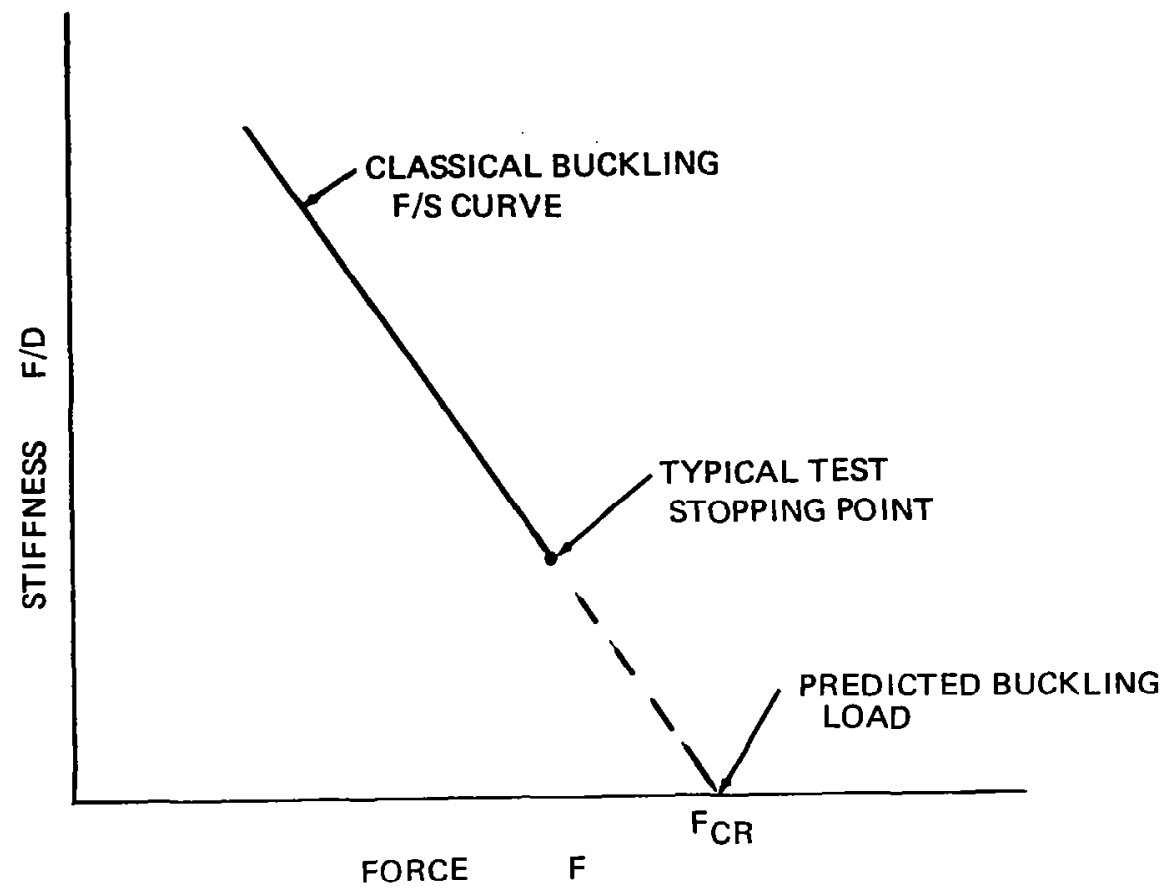

Figure 51: FORCE/STIFFNESS PLOT FOR GENERAL INSTABILITY

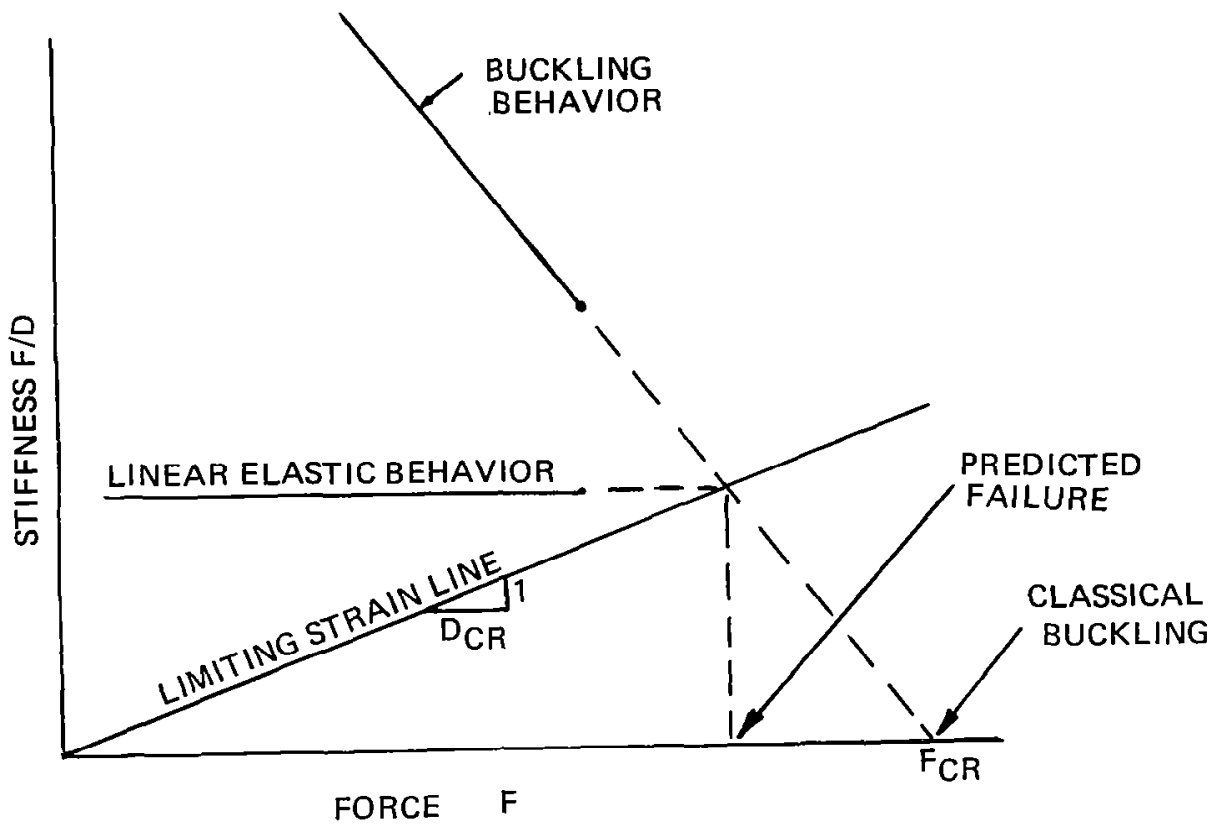

Figure 52: LIMITING STRAIN LINE ON F/S PLOT 
TABLE 2 (a): TEST LOAD CONDITIONS FOR DESIGN LOAD CONDITION 1 PANELS

\begin{tabular}{|c|c|c|c|c|}
\hline \multirow[t]{2}{*}{$\begin{array}{l}\text { TEST LOAD } \\
\text { CONDITION }\end{array}$} & \multicolumn{2}{|c|}{$\begin{array}{l}\text { COMP. VS. SHEAR } \\
\text { LOAD RATIO }\end{array}$} & \multicolumn{2}{|c|}{$\begin{array}{l}\text { LATERAL PRESSURE } \\
\mathbf{p}=\text { CONSTANT }\end{array}$} \\
\hline & $N_{x}$ & $N_{x y}$ & psi & $\left(\mathrm{kN} / \mathrm{m}^{2}\right)$ \\
\hline 1 & 1 & 0 & \multicolumn{2}{|l|}{0} \\
\hline 2 & 0 & 1 & \multicolumn{2}{|l|}{0} \\
\hline 3 & 1 & $1 / 5$ & \multicolumn{2}{|l|}{ o } \\
\hline 4 & 1 & $1 / 3$ & \multicolumn{2}{|l|}{0} \\
\hline 5 & 1 & 0 & \multicolumn{2}{|r|}{ (3.4) } \\
\hline 6 & 1 & 0 & \multicolumn{2}{|c|}{$1.0 \quad(6.9)$} \\
\hline 7 & 0 & 1 & \multicolumn{2}{|c|}{$0.5 \quad(3.4)$} \\
\hline 8 & 0 & 1 & \multicolumn{2}{|c|}{$1.0 \quad(6.9)$} \\
\hline 9 & 1 & $1 / 3$ & \multicolumn{2}{|c|}{$0.5 \quad(3.4)$} \\
\hline 10 & 1 & $1 / 3$ & \multicolumn{2}{|c|}{$1.0 \quad(6.9)$} \\
\hline E 2 (b): TEST & $\operatorname{CON}$ & WNS FOR & $\angle O A D$ & NDITION 2 \\
\hline \multirow[t]{2}{*}{$\begin{array}{l}\text { TEST LOAD } \\
\text { CONDITION }\end{array}$} & \multicolumn{2}{|c|}{$\begin{array}{l}\text { COMP. VS SHEAR } \\
\text { LOAD RATIO }\end{array}$} & \multirow{2}{*}{\multicolumn{2}{|c|}{$\begin{array}{c}\text { LATERAL PRESSURE } \\
p=\text { CONSTANT } \\
\text { psi }\left(\mathrm{kN} / \mathrm{m}^{2}\right)\end{array}$}} \\
\hline & $N_{x}$ & $N_{x y}$ & & \\
\hline 1 & 1 & 0 & \multicolumn{2}{|c|}{0} \\
\hline 2 & 0 & 1 & \multicolumn{2}{|c|}{0} \\
\hline 3 & 1 & $1 / 5$ & \multicolumn{2}{|c|}{0} \\
\hline 4 & 1 & $1 / 3$ & \multicolumn{2}{|c|}{0} \\
\hline 5 & 1 & 0 & \multicolumn{2}{|c|}{$1.0(6.9)$} \\
\hline 6 & 1 & 0 & \multicolumn{2}{|c|}{$2.0(13.8)$} \\
\hline 7 & 0 & 1 & \multicolumn{2}{|c|}{$1.0(6.9)$} \\
\hline 8 & 0 & 1 & \multicolumn{2}{|c|}{$2.0(13.8)$} \\
\hline 9 & 1 & $1 / 5$ & \multicolumn{2}{|c|}{$1.0(6.9)$} \\
\hline 10 & 1 & $1 / 5$ & \multicolumn{2}{|c|}{2.0 (13.8) } \\
\hline
\end{tabular}


Each of the panel tests was monitored by the Moire' technique in order to identify deformation modes and to aid in selecting the strain gage channels to produce the desired F/S plots. Several F/S plots were generated simultaneously using different strain gage data as input for each F/S plot. The F/S plots developed from the deflection or strain gage data best representing the critical deflection modes also produced the lowest buckling load predictions. The difference between outputs of two back-to-back strain gages was usually found to provide the best F/S indication of general panel instability.

The detailed test procedures are provided in Reference 11. 
Large amounts of test data were generated for each of the optimized configurations shown in Figure 3 as well as the screening test configurations shown in Figure 12. The data included the as-fabricated specimen dimensions, material coupon test results, load and strain gage data, F/S plots and Moire' photographs. More extensive amounts of test data were generated from the panel tests than from the local buckling and end closure tests. The significant portions of the local buckling and panel test data have been compiled and are available in References 9 and 11 .

A summary of the test data is presented below, and the test data are compared with theory. Correlation of the theory with test data consisted of two steps. The first step was a preliminary one in which analytical local buckling strengths were compared with local buckling test results, and the static strength equations were modified as necessary to achieve the desired correlation. Except in cases of pure shear loading, critical stresses from local buckling tests were determined from strain gage readings in critical locations and from average material coupon properties. In the case of pure shear loads applied to the local buckling specimens, critical stresses were calculated from the applied load and net section properties. The second step was a final data correlation in which analytically predicted failure loads were compared with test data from the full size, 40-in. X 40-in. (1m x 1m) panel specimens. The purpose of the final data correlation was to establish the validity of the analysis method for use in designing minimum mass structural panels to withstand specified design loads of compression, shear, and lateral pressure.

End closure test results are not presented since a detailed analysis and design optimization of the end closures was beyond the scope of this program. In general the end closure test results indicated that the strengths of those specimens were limited by the strength of the uniform sections rather than the end closures themselves. Thus, the end closure designs were considered adequate since the local buckling strengths of each of the four configurations were well above the full size panel strengths which form upper limits to the loads that can be applied to the panel end closures. The end closure design details and test results were discussed previously under "DESIGN EVOLUTION End Closure Evolution."

\section{Circular Tube Specimen Results}

Local buckling specimen test data. - The local buckling tests were conducted with specimens of the initial screening configuration (see Figure 14) whereas the full size panels were of the optimized design configuration. All of the circular tube specimens were well behaved and there were no abnormal occurrences or unexplained failures. Failure stresses from local buckling tests (specimens designated 2-2-U-X) and two large panel tests (specimens designated 2-2-P-x) are compared with analytical failure stresses in Table 3 . 
Table 3: CIRCULAR TUBE LOCAL BUCKLING TEST DATA SUMMARY

\begin{tabular}{|c|c|c|c|c|c|c|c|}
\hline $\begin{array}{c}\text { SPECIMEN } \\
\text { TYPE }\end{array}$ & $\begin{array}{c}\text { SPECIMEN } \\
\text { NO. }\end{array}$ & $\begin{array}{l}\text { LOAD } \\
\text { TYPE }\end{array}$ & $\begin{array}{l}\text { FAILUR } \\
\text { TEST }\end{array}$ & $\begin{array}{l}\text { STRESS } \\
\text { ORIGINAL } \\
\text { ANALYSIS }\end{array}$ & $\begin{array}{c}\text { KSI } \\
\left(M N / m^{2}\right) \\
\text { MODIFIED } \\
\text { ANALYSIS }\end{array}$ & $\begin{array}{l}\text { CORAELATIOA } \\
\text { ORIGINAL } \\
\text { ANALYSIS }\end{array}$ & $\begin{array}{l}\text { FACTOR } \\
\text { MODIFIED } \\
\text { A'NALYSIS }\end{array}$ \\
\hline $\begin{array}{l}\text { UNIFORM SECTION } \\
\text { LOCAL BUCKLING } \\
\text { SPECIMENS } \\
R=1.20 \mathrm{IN} . \\
t=.032 \mathrm{IN} .\end{array}$ & $\begin{array}{l}2-2 \cdot U-1 \\
2-2-U-2 \\
2-2-U-3 \\
2-2 \cdot U-4 \\
2-2-U-5\end{array}$ & $\begin{array}{c}B \\
S \\
C \\
C+S \\
C+B\end{array}$ & $\begin{array}{l}F_{B}=\begin{array}{c}78.2 \\
(540)\end{array} \\
F_{S}=\begin{array}{c}37.5 \\
(259)\end{array} \\
F_{C}=\begin{array}{c}69.2 \\
(477)\end{array} \\
F_{C}=\begin{array}{c}58.5 \\
(404)\end{array} \\
F_{S}=\begin{array}{c}17.8 \\
(123)\end{array} \\
F_{C}=\begin{array}{c}21.8 \\
(150)\end{array} \\
F_{B}=\begin{array}{c}58.8 \\
(406)\end{array}\end{array}$ & 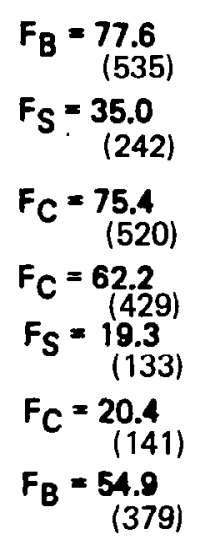 & 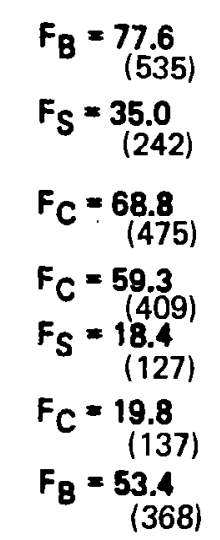 & $\begin{array}{l}1.01 \\
1.07 \\
.92\end{array}$ & $\begin{array}{r}1.01 \\
1.07 \\
1.02 \\
.97 \\
1.10\end{array}$ \\
\hline $\begin{array}{l}40 \text { IN. } X 40 \text { IN } \\
\text { PANEL } \\
\text { SPECIMENS } \\
\text { (TESTS TO } \\
\text { FAILURE ONLY) } \\
\qquad \begin{array}{l}R=1.34 \text { IN. } \\
t=.025 \mathrm{IN} .\end{array}\end{array}$ & $2-2 \cdot P \cdot 3$ & $c+s$ & 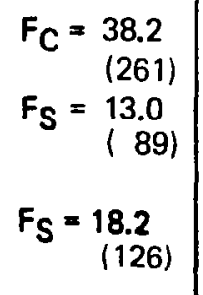 & $\begin{array}{l}F_{C}=30.7 \\
(212) \\
F_{S}=\begin{array}{c}10.9 \\
(75)\end{array} \\
F_{S}=\begin{array}{c}13.6 \\
(94)\end{array}\end{array}$ & $\begin{array}{l}F_{C}=36.0 \\
(248) \\
F_{S}=\begin{array}{l}12.3 \\
(85)\end{array} \\
F_{S}=\begin{array}{c}17.6 \\
(121)\end{array}\end{array}$ & 1.33 & 1.00 \\
\hline
\end{tabular}


The correlation factors shown in the table are calculated from the equation,

$$
\text { C.F. }=\frac{1}{2}\left\{R_{c}+R_{b}+I\left(R_{c}+R_{b}\right)^{2}+4 R_{s}{ }^{2} I^{1 / 2}\right\}
$$

which is derived from the interaction equation,

$$
R_{c}+R_{b}+R_{s}^{2}=1
$$

where $R_{c}, R_{b}$, and $R_{s}$ are stress ratios of actual stresses at failure to critiical stresses in pure compression, bending, and shear respectively. The correlation factor is the ratio of test failure stress to analytical failure stress. Thus, a correlation factor greater than unity indicates that the analysis is conservative.

Note that the local buckling data correlated relatively well with the original analysis, however, large panel failure data indicated the analysis is too conservative. Therefore, the theory was modified to give the improved correlation factor shown in the last column of Table 3 . Load interaction curves are shown in Figure 53 with these data plotted before and after modification to the theory.

On the basis of the correlation with the original analysis (see reference 9), the following modifications to the analyses were made:

(1) The correlations with test of specimens $2-2-U-3$ and 2-2-U-4 are brought within desired limits by applying a knockdown factor of .9 to the expression for $F_{\mathrm{cc}}$ (see Appendix). Thus,

$$
F_{c c}=0.738 \eta_{3} E(t / R)^{1.19}
$$

(2) The correlations with tests of the panel specimens, 2-2-P-1 and 2-2-P-3, are brought within desired limits by changing both the coefficient and exponent of the expression for the shear buckling coefficient (see Appendix) as follows:

$$
k_{s}=3.3 \mathrm{z}^{.585}
$$

This change is primarily a length effect which is identified in the analysis of Reference 15 by a series of curves which give $k_{S}$ as a function of $Z$ for various length ratios $(a / b)$. The original expression for $k_{s}$ shown in the Appendix was taken from a curve for $a / b=\infty$. The change represented by the above equation approximates a curve closer to an $a / b$ equal to 3 , thus reducing the length effect for long panels in this application. 


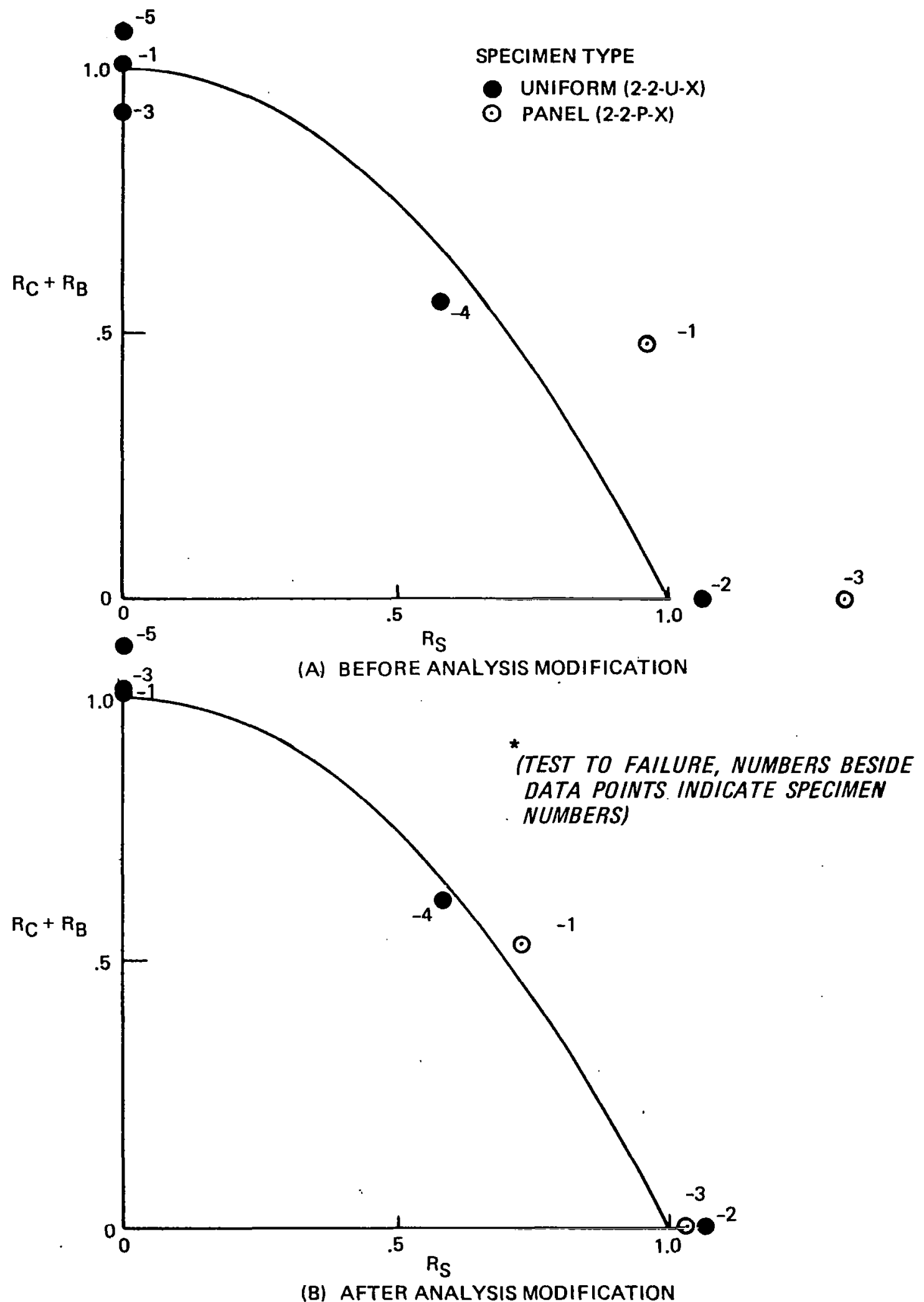

Figure 53: CIRCULAR TUBE LOCAL BUCKLING COMBINED LOAD INTERACTION PLOT * 
Panel test data. - Three 40 in. $X 40$ in. ( $1 \mathrm{~m} X 1 \mathrm{~m}$ ) panel specimens of the type 2 configuration $(2-2-\mathrm{P}-1,2-2-\mathrm{P}-2,2-2-\mathrm{P}-3)$ were each tested in the test load conditions shown in Table $2(\mathrm{~b})$. Failure loads were predicted for each of the 10 load conditions using the force-stiffness technique (reference 8) and are compared with the modified theory in Table 4. Actual panel failure loads are indicated by the asterisk for the -1 and the -3 panels. Only the major load component, $\mathrm{N}_{\mathrm{x}}$ or $\mathrm{N}_{\mathrm{xy}}$, is given for each load condition.

Test loads tabulated are nominal values determined from the applied loads assuming uniform stress distribution with a calculated panel net-to-gross area ratio of 0.396 ( 60.4 percent of gross area is edge chord area) and a net panel width of 40 inches (1m). Shear load is assumed to be carried entirely in the net panel. Net panel test loads were also determined using strain gage data from the panel center region to ensure against possible unconservative correlations which would result if actual panel center loads were significantly less than the nominal values. However, panel center loads were found to be slightly higher than the nominal values. Consequently, the correlation factors shown are based on nominal loads.

A graphical representation of the theoretical panel failure load interaction surface with force-stiffness test data is seen in Figure 54. Curves are shown for three different values of pressure. The numbers beside data points indicate test load conditions. The actual panel failures of the -1 and -3 panels are shown by the cross symbol. Test failure of the -2 panel occurred prematurely at the edges during an application of load condition 1 . Therefore, the actual failure load for this specimen is not valid for use in correlation. The predominant failure mode for all panels and test conditions is bead crippling as can be seen from Figure 54. Panel instability becomes a factor only under the conditions $\mathrm{R}_{\mathrm{b}}=\mathrm{R}_{\mathrm{S}}=0$; even then, some test results indicate bead crippling.

Pane1 failure modes. - The pane1 2-2-P-1 failure occurred without significant prior distortion. The back side of the failed panel is shown in Figure 55. The appearance of the failed panel suggests that the failure initiated near the panel center and propagated toward, but not through the end closures. This behavior indicated that the design of the test beam had resulted in the desired stress distribution within the test panel.

Pane1 2-2-P-2 was tested under the various load conditions given in Table 4 before being tested to failure under axial compression. Figure 56 shows the front surface of the failed panel which indicates that failure was due to local buckling in the flat area adjacent to the loaded edge.

Panel 2-2-P-3 also failed at the edge of the panel under combined axial load and lateral pressure as shown in Figure 57. After this failure, the panel appeared to be otherwise undamaged; consequently, it was loaded to failure in pure shear. The corresponding $\mathrm{F} / \mathrm{S}$ data was virtually identical to the $\mathrm{F} / \mathrm{S}$ data obtained prior to the edge failure indicating the capability of the panel to carry shear was not reduced; the failure occurred at $100 \%$ of the predicted shear failure load. The photograph of the failed panel, Figure 58 shows that 
Table 4: CIRCULAR TUBE PANEL TEST DATA SUMMARY (F/S DATA)

\begin{tabular}{|c|c|c|c|c|c|c|c|c|c|}
\hline \multirow{3}{*}{\multicolumn{2}{|c|}{$\begin{array}{l}\text { LOAD } \\
\text { COND }\end{array}$}} & \multirow{4}{*}{$\begin{array}{c}\text { LOAD } \\
\text { TYPE }\end{array}$} & \multicolumn{4}{|c|}{$\begin{array}{c}\text { ULTIMATE LOAD, } \\
N_{x} \text { OR } N_{x y}-\text { LB./IN. }(k N / m)\end{array}$} & \multirow{2}{*}{\multicolumn{3}{|c|}{ CORRELATION FACTOR }} \\
\hline & & & \multirow{2}{*}{$\begin{array}{l}\text { MODIFIED } \\
\text { ANALYSIS }\end{array}$} & \multicolumn{3}{|c|}{ TEST } & & & \\
\hline & & & & 2-2.P-1 & -2 & -3 & \multirow{2}{*}{$\frac{2-2+P-1}{.07}$} & \multirow{2}{*}{$\frac{-2}{(1.03)}$} & \multirow{2}{*}{$\frac{3}{95}$} \\
\hline 1 & BC & & $\begin{array}{c}3098 \\
(542)\end{array}$ & $\begin{array}{l}3000 \\
(525)\end{array}$ & $\begin{array}{c}3180 \\
(556)\end{array} \mid$ & $\begin{array}{l}2940 \\
(514)\end{array}$ & & & \\
\hline & PI & & $\begin{array}{c}3098 \\
(542)\end{array}$ & $\begin{array}{c}3080 \\
(539)\end{array}$ & 2880 & 3000 & $(.80)$ & .93 & $(.97)$ \\
\hline 2 & & S & $\begin{array}{l}876 \\
(153)\end{array}$ & $\begin{array}{l}870 \\
(152)\end{array}$ & $\begin{array}{l}895 \\
(157)\end{array}$ & $\begin{array}{c}878 \\
(154)\end{array}$ & .90 & 1.02 & 1.00 \\
\hline 3. & & $\mathrm{C}+\mathrm{S}$ & 2615 & $\begin{array}{r}2715 \\
(475)\end{array}$ & $\begin{array}{c}3070 \\
(537)\end{array}$ & $\begin{array}{c}2685 \\
(470)\end{array}$ & 1.04 & 1.17 & 1.08 \\
\hline 4 & & $\mathrm{C}+\mathrm{S}$ & $\begin{array}{l}1966 \\
(344)\end{array}$ & 2080 & 2090 & 2040 & 1.06 & 1.06 & 1.04 \\
\hline 5 & & $\mathrm{C}+\mathrm{B}$ & $\begin{array}{c}2648 \\
(463)\end{array}$ & $\begin{array}{c}3200 \\
(560)\end{array}$ & $\begin{array}{c}2685 \\
(470)\end{array}$ & $\begin{array}{c}2705 \\
(473)\end{array}$ & 1.21 & 1.01 & 1.02 \\
\hline 6 & & $\mathrm{C}+\mathrm{B}$ & $\begin{array}{c}2300 \\
(402)\end{array}$ & $\begin{array}{r}2750 \\
(481)\end{array}$ & $\begin{array}{c}2425 \\
(424)\end{array} \mid$ & $\begin{array}{l}2210 \\
(387)\end{array}$ & 1.20 & 1.05 & 0.06 \\
\hline 7 & & $S+B$ & $\begin{array}{l}849 \\
(148)\end{array}$ & $\begin{array}{c}842 \\
(147)\end{array}$ & $\begin{array}{l}885 \\
(155)\end{array}$ & $\begin{array}{l}858 \\
(150)\end{array}$ & .99 & 1.04 & 1.01 \\
\hline 8 & & $S+B$ & $\begin{array}{l}823 \\
(144)\end{array}$ & $\underset{(T 46)}{837}$ & $\begin{array}{l}868 \\
(152)\end{array}$ & $\begin{array}{l}818 \\
(143)\end{array}$ & 1.02 & 1.05 & .90 \\
\hline 9 & & $C+S+B$ & $\begin{array}{c}2325 \\
(407)\end{array}$ & $\begin{array}{c}2485 \\
(435)\end{array}$ & $\begin{array}{c}2475 \\
(433)\end{array} \mid$ & $\begin{array}{c}2390 \\
(418)\end{array}$ & 1.07 & 1.06 & 1.03 \\
\hline$* 10$ & & $\mathrm{C}+\mathrm{S}+\mathrm{B}$ & $\begin{array}{c}2074 \\
(263)\end{array}$ & $\begin{array}{r}2040 \\
(357)\end{array}$ & $\begin{array}{c}2230 \\
(390)\end{array} \mid$ & $\begin{array}{l}2100 \\
(368)\end{array}$ & .98 & 1.08 & 1.01 \\
\hline \multicolumn{7}{|c|}{$\begin{array}{l}\text { - ACTUAL FAILURE LOADS } \\
\text { PANEL DESIGN LOAD CONDITION }\end{array}$} & 1.053 & 1.047 & 1.004 \\
\hline \multicolumn{10}{|c|}{$\begin{array}{l}\text { ALL FAILURES ARE BEAD CRIPPLING (BC) EXCEPT FOR PANEL INSTABILITY (PI) AS NOTEDIN } \\
\text { CONDITION } 1\end{array}$} \\
\hline
\end{tabular}



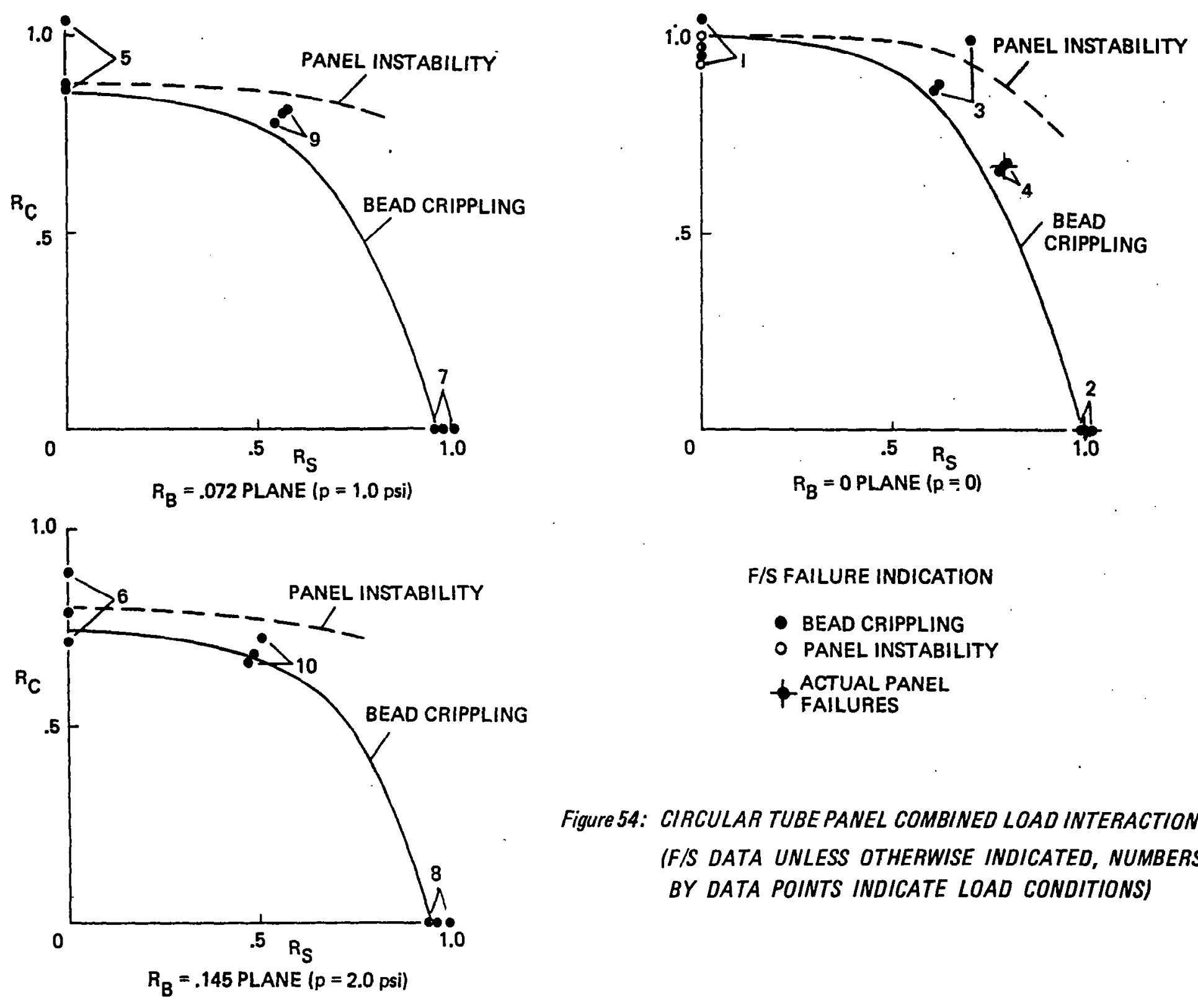

Figure 54: CIRCULAR TUBE PANEL COMBINED LOAD INTERACTION PLOT

(F/S DATA UNLESS OTHERWISE INDICATED, NUMBERS BY DATA POINTS INDICATE LOAD CONDITIONS)

\section{F/S FAILURE INDICATION}

- BEAD CRIPPLING

- PANEL INSTABILITY $\rightarrow$ ACTUAL PANEL FalluRes 


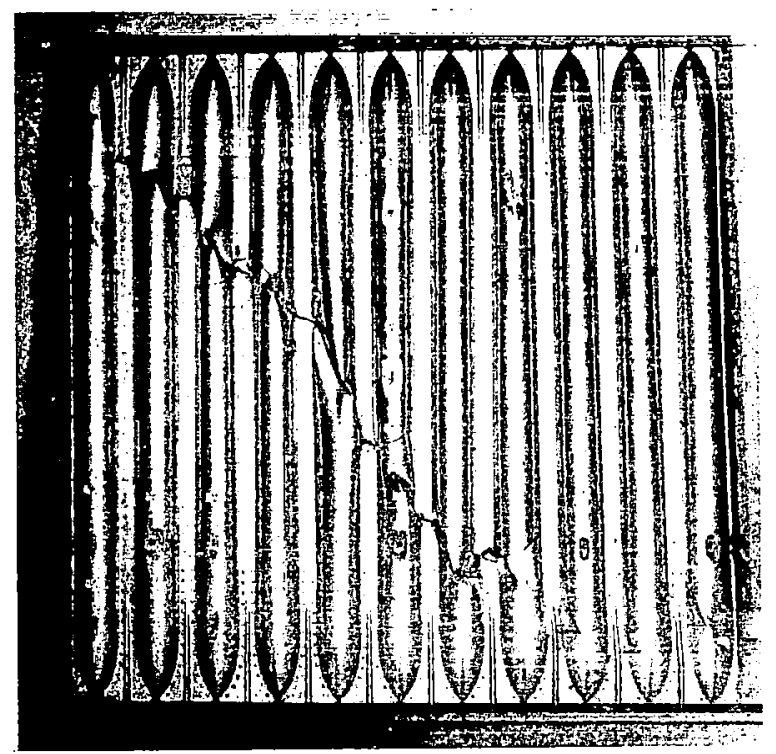

Figure 55: FAILED PANEL 2-2-P-1

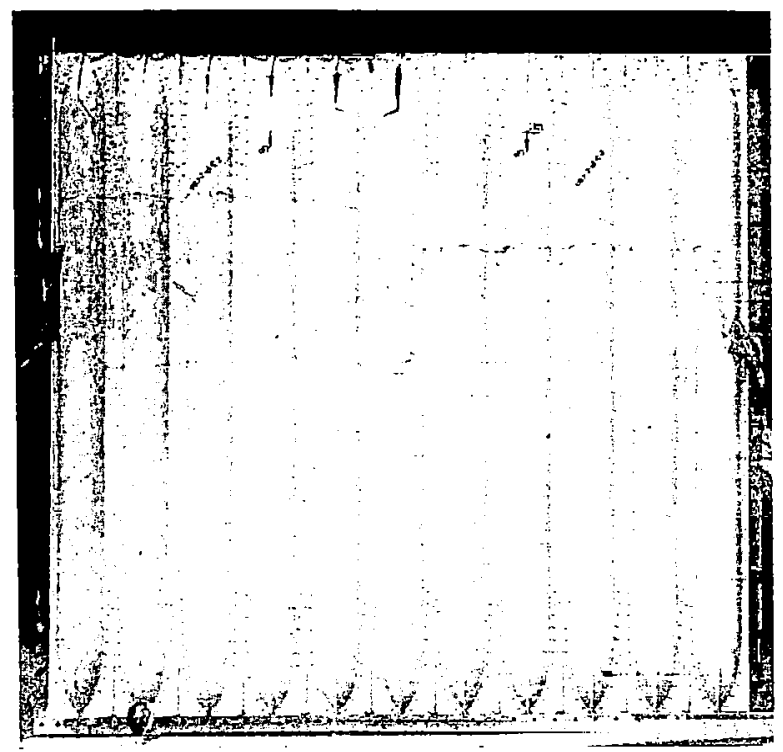

Figure 56: FAILED PANEL 2-2-P-2

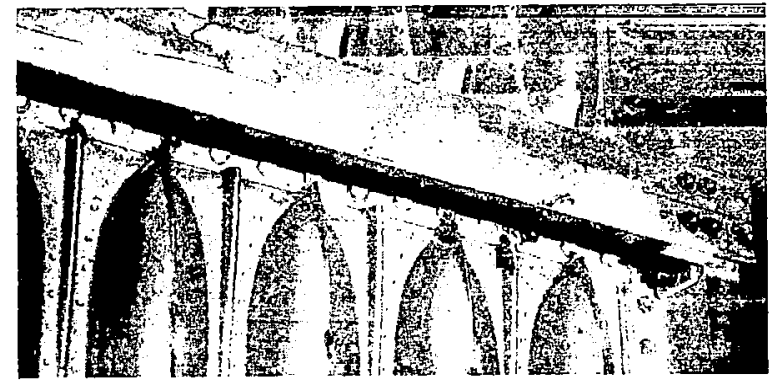

Figure 57: FAILED EDGE OF PANEL 2-2-P-3

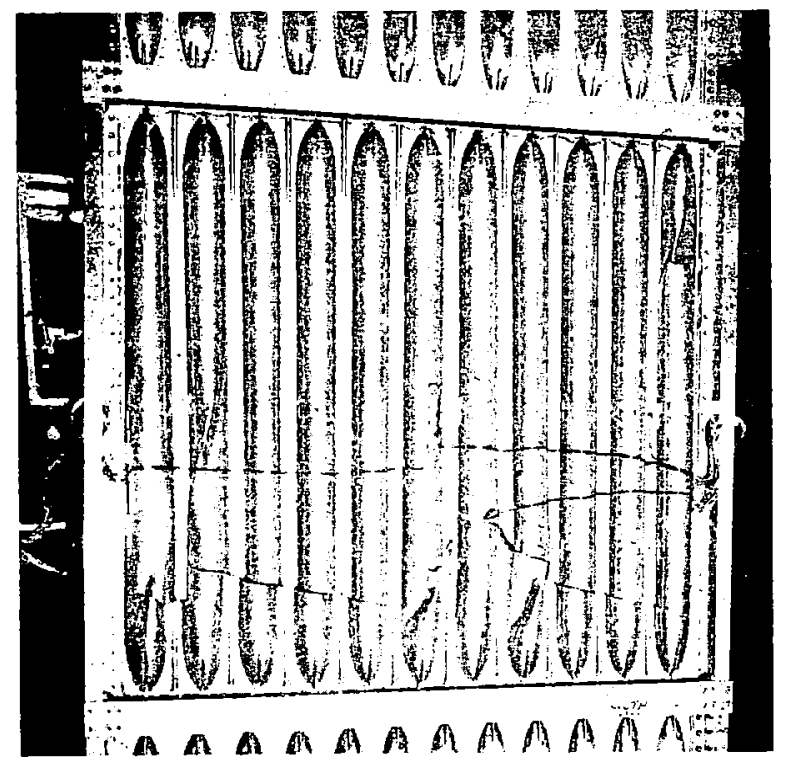

Figure 58: FAILED PANEL 2-2.P-3 
the two failures occurred in different parts of the panel, further suggesting that the panel edge failure did not contribute to the final shear failure.

The panel edge failures that occurred in panels $2-2-\mathrm{P}-2$ and $2-2-\mathrm{P}-3$ could be interpreted as indicating an inadequate end closure design. However, both of these failures occurred at axial compression load values in excess of the axial load for which the panel was designed, and they occurred after the panel design strength had been demonstrated by the F/S technique.

Summary of results for circular tube specimens. - The circular tube test results in most cases either met or exceeded strength predictions based on the modified theory. The modifications have resulted in lighter weight panel designs than had been predicted initially. This is illustrated in Figure 59 which shows panel mass plotted versus panel end load. The upper curve was taken from Figure 2 which reflects the original strength analysis. The lower curve was generated using test results to modify the analysis and shows the improved panel efficiency.

The consistent structural performance of the circular tube panel indicates a level of confidence which warrants the use of this concept in the design load range investigated. Application of this panel concept should result in increased structural efficiency in many types of future aerospace structures such as advanced space vehicles, missiles, interstages, and high speed cruise vehicles.

\section{Fluted Single Sheet Specimen Results}

Local buckling specimen test data. - Failure stresses from local buckling test data are compared with analytical failure stresses in Table 5 and Figure 60. The correlation factors are calculated in the same way described for panel type 2. Five test data points were obtained from specimen 1A-2-U-5, four of which were obtained by using the $F / S$ nondestructive test technique which worked quite well in predicting diagonal buckling failures. Force-stiffness predictions from these tests are shown in Figure 61. The correlations shown in Table 5 and Figure 60 are quite good and would be considered acceptable without analysis modification except for the one data point representing combined loading of compression, bending, and shear on specimen $1 \mathrm{~A}-2-\mathrm{U}-5$. This data point suggests the possibility that bending interacts with compression and shear in the diagonal buckling mode. Such interaction is not recognized in the present analysis of this failure mode, and no modification to analysis was made.

Panel test data. - Two 40 in. $x 40$ in. ( $1 \mathrm{~m} \times 1 \mathrm{~m}$ ) panel specimens of the type 1A configuration $(1 \mathrm{~A}-1-\mathrm{P}-1,1 \mathrm{~A}-1-\mathrm{P}-2)$ were each tested in the ten different load conditions shown in Table $2(a)$.

In testing the -1 panel in axial compression, a pronounced nonuniform load at the panel center was observed which caused the net compression to be approximately 40 percent higher than the nominal applied value. This peaking of the compression load is caused by a mismatch between the panel specimen and attached edge chords. These edge chords, which were used for all panels, 


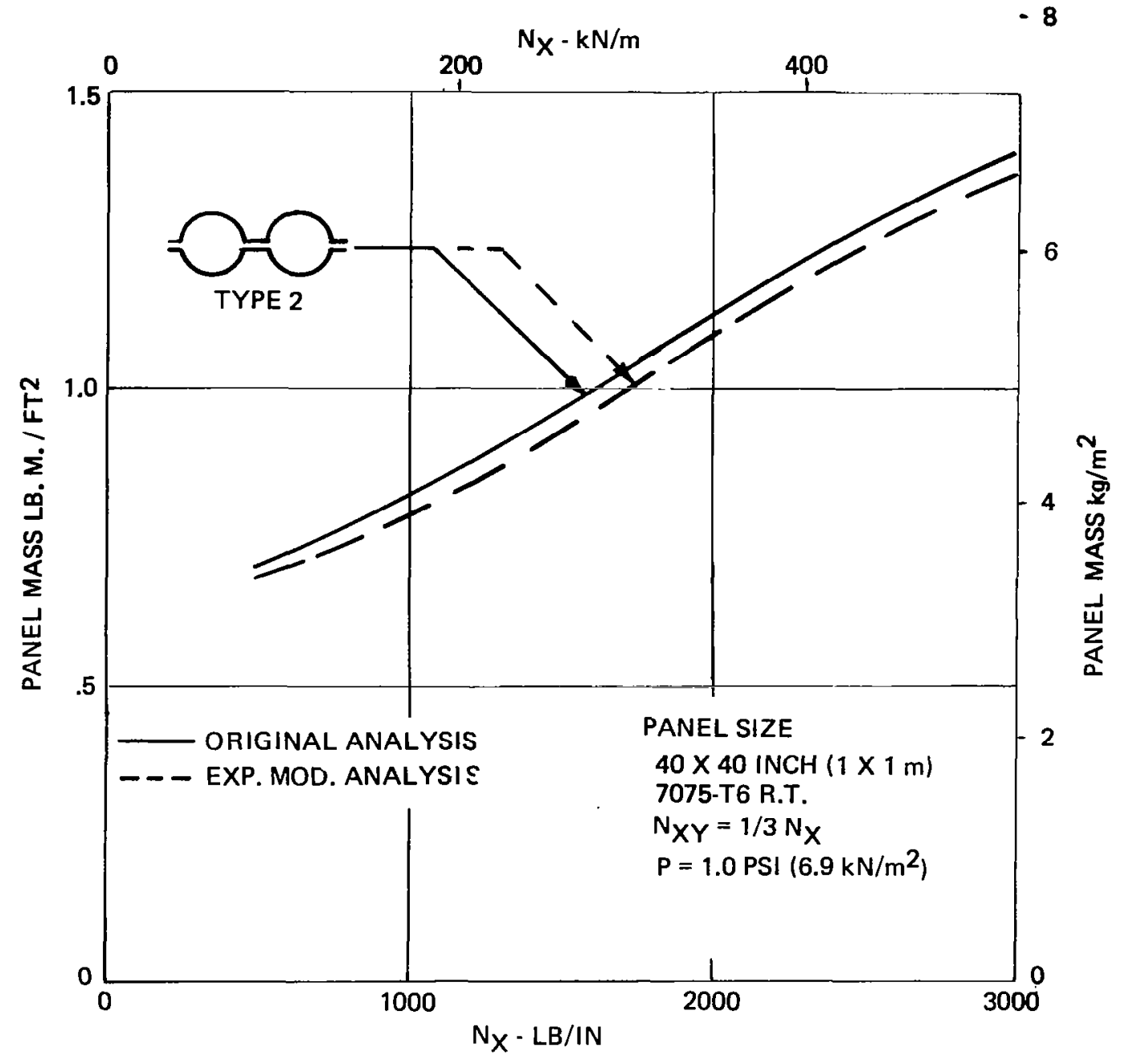

Figure 59: PANEL MASS VS. PANEL END LOAD 
Table 5: FLUTED SINGLE SHEET LOCAL BUCKLING TEST RESULTS

\begin{tabular}{|c|c|c|c|c|c|}
\hline SPECIMEN NO. & $\begin{array}{l}\text { LOAD } \\
\text { TYPE }\end{array}$ & FAILURE MODE & $\begin{array}{ll} & \text { FAILURE } \\
& \text { KSI IM } \\
\text { TEST } & \end{array}$ & $\begin{array}{l}\text { STRESS } \\
\left.1 / \mathrm{m}^{2}\right) \\
\text { ORIGINAL } \\
\text { ANALYSIS }\end{array}$ & $\begin{array}{l}\text { CORRELATION } \\
\text { FACTOR }\end{array}$ \\
\hline$* 1 A-2 \cdot U-1$ & $\mathbf{S}$ & WEB CRIPPLING & $F_{S}=31.8 \quad(219)$ & $F_{S}=30.2 \quad(208)$ & 1.05 \\
\hline 1A-2.U-2 & $\mathbf{S}$ & DIAGONAL BUCKLING & $F_{S}=13.7$ & $F_{S}=12.6 \quad(87)$ & 1.09 \\
\hline IA-2-U-3 & $C+B$ & $\begin{array}{c}\text { (LARGE DEFLECTION - } \\
\text { NO FAILURE) }\end{array}$ & - & - & - \\
\hline $1 A-2-U-4$ & $c+s$ & DIAGONAL BUCKLING & $\begin{array}{l}F_{C}=19.2 \\
F_{S}=8.95 \quad(132)\end{array}$ & $\begin{array}{l}F_{C}=18.5 \\
F_{S}=8.60\end{array}$ & 1.04 \\
\hline 1A-2.U-5 & $C+S$ & DIAGONAL BUCKLING & $\begin{array}{l}F_{C}=19.3 \\
F_{S}=9.41\end{array}+\begin{array}{r}(133) \\
(65)\end{array}$ & $\begin{array}{l}F_{C}=18.0 \quad(124) \\
F_{S}=8.80 \quad(61)\end{array}$ & 1.07 \\
\hline 1A.2.U.5 & $c+S$ & DIAGONAL BUCKLING & $\begin{array}{l}F_{C}=8.37 \\
F_{S}=11.8\end{array}+(58)$ & $\begin{array}{ll}F_{C}=7.90 & (55) \\
F_{S}=11.2 & (77)\end{array}$ & 1.06 \\
\hline 1A-2-U.5 & $C+B+S$ & DIAGONAL BUCKLING & $\begin{array}{l}F_{C}=16.5 \\
F_{S}=7.96\end{array}$ & $\begin{array}{ll}F_{C}=18.1 & \{125\} \\
F_{S}=8.75 & (60)\end{array}$ & 0.91 \\
\hline 1A-2-U-5 & $\mathbf{s}$ & DIAGONAL BUCKLING & $F_{S}=14.0$ & $F_{S}=12.6$ & 1.11 \\
\hline $1 A \cdot 2 \cdot U-5$ & $S+B$ & DIAGONAL BUCKLING & $F_{S}=12.9$ & $F_{S}=12.7$ & 1.02 \\
\hline 1A-2-U-8 & B & WEB CRIPPLING & $F_{B}=78.4 \quad\{541\rangle$ & $F_{B}=73.8 \quad(509)$ & 1.06 \\
\hline 1A-2-U.9 & C & DIAGONAL BUCKLING & $F_{C}=33.5$ & $F_{C}=34.6$ & .97 \\
\hline
\end{tabular}




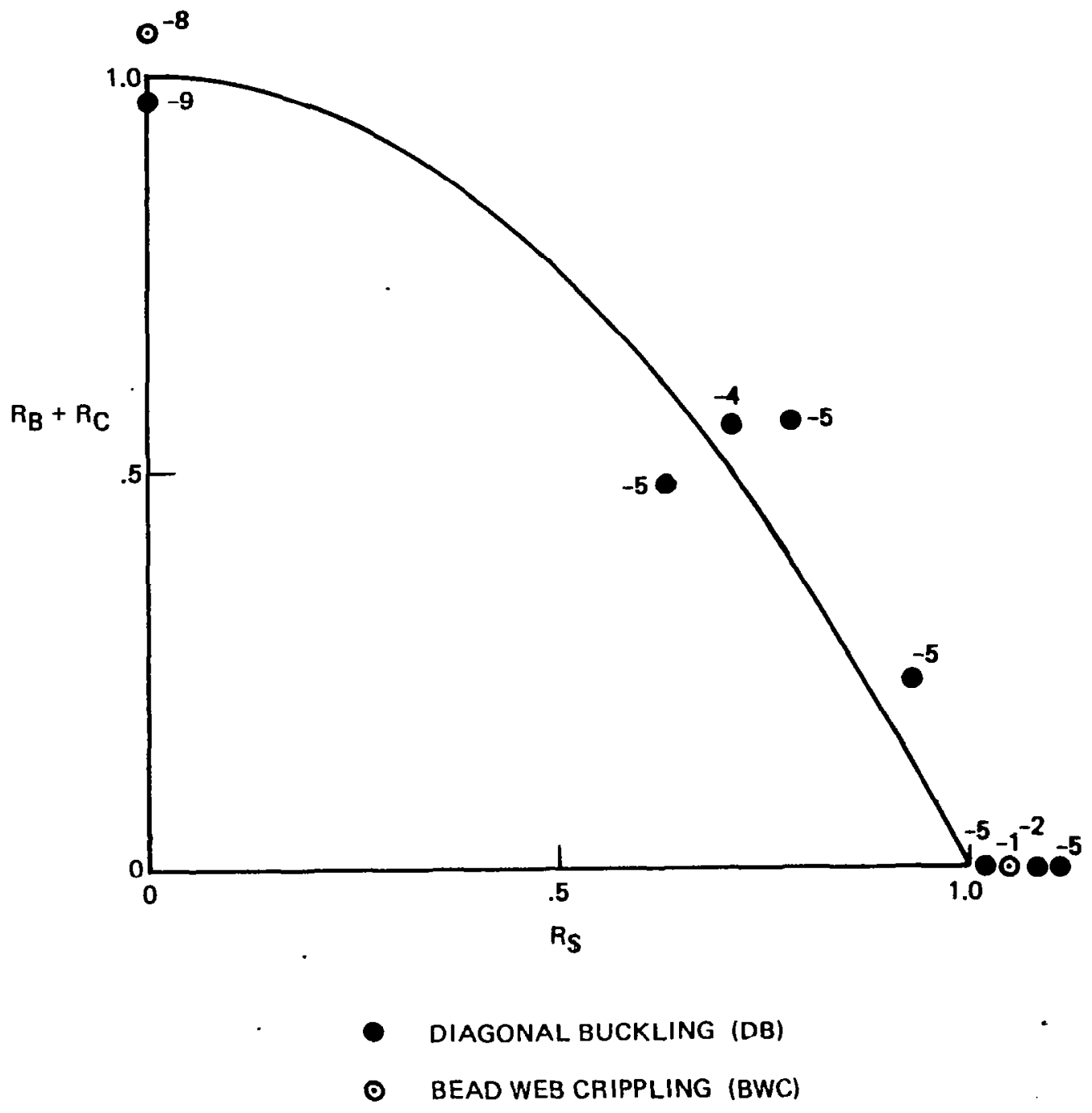

Figure 60: LOCAL BUCKLING TEST/ANALYSIS CORRELATION - PANEL TYPE 1A (NUMBERS BY DATA POINTS INDICATE SPECIMEN NUMBER) 


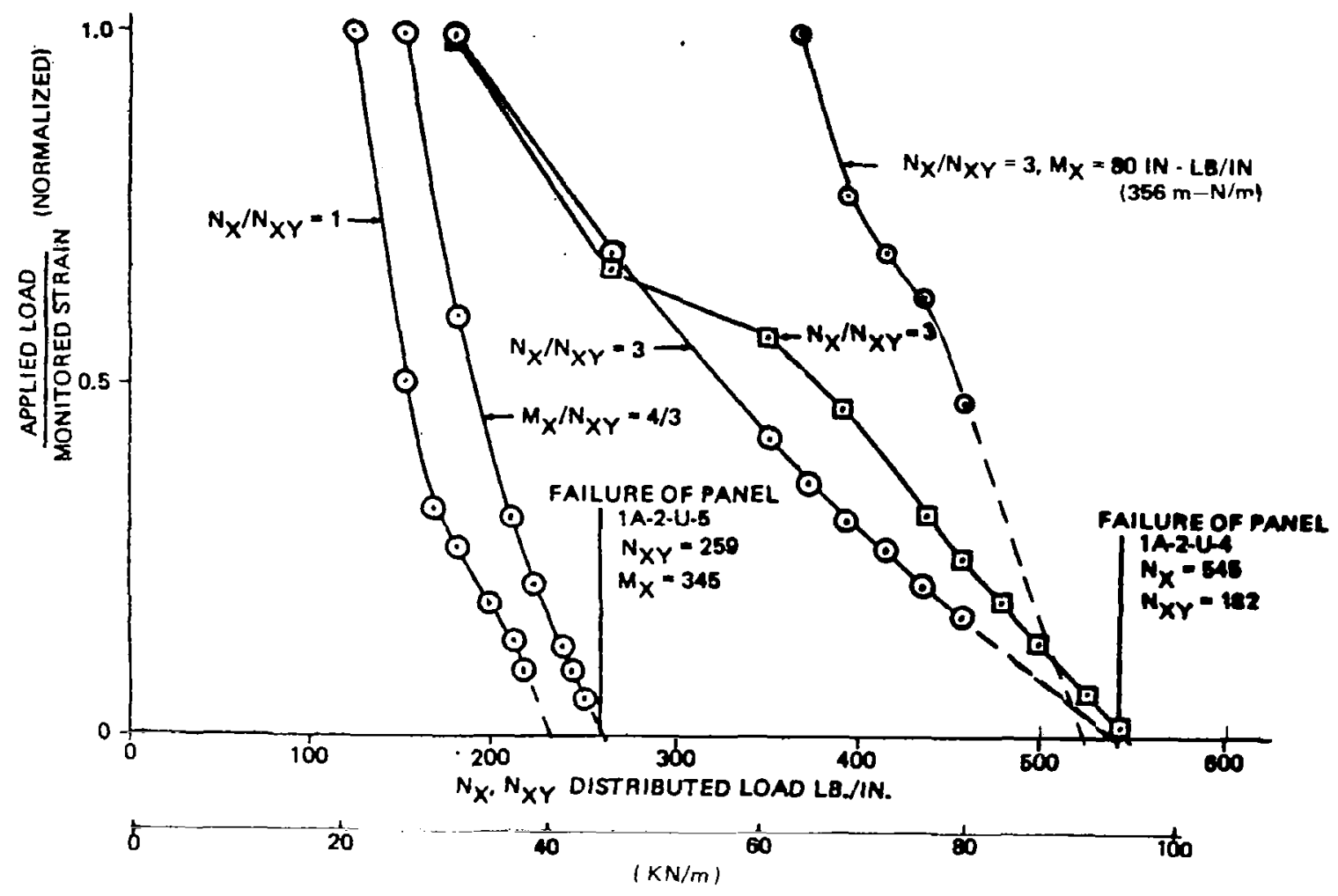

Figure 61: FORCE / STIFFNESS NONDESTRUCTIVE TESTING OF 1A-2-U-5 SPECIMEN 
were better suited to the tubular panels than to the single sheet panels which have a much smaller net-to-gross area ratio. The shear load distribution in the panel was found to be essentially uniform.

The compression load peaking caused the load ratios of $N_{x}$ to $N_{x y}$ at the panel center to be considerably different from the nominal values given in Table 2(a). On the basis of the -1 panel test results, the applied loads were adjusted to give panel center load ratios equal to those given in the table. These adjusted loads were applied in testing the -2 panel.

Analytical failure loads for these panels were computed from average material coupon test properties and average measured dimensions of the cross section (see reference 9). A different set of analytical failure loads was calculated for each panel because of the different test load ratios of $\mathrm{N}_{\mathbf{x}}$ to $\mathrm{N}_{\mathrm{xy}}$. The analytical failure loads are compared with the test results in Table 6 . Only the major component, $\mathrm{N}_{\mathrm{X}}$ or $\mathrm{N}_{\mathrm{xy}}$, is given for each load condition. Test loads are net panel loads determined using strain gage data from the panel center region.

All test results are F/S failure predictions except for the actual failure loads indicated for load condition 10. The diagonal buckling mode was apparently critical in all the test load conditions. This mode of failure agrees with that predicted by analysis except for load conditions 5 and 6 where bead web crippling was predicted to be critical. The failure modes are indicated in Figure 62 which shows a graphical representation of the theoretical failure load interaction surface test data.

The average test/analysis correlation of 0.85 achieved for the type 1A panel indicates the analysis to be unconservative. This appears to be due to a length effect which is not included in the present diagonal mode buckling analysis. Additionally, some interaction between bending and compression in the diagonal mode, which is not recognized in the present analysis, may also exist. These effects could not be accounted for in the theory within an acceptable level of effort for this program. Consequently, no modifications to the theory for the single sheet fluted panel were made.

The diagonal mode buckles observed in the fluted single sheet panels are illustrated in the Moire' photographs of pane1 1A-1-P-2. Figure 63 shows the panel loaded to 90 percent of the predicted shear strength and Figure 64 shows the panel at 80 percent of the design load condition which includes compression, shear and 1 psi $\left(6.9 \mathrm{kN} / \mathrm{m}^{2}\right)$ lateral pressure. Figure 65 shows the panel after the failure which occurred when attempting to load it beyond 89 percent of the design 1oad. The shapes of the beads, distorted by the diagonal mode buckles, are best observed by viewing the shape of the shadows from the heavy grid lines.

Summary of results for fluted single sheet specimen. - Further analytical effort is required to derive an improved analysis suitable for design use. The consistent test results shown in Figure 62 suggest that an improved theory could lead to design modifications and thereby achieve a high structural efficiency. Improved efficiency, however, may be limited to low-1oad 
Table 6: FLUTED SINGLE SHEET PANEL TEST RESULTS SUMMARY (F/S DATA EXCEPT WHERE NOTED)

\begin{tabular}{|c|c|c|c|c|c|c|c|}
\hline \multirow[b]{2}{*}{$\begin{array}{l}\text { LOAD } \\
\text { COND. }\end{array}$} & \multirow[b]{2}{*}{$\begin{array}{l}\text { LOAD } \\
\text { TYPE }\end{array}$} & \multicolumn{3}{|c|}{$1 A-1-P-1$} & \multicolumn{3}{|c|}{ 1A-1-P-2 } \\
\hline & & \multicolumn{2}{|c|}{$\begin{array}{c}\text { ULTIMATE LOAD } \\
N_{x} \text { OR } N_{x y}-\text { LB./IN. }(\mathrm{kN} / \mathrm{m})\end{array}$} & $\begin{array}{l}\text { CORRELATION } \\
\text { FACTOR }\end{array}$ & \multicolumn{2}{|c|}{\begin{tabular}{|c|} 
ULTIMATE LOAD \\
$N_{X}$ OR $_{X Y^{-}}$LB./IN. $(\mathrm{kN} / \mathrm{m})$
\end{tabular}} & $\begin{array}{l}\text { CORRELATION } \\
\text { FACTOR }\end{array}$ \\
\hline 1 & C & $1093(191)$ & $880(154)$ & .80 & 1093 (191) & $912(160)$ & .83 \\
\hline 2 & S & $249 \quad(44)$ & $206 \quad(36)$ & .83 & $249 \quad(44)$ & 225 (39) & .90 \\
\hline 3 & $\mathrm{C}+\mathrm{S}$ & $867(152)$ & $790(138)$ & .91 & 777 (136) & $690(121)$ & .89 \\
\hline 4 & $\mathrm{C}+\mathrm{S}$ & $708(124)$ & $656(115)$ & .93 & $588(103)$ & $535 \quad(94)$ & .91 \\
\hline 5 & $\mathrm{C}+\mathrm{B}$ & $+1070(187)$ & $870(152)$ & .81 & $+1070 \quad(187)$ & $880(154)$ & .82 \\
\hline 6 & $\mathrm{C}+\mathrm{B}$ & † 938 (164) & 705 (123) & .75 & t 938 (164) & 680 (119) & .72 \\
\hline 7 & $S+B$ & $249 \quad(44)$ & $217 \quad(38)$ & .87 & $249 \quad(44)$ & $218 \quad(38)$ & .88 \\
\hline 8 & $S+B$ & $249 \quad(44)$ & $212 \quad(37)$ & .85 & $249 \quad(44)$ & $212 \quad(37)$ & .85 \\
\hline 9 & $C+S+B$ & $685(120)$ & $618(108)$ & .90 & $584(102)$ & $530 \quad(93)$ & .91 \\
\hline$* 10$ & $\mathrm{C}+\mathrm{S}+\mathrm{B}$ & $667(117)$ & *529 & .79 & $548 \quad(96)$ & - $487 \quad(85)$ & .89 \\
\hline & & & Ave. & .844 & & Ave. & .860 \\
\hline \multicolumn{8}{|c|}{$\begin{array}{l}\text { - ACTUAL FAILURE LOADS } \\
\text { PANEL DESIGN LOAD CONDITION }\end{array}$} \\
\hline t II & renctio & נת & 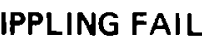 & - & n-mor & ser & \\
\hline
\end{tabular}


in
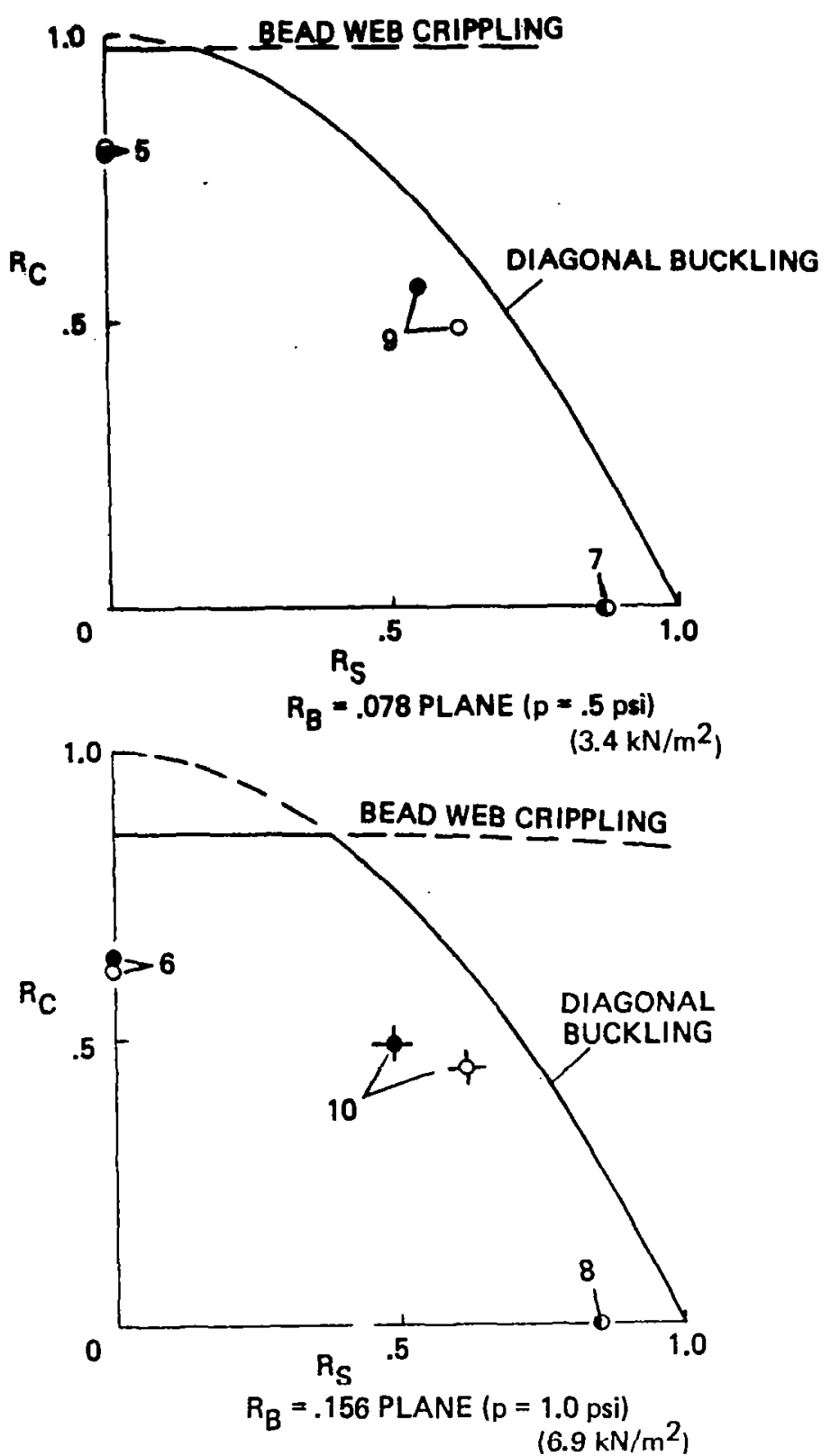

BEAD WEB CRIPPLING
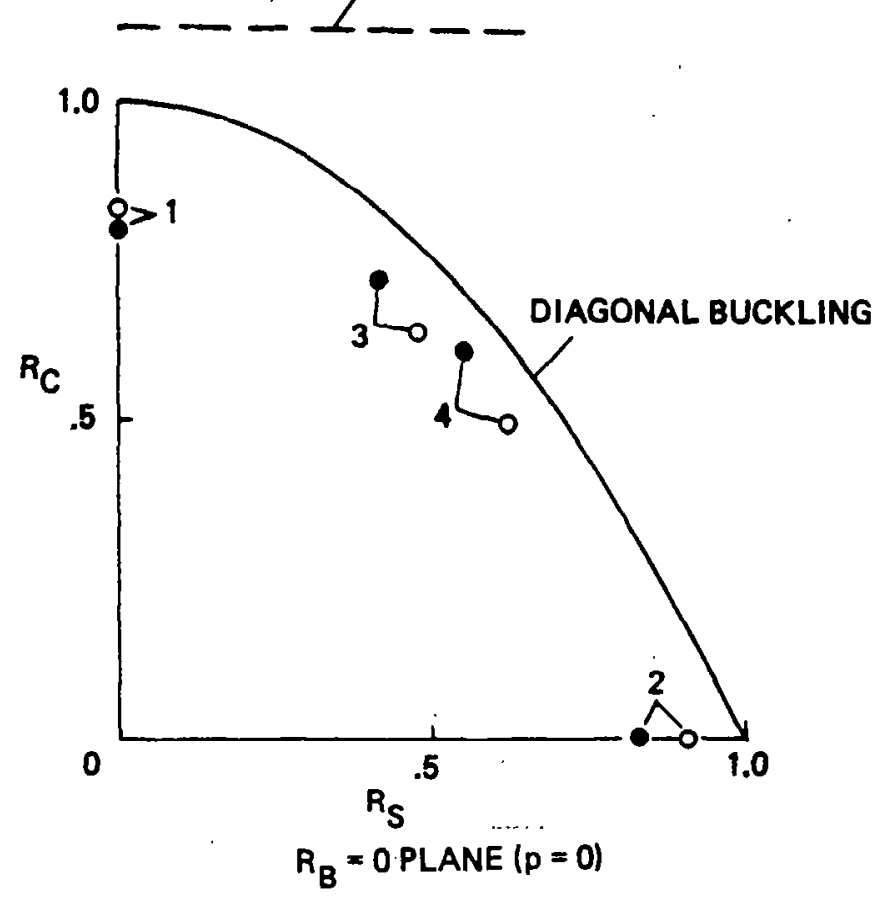

F/S FAILURE INDICATION

- 1A-1.P-1 $\rightarrow$ ACTUAL PANEL

- 1A-1.P-2 -

Figure 62 - THEORETICAL FAILURE LOAD INTERACTION SURFACE SHOWING CORRELATION WITH TEST DATA PANEL TYPE IA INUMBERSBY DATA. POINTS INDICATE LOAD CONDITIONS) 


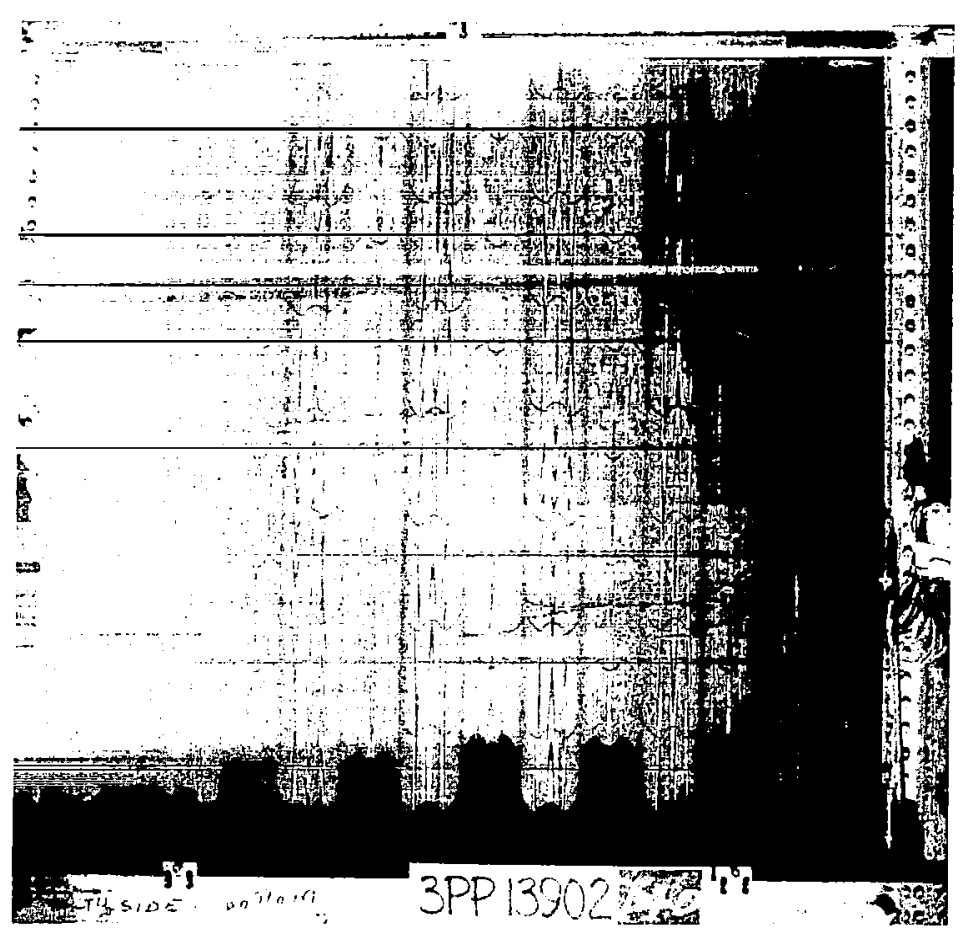

Figure 63: PANEL 1A-1-P-2 LOADED TO 90\% $\mathrm{N}_{X Y}$

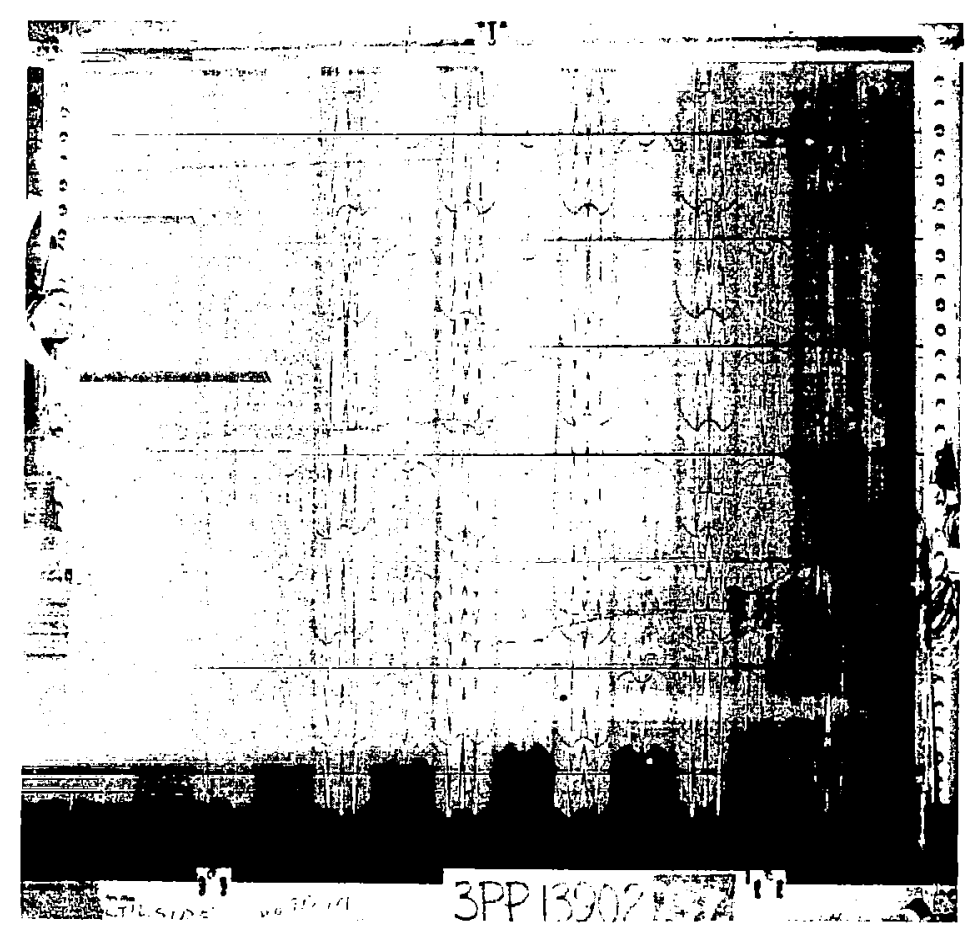

Figure 64: PANEL 1A-1.P-2 LOADED TO 89\% OF DESIGN LOAD 


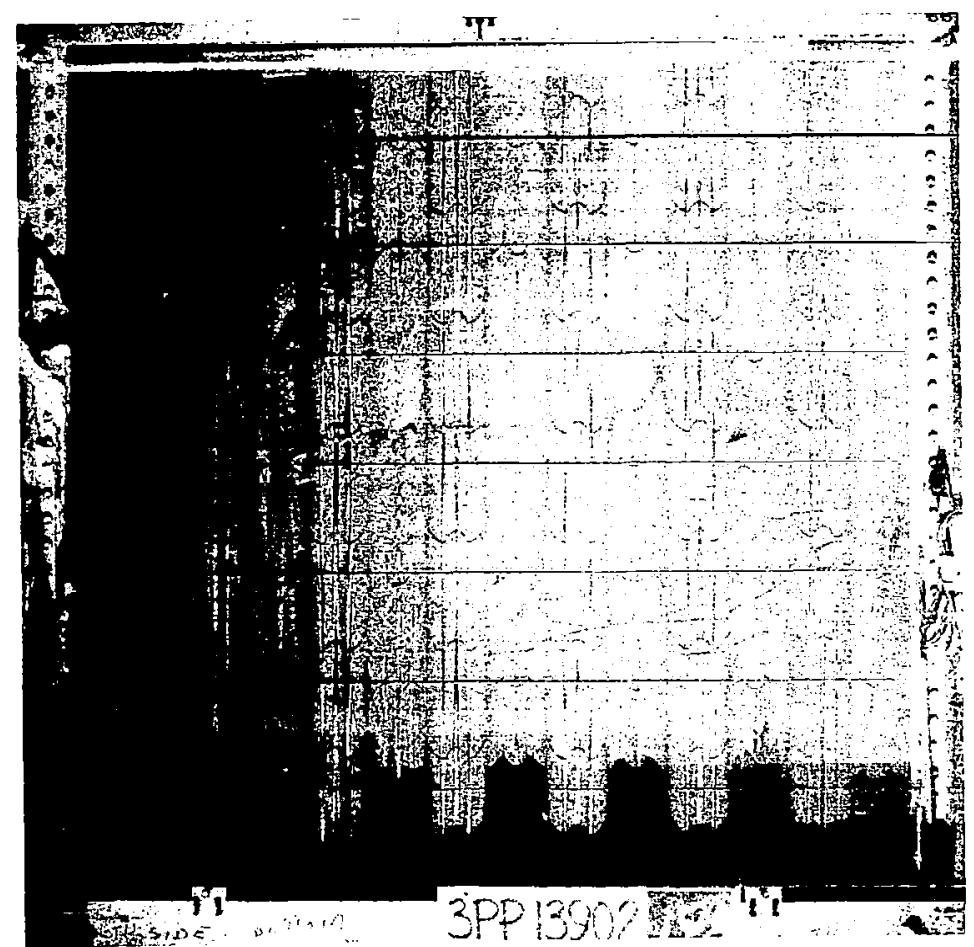

Figure 65: PANEL 1A-1-P-2 FAILED AT 89\% OF DESIGN LOAD 
conditions because out-of-plane deflections occur in the end closures when the panel is loaded in shear (see section on Single Sheet End closures). It appears that these deflections, which become increasingly more significant as the design shear load increases, can be avoided by an attachment method which does not reduce the panel cross-section shape to a flat sheet at the panel ends.

\section{Low Load Fluted Tube Specimen Results}

Local buckling specimen test data. - Failure stresses from local buckling test data are compared with analytical failure stresses in Table 7 and Figure 66 . The correlation reveals apparent conservatism in most of the results. In the case of flat buckling this is due partly to the separation of the two sheets by the bond layer resulting in increased bending stiffness, and partly to the assumption of simple support at the edges of the flat in the buckling analysis. In spite of the apparent conservatism shown by the test data in bead web crippling under combined load there was indication in testing the 30-in. $(76-\mathrm{cm})$ long specimen, 2A-1-U-1C, that complex modes involving distortion of the cross section and having fairly long wave lengths were occurring. These modes probably could not develop in the shorter specimens, but it was expected that they could occur in the full size panels and considerably reduce the actual buckling stresses. For this reason no analysis modification was at tempted on the basis of the local buckling correlations.

Panel test data. - Only one 40 in. $X 40$ in. ( $1 \times 1 \mathrm{~m}$ ) panel of the type 2A-1 configuration was tested. Ten test load conditions were defined slightly different from those given in Table $2(a)$ to increase the amount of shear data. The conditions are as follows:

\begin{tabular}{cccc} 
TEST LOAD & \multicolumn{2}{c}{ COMP. VS . SHEAR } & LATERAL PRESSURE \\
CONDITION & \multicolumn{2}{c}{ LOAD RATIO } & $\mathrm{p}=$ CONSTANT \\
& $\mathrm{N}_{\mathrm{x}}$ & $\mathrm{N}_{\mathrm{XY}}$ & $\mathrm{psi}\left(\mathrm{kN} / \mathrm{m}^{2}\right)$ \\
1 & 1 & 0 & 0 \\
2 & 0 & 1 & 0 \\
3 & 1 & $1 / 5$ & 0 \\
4 & 1 & $1 / 3$ & 0 \\
5 & 1 & $1 / 2$ & 0 \\
6 & 1 & 0 & $1.0(6.9)$ \\
7 & 0 & 1 & $1.0(6.9)$ \\
8 & 0 & 1 & $2.0(13.8)$ \\
9 & 1 & $1 / 3$ & $.5(3.45)$ \\
10 & 1 & $1 / 3$ & $1.0(6.9$
\end{tabular}


Table 7 : CORRELATION OF LOCAL BUCKLING TEST RESULTS WITH ANALYSIS - PANEL TYPE 2A-1

\begin{tabular}{|c|c|c|c|c|c|}
\hline SPECIMEN NO. & $\begin{array}{l}\text { LOAD } \\
\text { TYPE }\end{array}$ & FAILURE MODE & $\begin{array}{r}\text { FAILURE } \\
\text { KSI } \\
\text { TEST }\end{array}$ & $\begin{array}{l}\text { STRESS } \\
\text { (MN/m }{ }^{2} \text { ) } \\
\text { ORIGINAL } \\
\text { ANALYSIS }\end{array}$ & $\begin{array}{l}\text { CORRELATION } \\
\text { FACTOR }\end{array}$ \\
\hline$=2 A-1 \cdot U-1$ & C & FLAT BUCKLING & $\odot F_{C}=24.2$ & $F_{C}=15.6 \quad(108)$ & 1.56 \\
\hline 2A-1-U.1 & C & WEB CRIPPLING & $F_{C}=39.0 \quad(269)$ & $F_{C}=39.4 \quad(272)$ & .99 \\
\hline $2 A \cdot 1-U-2$ & C & FLAT BUCKLING & $O F_{C}=23.4(161)$ & $F_{C}=15.6$ & 1.51 \\
\hline $2 A \cdot 1 \cdot U-2$ & C & WEB CRIPPLING & $F_{C}=37.0$ & $F_{C}=39.4 \quad(272)$ & .94 \\
\hline 2A-1.U-3 & $C+B$ & WEB CRIPPLING & $\begin{array}{ll}F_{C}=25.5 & (176) \\
F_{S}=44.5 & (307)\end{array}$ & $\begin{array}{ll}F_{C}=15.4 & (106) \\
F_{S}=27.4 & (189)\end{array}$ & 1.66 \\
\hline $2 A-1 \cdot U-4$ & s & WEB CRIPPLING & $F_{S}=25.5 \quad(176)$ & $F_{S}=19.5 \quad(135)$ & 1.31 \\
\hline $2 A-1 \cdot U-5$ & $B+S$ & WEB CRIPPLING & $\begin{array}{l}F_{B}=50.5 \quad(348) \\
F_{S}=17.7 \quad(122)\end{array}$ & $\begin{array}{l}F_{B}=30.8 \\
F_{S}=10.8\end{array}$ & 1.64 \\
\hline $2 A-1-U \cdot 6$ & $c+s$ & WEB CRIPPLING & $\begin{array}{l}F_{C}=37.3 \quad(257) \\
F_{S}=11.6 \quad(80)\end{array}$ & $\begin{array}{l}F_{C}=30.1 \quad(208) \\
F_{S}=9.35\end{array}$ & 1.24 \\
\hline 2A-1-U-7 & $C+B+S$ & WEB CRIPPLING & $\begin{array}{ll}F_{C}=25.0 & (172) \\
F_{B}=48.4 & (334) \\
F_{S}=6.12 & (42)\end{array}$ & $\begin{array}{l}F_{C}=14.1 \quad(97) \\
F_{B}=27.2 \quad(188) \\
F_{S}=3.44\end{array}$ & 1.78 \\
\hline $2 A-1 \cdot U-10$ & B & WEB CRIPPLING & $F_{B}=70.7 \quad(488)$ & $F_{B}=44.1 \quad(304)$ & 1.60 \\
\hline \multicolumn{6}{|c|}{$\begin{array}{l}\text { " } L=30 \mathrm{IN} .(.76 \mathrm{~m}) \quad \text { ALL OTHER SPECIMENS, L = } 10 \mathrm{IN} .(.25 \mathrm{~m}) \\
\text { O FLAT BUCKLING STRESSES IDENTIFIED FROM F/S PLOTS. }\end{array}$} \\
\hline
\end{tabular}



$-3$
$-10$
( ) -1
o -2

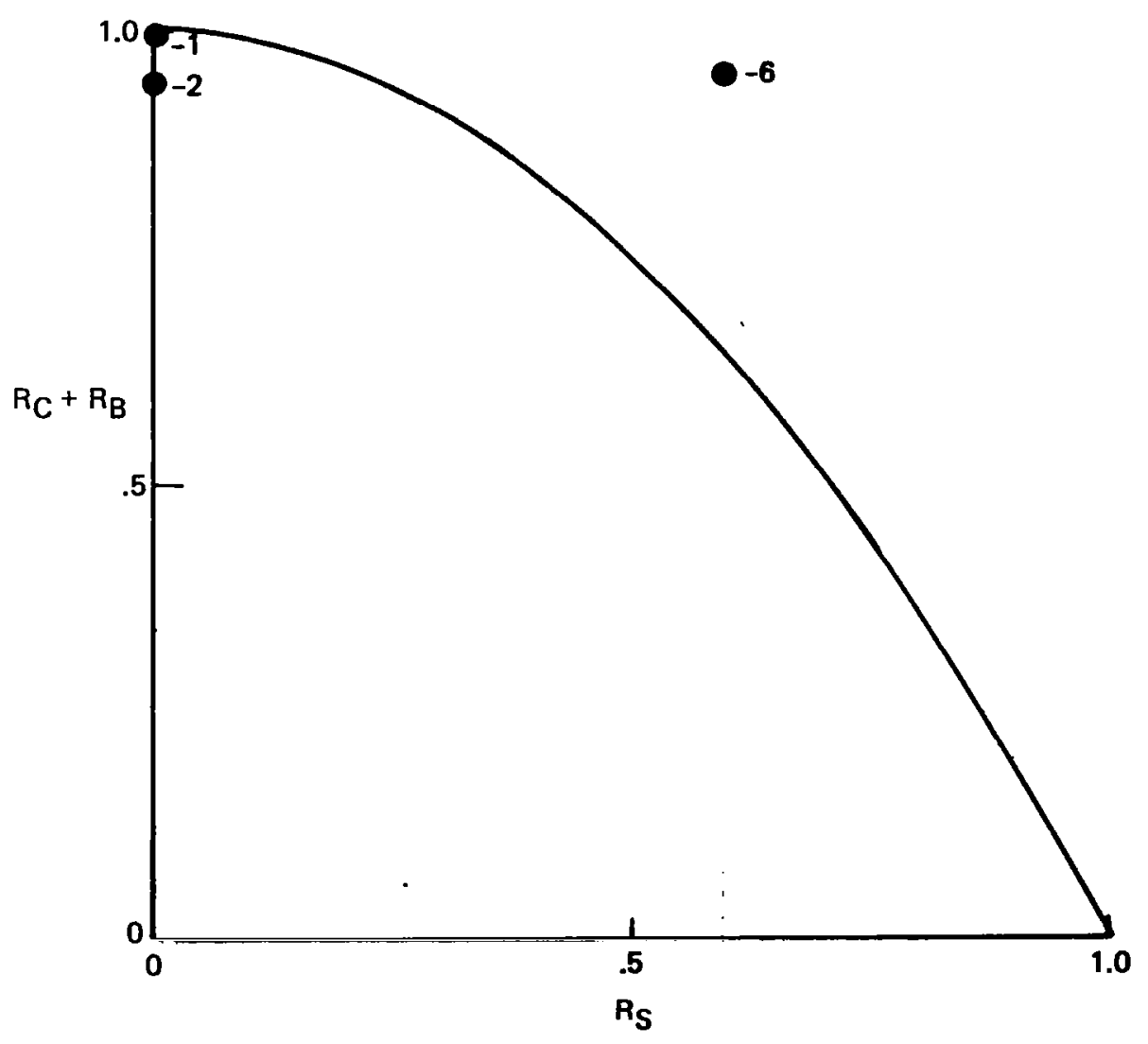

- BEAD WEB CRIPPLING (BWC)
- FLAT BUCKLING (FC)

Figure 66 LOCAL BUCKLING TEST/ANAL YSIS CORRELATION - PANEL TYPE 2A-1 (TEST TO FAILURE, NUMBERS BY DATA POINTS INDICATE SPECIMEN NUMBER) 
Force/stiffness data indicated premature panel instability failure in nearly all load conditions due to pronounced effects of tube distortional modes. In the case of compression and bending loads the distortion observed was flattening of the tubes, while more complex distortions appeared to occur in the presence of shear loads. Figure 67 illustrates these distortions of the panel when loaded in shear. Shadows cast from heavy grid lines placed on the Moire' glass at 5 inch $(127 \mathrm{~mm})$ intervals give a very clear, although slightly exaggerated, profile of the panel surface. In pressurizing the panel it appeared that the tubes might collapse before reaching 2 psi; therefore the panel was not tested in load condition 8. The panel was tested to failure load in load condition 1 , however elastic panel instability occurred causing no permanent damage.

After completing the first series of tests the panel was modified by inserting stiffening posts to prevent bead flattening (see reference 10). Six pairs of holes were drilled on the unpressurized side of the panel at the intersections of the bead web and flute. A 0.10 inch $(0.25 \mathrm{~cm})$ diameter pin, notched at the proper length to maintain the correct internal depth of the tube, was inserted in each hole. The edge of the hole was engaged in the notch and the pin was wedged in place in the hole. The modified panel was designated $2 A-1-P 1 M$ and was retested.

The test results are compared with the analysis in Table 8 and Figure 68 . Average material coupon properties and average measures panel cross section dimensions were used in the analysis. Test loads are nominal values determined from the applied loads assuming uniform stress distribution with a calculated panel net-to-gross ratio of .303 (69.7 percent of gross area is edge chord area) and a net panel width of 43.3 inches $(1.1 \mathrm{~m})$. The trends shown in Figure 68 for both test data and theory indicate a shift in failure mode from panel instability to bead web crippling as lateral pressure is increased. However, the test data are in poor agreement with theory.

Nevertheless, significant improvement in the test results was observed with this type of post stiffening. Figure 67 shows the original panel loaded to 60 percent of the predicted shear load and Figure 69 shows the modified panel at the same load. Correspondingly, Figures 70 and 71 show the original and the modified panel loaded to 1 psi $\left(6.9 \mathrm{kN} / \mathrm{m}^{2}\right)$ and 50 percent of the axial and shear load corresponding to the panel design condition. Both sets of Moire' photographs indicate that the addition of the spacers significantly reduced the panel deflections. The panel was eventually tested to failure in the design load condition at 99 percent of the analytical failure load. However, the panel was still deficient in the presence of large shear components as can be seen in Figure 68. This is apparently due to the inability of simple post stiffening to provide adequate support against tube distortion other than flattening.

Summary of results for low load fluted tubular specimens. - Tests of the first low load fluted tubular panel revealed unanticipated tube flattening under bending load and tube twisting under shear load. It was determined that further testing of the Type 2A-1 panels, even with post type inserts was not 


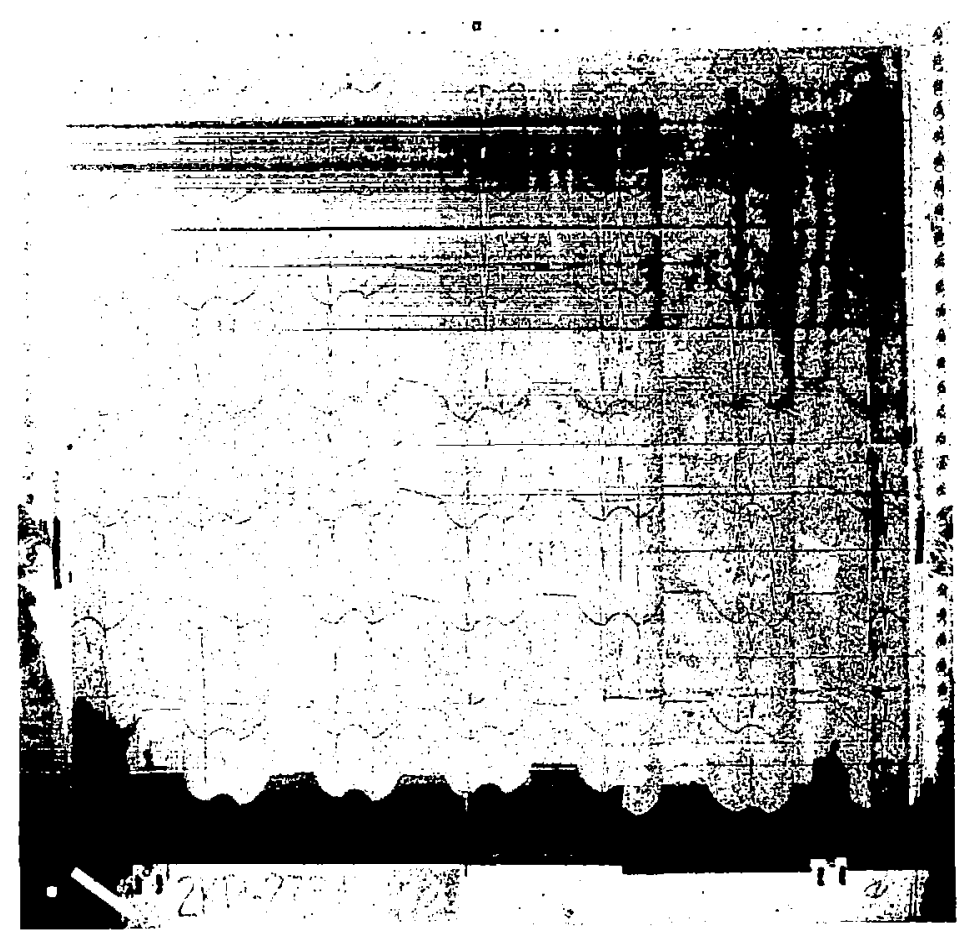

Figure 67: PANEL 2A-1-P-1 AT 60\% OF $N_{X Y}$ 
Table 8: LOW LOAD FLUTED TUBE PANEL TEST RESULTS SUMMARY (F/S DATA)

\begin{tabular}{|c|c|c|c|c|c|c|}
\hline \multirow{3}{*}{$\begin{array}{l}\text { LOAD } \\
\text { COND. }\end{array}$} & \multirow{3}{*}{$\begin{array}{l}\text { LOAD } \\
\text { TYPE }\end{array}$} & \multicolumn{3}{|c|}{ ULTIMATE LOAD $N_{x}$ OR $N_{x y} L B / I N(k N / m)$} & \multirow{2}{*}{\multicolumn{2}{|c|}{$\begin{array}{c}\text { CORAELATION } \\
\text { FACTOR }\end{array}$}} \\
\hline & & \multirow{2}{*}{$\begin{array}{l}\text { ORIGINAL } \\
\text { ANALYSIS }\end{array}$} & \multicolumn{2}{|c|}{ TEST } & & \\
\hline & & & $2 A-1-P-1$ & 2A-1-P-1M & $2 A-1-P-1$ & $2 A-1-P-1 M$ \\
\hline 1 & C & $\begin{array}{c}700(122) \\
F B\end{array}$ & $\begin{array}{cc}530 & (93) \\
P 1 & \end{array}$ & $\begin{array}{c}660(116) \\
P I\end{array}$ & 0.76 & 0.94 \\
\hline 2 & $\mathbf{S}$ & $\begin{array}{cc}440 & (77) \\
P I & \end{array}$ & $\begin{array}{cc}270 & (47) \\
P 1 & \end{array}$ & $\begin{array}{c}338 \\
P I\end{array}$ & 0.61 & 0.78 \\
\hline 3 & $\mathrm{C}+\mathrm{S}$ & $682(119)$ & $\begin{array}{cc}535 & (94\} \\
\mathrm{PI} & \end{array}$ & $\begin{array}{c}630(110) \\
P I\end{array}$ & 0.78 & 0.92 \\
\hline 4 & $C+S$ & $\begin{array}{r}652(114) \\
\text { FB-PI }\end{array}$ & $\begin{aligned} 470 & (82) \mid \\
P 1 & \end{aligned}$ & $\underset{\mathrm{PI}}{590(103)}$ & 0.72 & 0.90 \\
\hline 5 & $\mathrm{C}+\mathrm{S}$ & $\begin{array}{cc}545 & (95) \\
\mathrm{PI} & \end{array}$ & $\begin{array}{cc}366 & (64) \\
\text { PI } & \end{array}$ & $\begin{array}{c}420 \\
\mathrm{PI}\end{array}$ & 0.67 & 0.77 \\
\hline 6 & $C+B$ & $\begin{array}{l}483(84) \\
\text { BWC }\end{array}$ & $\begin{array}{l}458(80) \\
\text { BWC }\end{array}$ & $\begin{array}{l}485 \text { (85) } \\
\text { BWC }^{\prime}\end{array}$ & 0.95 & 1.00 \\
\hline 7 & $\mathrm{~S}+\mathrm{B}$ & $\begin{array}{cc}440 & (77) \\
P 1 & \end{array}$ & $\begin{array}{rr}335 & (59) \\
\text { P1 } & \end{array}$ & $\begin{array}{c}350 \\
\mathrm{PI}\end{array}$ & 0.74 & 0.80 \\
\hline 8 & $\mathbf{S + B}$ & $\begin{array}{cc}440 & (77) \\
\mathrm{PI} & \end{array}$ & - & - & - & - \\
\hline 9 & $\mathrm{C}+\mathrm{S}+\mathrm{B}$ & $\begin{array}{l}605(106) \\
B W C\end{array}$ & $\begin{array}{ll}525 & (92) \\
\text { PI-BWC } & \end{array}$ & - & 0.87 & - \\
\hline$* 10$ & $C+S+B$ & $\begin{array}{l}467 \quad(82) \\
B W C\end{array}$ & $\begin{array}{cc}378 & (66) \\
\mathrm{PI}-\mathrm{BWC} & \\
\end{array}$ & $\begin{array}{c}462(81) \\
\mathrm{BCW}\end{array}$ & 0.81 & 0.98 \\
\hline & & & & AVE. & 0.768 & 0.888 \\
\hline
\end{tabular}



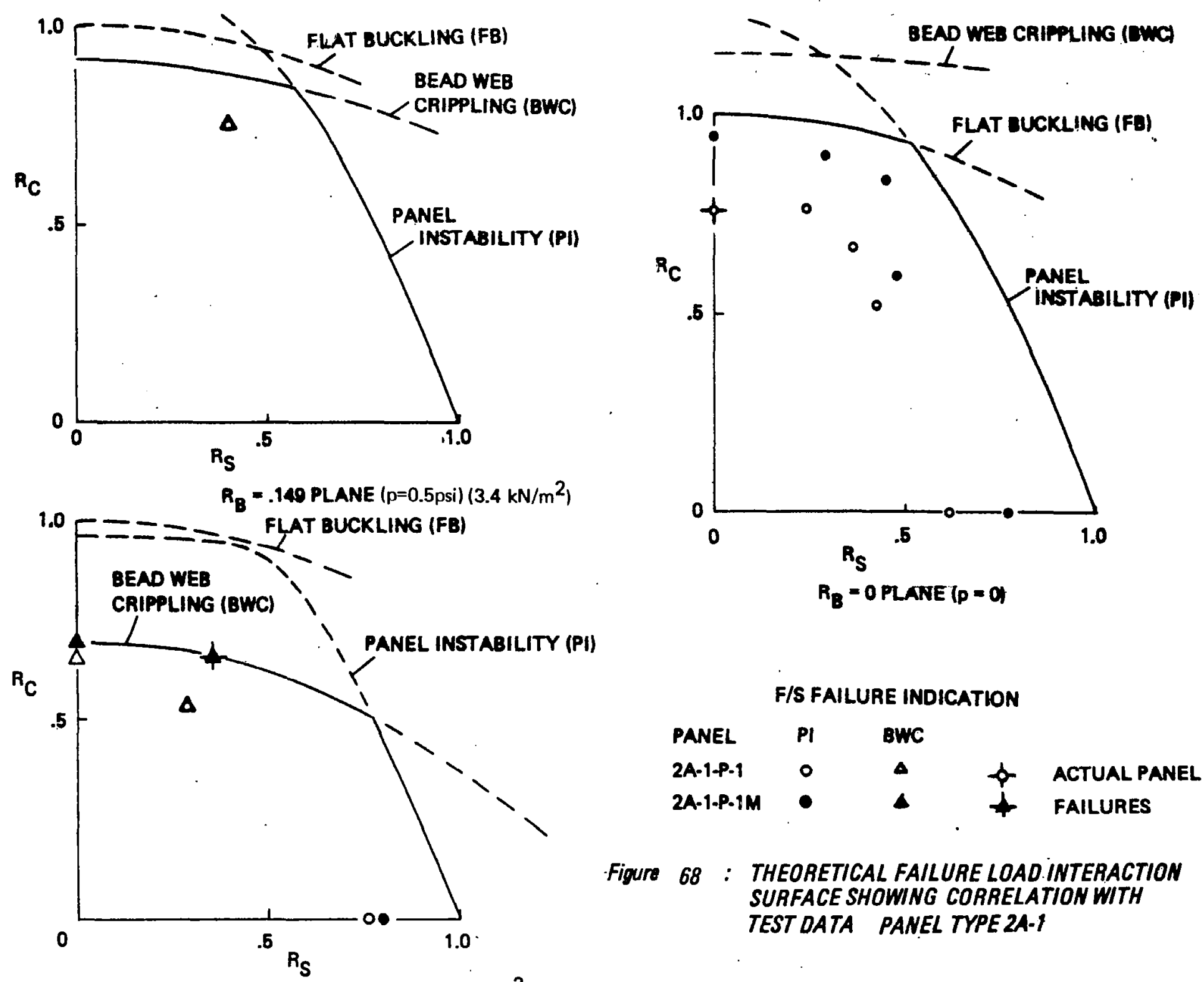

Figure 68 : THEORETICAL FAILURE LOAD INTERACTION SURFACE SHOWING CORRELATION WITH TEST DATA PANEL TYPE 2A-I

$R_{B}=.298$ PLANE ( $\left.p=1.0 \mathrm{psi}\right)\left(6.9 \mathrm{kN} / \mathrm{m}^{2}\right)$ 


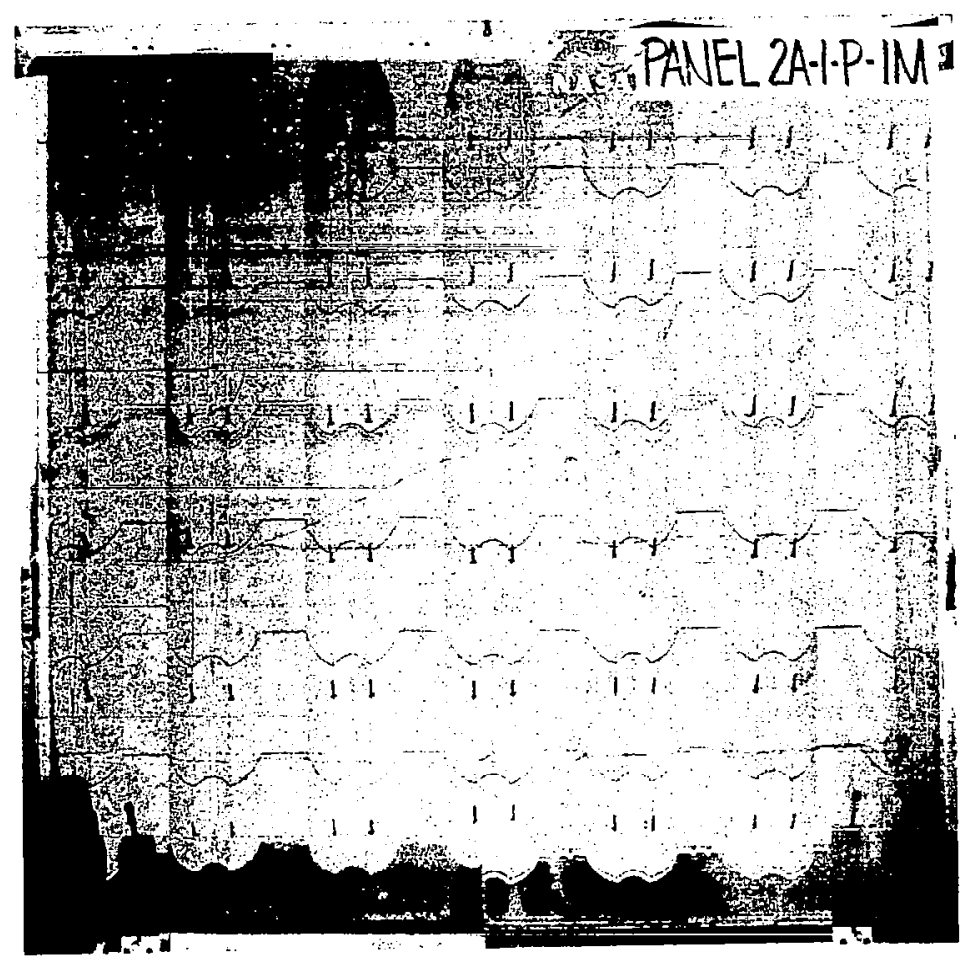

Figure 69: PANEL 2A-1-P.1M AT 60\% OF $N_{X Y}$ 


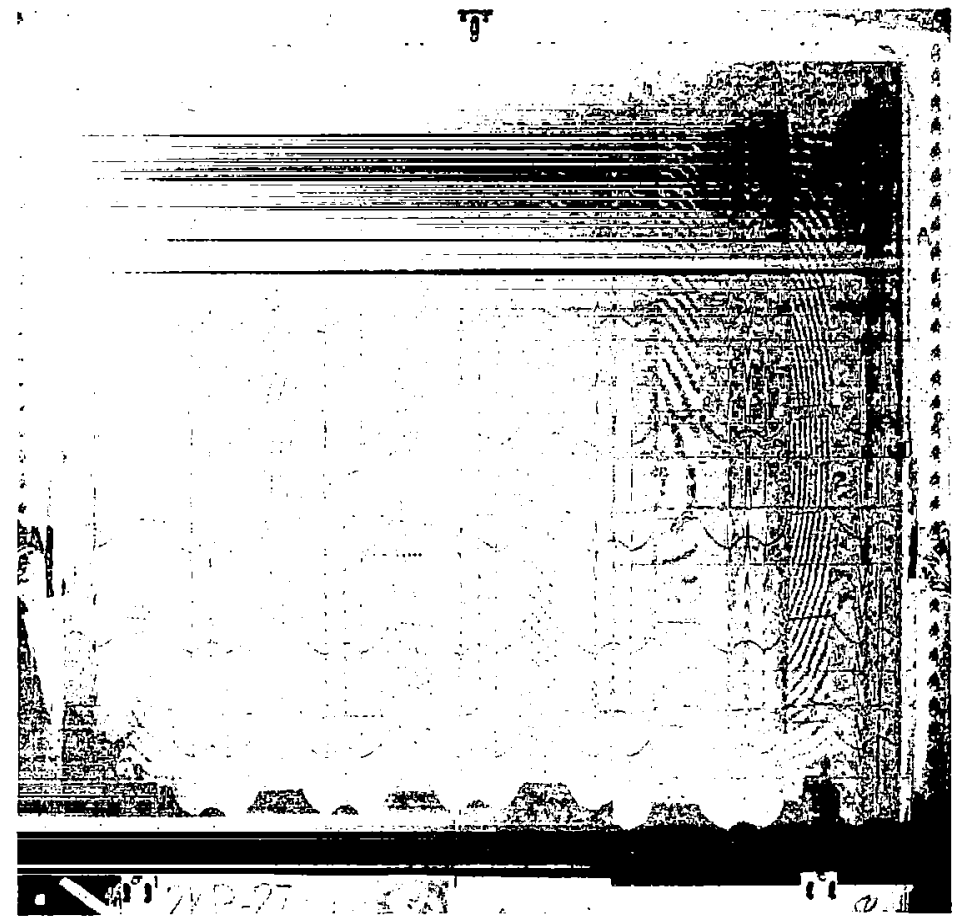

Figure 70: PANEL 2A-1-P-1 AT 1 PSI AND 50\% OF $N_{X} A N D N_{X Y}$

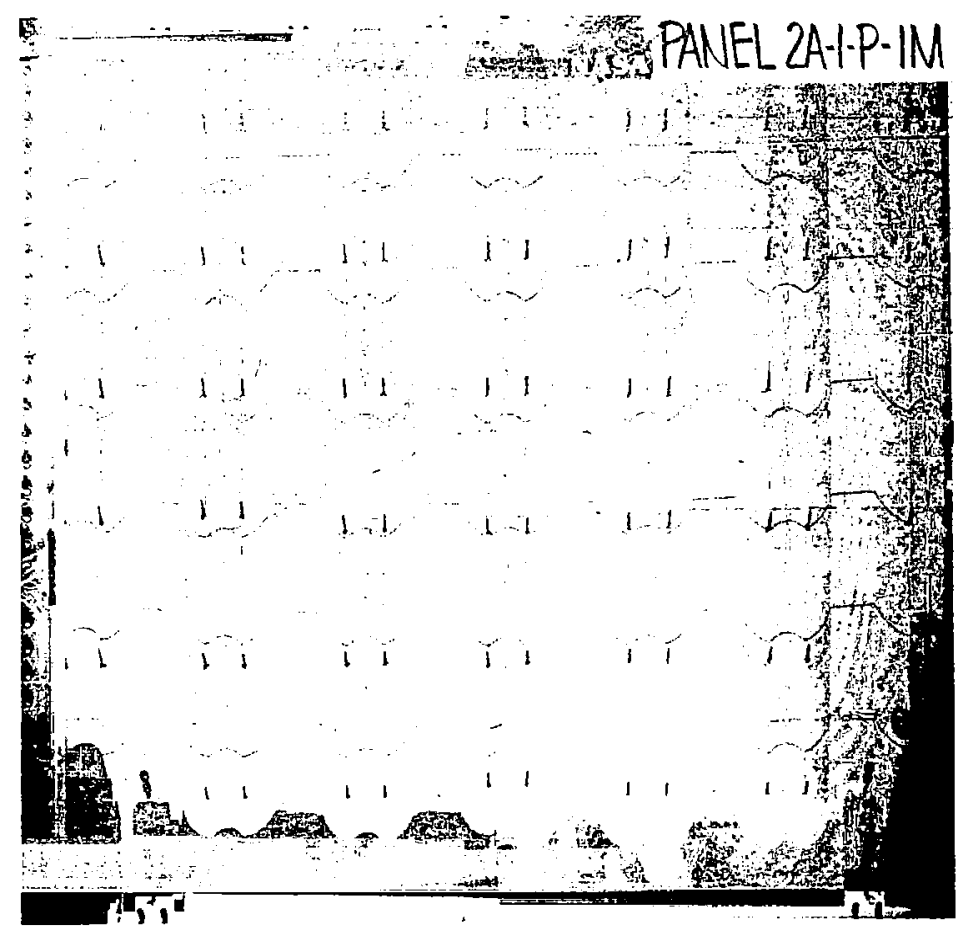

Figure 71: PANEL 2A-1.P-1M AT 1 PSI AND 50\% OF $N_{X} A N D N_{X Y}$ 
warranted and that further study of the tube distortions could best be accomplished using the Type 2A-2 panels.

\section{High Load Fluted Tube Panels}

Local buckling specimen test data. - Failure stresses from local buckling test data are compared with analytical failure stresses in Table 9 and Figure 72. The correlation pattern with the original analysis is similar to that seen in the type 2A-1 specimen tests. The poorer correlation in the case of the two compression specimens is evidence of greater susceptibility of this panel configuration to the cross section distortional mode.

On the basis of the correlation of test data with the original analysis, the following modifications to the bead crippling analysis were made:

(1) The correlations with test specimens $2 \mathrm{~A}-2-\mathrm{U}-1$ and $2 \mathrm{~A}-2-\mathrm{U}-2$ are brought within the desired limits by applying a knockdown factor of .8 to the expression for $\mathrm{F}_{\mathrm{CC}}$ in the Appendix.

Thus,

$$
F_{c c}=.656 n_{3} E(t / R)^{1.19}
$$

(2) The correlation with test of specimen $2 \mathrm{~A}-2-\mathrm{U}-3$, in shear only is brought within desired limits by applying a factor of 1.4 to the expression for $\mathrm{F}_{\mathrm{CS}}$ in the Appendix.

Thus,

$$
F_{c s}=1.4 \eta_{2} G k_{s}\left(t / s_{c}\right)^{2}
$$

The expression for $\mathrm{k}_{\mathrm{s}}$ and for $\mathrm{z}$ in the Appendix are unchanged.

(3) To give better correlation with the remainder of the Type 2A-2 1ocal buckling test data the exponent of the shear term in the standard interaction equation for bead crippling is changed from 2 to 4.5 .

Thus, for bead crippling only,

$$
R_{c}+R_{s}^{4.5}=1
$$

The improved correlation achieved with these modifications to the bead crippling analysis is apparent in Table 9 and Figure 72.

No flat buckling test data were obtained from tests of the Type 2A-2 local buckling specimens because they failed in bead web crippling before significant flat buckling modal behavior was observed. However, the flat buckling analysis is known to be conservative (see reference 9). To obtain more realistic correlation of analysis with panel test data it was decided to modify the flat buckling analysis using the available data from the Type 2A-1 
TAble 9 : CORRELATION OF LOCAL BUCKLING TEST RESUL TS WITH ANALYSIS - PANEL TYPE 2A-2

\begin{tabular}{|c|c|c|c|c|c|c|c|}
\hline \multirow{2}{*}{ SPECIMEN NO. } & \multirow{2}{*}{$\begin{array}{l}\text { LOAD } \\
\text { TYPE }\end{array}$} & \multirow{2}{*}{ FAILURE MODE } & \multicolumn{3}{|c|}{ FAILURE STRESS - KSI $\left(\mathrm{MN} / \mathrm{m}^{2}\right)$} & \multicolumn{2}{|c|}{$\begin{array}{l}\text { CORRELATION } \\
\text { FACTOR }\end{array}$} \\
\hline & & & TEST & $\begin{array}{l}\text { ORIGINAL } \\
\text { ANALYSIS }\end{array}$ & $\begin{array}{l}\text { MODIFIED } \\
\text { ANALYSIS }\end{array}$ & $\begin{array}{l}\text { ORIGINAL } \\
\text { ANALYSIS }\end{array}$ & $\begin{array}{l}\text { MODIFIED } \\
\text { ANALYSIS }\end{array}$ \\
\hline $2 A-2 \cdot U-1$ & C & WEB CRIPPLING & $F_{C}=50.6 \quad(349)$ & $F_{C}=64.3(444)$ & $F_{C}=51.5(355)$ & .79 & .98 \\
\hline $2 A-2-U-2$ & c & WEB CRIPPLING & $F_{C}=53.5 \quad(369)$ & $F_{C}=64.3(444)$ & $F_{C}=51.5(355)$ & .83 & 1.04 \\
\hline $2 A-2-U-3$ & $\mathbf{s}$ & WEB CRIPPLING & $F_{S}=25.5 \quad(176)$ & $F_{S}=18.2(126)$ & $F_{S}=25.4(175)$ & 1.40 & 1.00 \\
\hline $2 A-2: U \cdot 4$ & $c+s$ & WEB CRIPPLING & $\begin{array}{l}F_{C}=37.7 \quad(260) \\
F_{S}=24.8(171)\end{array}$ & $\begin{array}{l}F_{C}=22.3(154) \\
F_{S}=14.7(101)\end{array}$ & $\begin{array}{l}F_{C}=31.3(216) \\
F_{S}=20.6(142)\end{array}$ & 1.69 & 1.20 \\
\hline $2 A-2-4-6$ & $C+B$ & WEB CRIPPLING & $\begin{array}{l}F_{C}=35.9 \quad(248) \\
F_{B}=37.3 \quad(257)\end{array}$ & $\begin{array}{l}F_{C}=32.6 \quad(225) \\
F_{B}=33.9 \quad(234)\end{array}$ & $\begin{aligned} F_{C} & =29.4(203) \\
* F_{B} & =30.5(210)\end{aligned}$ & 1.10 & 1.22 \\
\hline $2 A-2-U-7$ & $\mathbf{B}+\mathbf{S}$ & WEB CRIPPLING & $\begin{array}{ll}F_{B}=39.3 & (271) \\
F_{S}=22.1 & (152)\end{array}$ & $\begin{array}{l}F_{B}=25.8(178) \\
F_{S}=14.5 \quad(100)\end{array}$ & $\begin{array}{l}F_{B}=38.1(263) \\
F_{S}=21.4(148)\end{array}$ & 1.52 & 1.03 \\
\hline $2 A-2-U-9$ & $C+B+S$ & WEB CRIPPLING & $\begin{array}{l}F_{C}=23.2 \quad(160) \\
F_{B}=36.5 \\
F_{S}=12.6\end{array}$ & $\begin{array}{l}F_{C}=16.0(110) \\
F_{B}=25.2(174) \\
F_{S}=8.69(60)\end{array}$ & $\begin{array}{l}F_{C}=23.1(159) \\
F_{B}=36.3(250) \\
F_{S}=12.6(87)\end{array}$ & 1.45 & 1.00 \\
\hline 2A-2-U-10 & B & WEB CRIPPLING & $F_{B}=68.3 \quad(471)$ & $F_{B}=67.8 \quad(468)$ & ${ }^{*}{ }^{*} F_{B}=67.8(468)$ & 1,01 & 1.01 \\
\hline
\end{tabular}




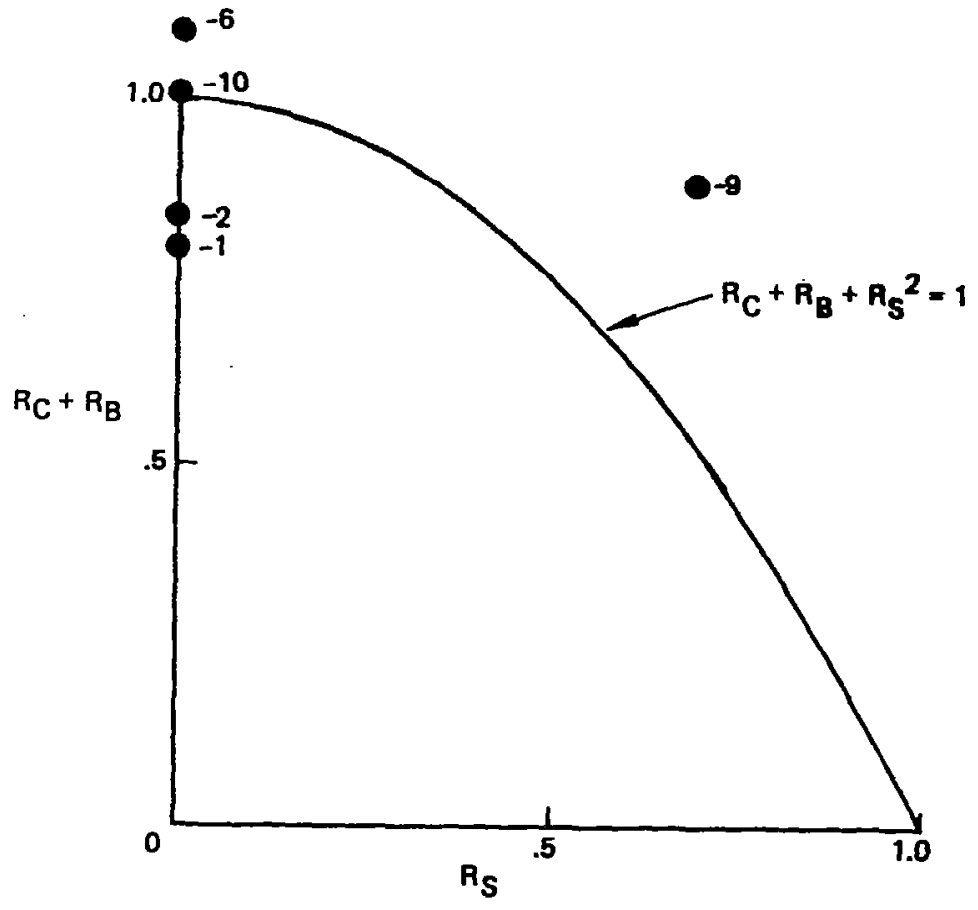

-4

$\rightarrow$

(A) BEFORE ANALYSIS MODIFICATION

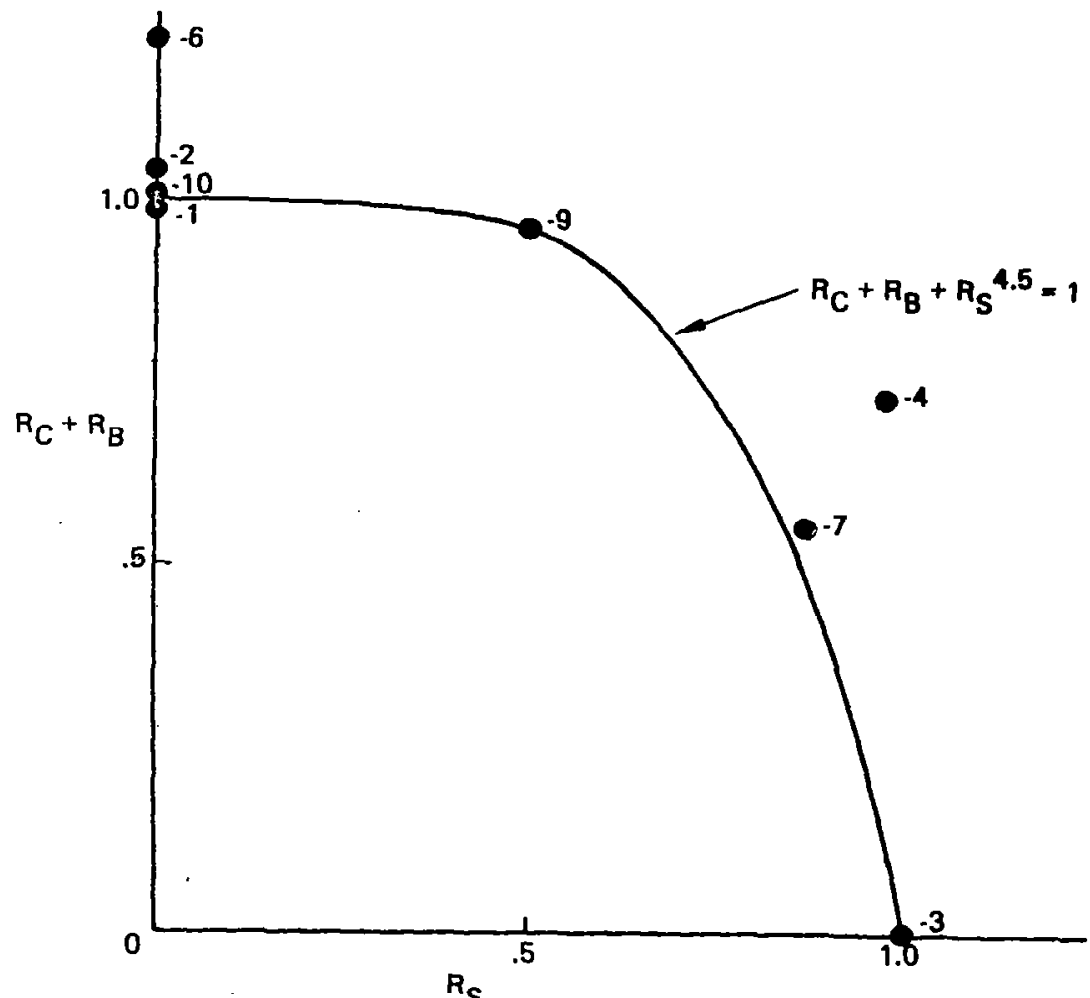

(B) AFTER ANALYSIS MODIFICATION

Figure 72: LOCAL BUCKLING TEST/ANALYSIS CORRELATION-PANEL TYPE 2A-2 ITEST TO FAILURE IN BEAD WEB CRIPPLING, NUMBERS BY DATA POINTS INDICATE SPECIMEN NUMBER) 
local buckling specimens. Therefore, on the basis of the flat buckling test results for specimens $2 \mathrm{~A}-1-\mathrm{U}-1$ and $2 \mathrm{~A}-1-\mathrm{U}-2$ given in Table 7 and Figure 66, a factor of 1.5 is applied to the expressions for $F_{f c}$ and $F_{f s}$ in the Appendix.

Thus,

$$
\begin{aligned}
& F_{f c}=1.5 \pi^{2} \eta_{4} \mathrm{Et}^{2} /\left[3 \mathrm{f}^{2}\left(1-\nu^{2}\right)\right] \\
& \mathrm{F}_{f s}=8.025 \pi^{2} \eta_{4} \mathrm{Et} /\left[12 \mathrm{f}^{2}\left(1-\nu^{2}\right)\right]
\end{aligned}
$$

Panel test data. - Three $40 \mathrm{In} . \times 40 \mathrm{In}$. (1m x 1m) panel specimens of the type 2A-2 configuration were tested under the ten test 1 oad conditions described in Table 2(b). In testing the first specimen it was immediately apparent that the effect of tube distortional modes was even greater than that observed in the type 2A-1 panel. Therefore, the first specimen was modified by post stiffening similar to that described for the type 2A-1 panel. This specimen was then redesignated $2 \mathrm{~A}-2-\mathrm{P}-1 \mathrm{M}$ and tested. The second and third specimens, designated $2 \mathrm{~A}-2-\mathrm{P}-2 \mathrm{M}$ and $2 \mathrm{~A}-2-\mathrm{P}-3 \mathrm{M}$, respectively, were modified by the addition of tube stabilizers inserted during the panel assembly. Photographs of these inserts are shown in Figures 43 and 44.

Analytical failure loads are compared with test data for these three panels in Table 10. Average material coupon properties and average measured panel cross section dimensions were used in the analysis as previously described. Test loads are nominal values determined from the applied loads assuming uniform stress distribution with a calculated panel net-to-gross area ratio of .350 (65 percent of gross area is edge chord area) and a net panel width of 42.8 inches $(1.09 \mathrm{~m})$. All test data shown in the figures are from F/s indications of local buckling except where actual panel failures are indicated. The F/S local buckling indications and the test/analysis correlations for specimens $2 \mathrm{~A}-2-\mathrm{P}-1 \mathrm{M}$ and $2 \mathrm{~A}-2-\mathrm{P}-2 \mathrm{M}$ are based on the original static strength equations presented in the Appendix. The $\mathrm{F} / \mathrm{S}$ indications and test/analysis correlations for specimen $2 \mathrm{~A}-2-\mathrm{P}-3 \mathrm{M}$ are based on the modified equations described in the section "Local Buckling Specimen Test Data."

lhe first specimen (2A-2-P-IM) was found deficient in all load conditions with premature failure indicated in panel instability or flat buckling at loads averaging 71.5 percent of the analytical failure loads. The specimen finally failed due to bead web crippling in the design load condition at only 63 persent of the analytical failure load. The failure occurred at a location away from the panel center which was not covered by $\mathrm{F} / \mathrm{S}$ instrumentation. It sppeared to be caused by a reduction in curvature of the bead web. This disLortion was apparently due to the flexibility of the tubes which results in inadequate transfer of shear load into the fluted tubes.

lhe second specimen (2A-2-P-2M) contained modified post type tube stabilizer inserts which were designed to prevent tube flattening and to provide stiffening against other distortional modes that could be identified. Early in the esting of this spectmen an edge defect was discovered which was expected to ause premature edge failure, similar to that which occurred in the case of 
Table 10: HIGH LOAD FLUTED TUBE PANEL TEST RESULTS SUMMARY (F/S DATA)

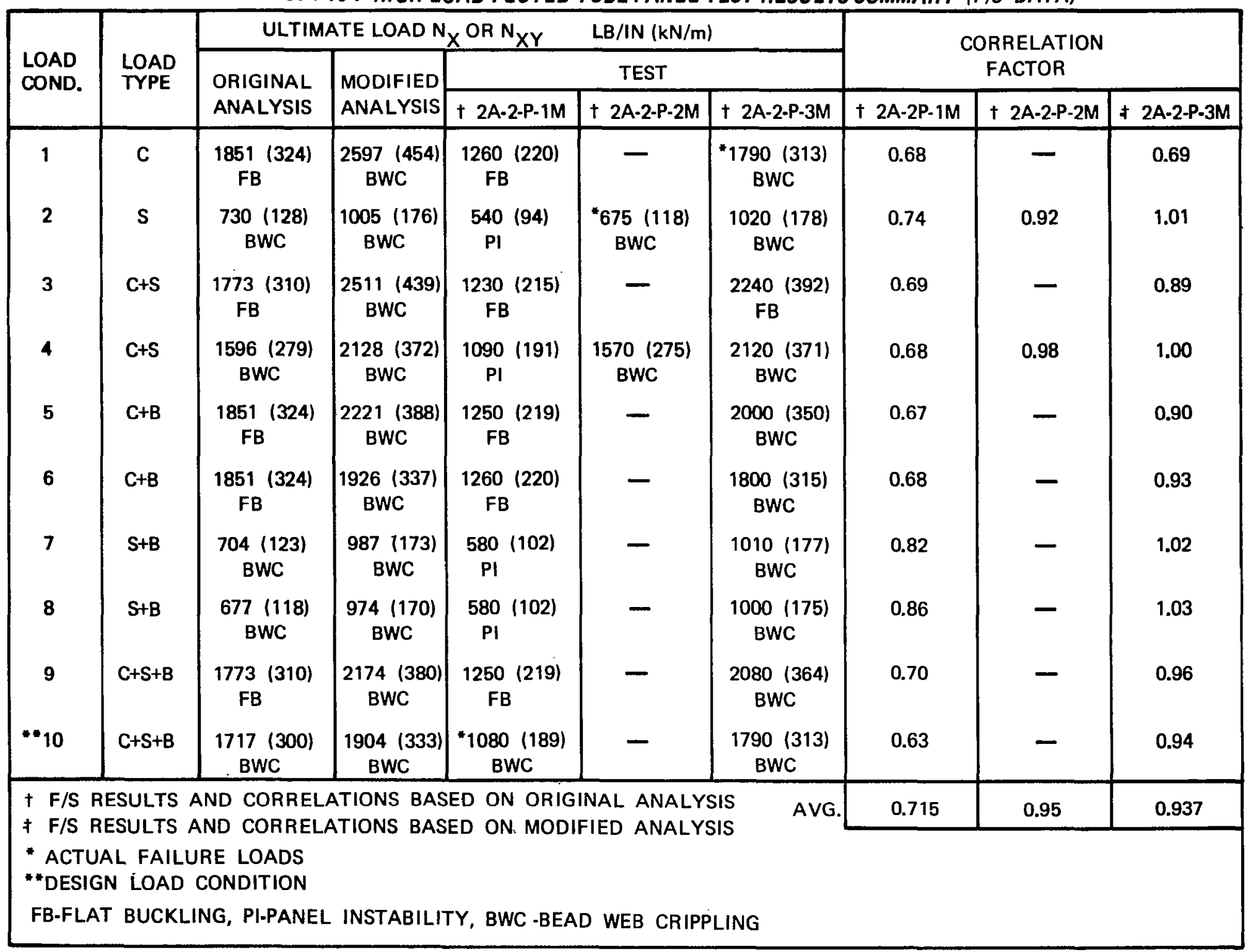


panel 2-2-P-2, if loaded in axial compression. It was decided to test the panel to failure in shear rather than risk the edge failure in another load condition. Consequently, test data are only available for two load conditions. These data show a marked improvement with this type of tube stabilization. Figure 73 shows a Moire' photograph of the panel loaded to 88 percent of the predicted shear strength. Figure 74 shows the nature of the panel failure which occurred when the shear load was increased to 92 percent.

The third specimen (2A-2-P-3M) contained a modified arch type of tube stabilizer insert. The insert was designed to maintain the radius of curvature of the tube side walls (the bead web) as well as provide stiffness against the other tube distortional modes. The test results shown an improvement in average load carrying capability from 71.5 percent of the analytical failure load for the first specimen to 93.7 percent for the third specimen.

The test results from specimien $2 \mathrm{~A}-2-\mathrm{P}-3 \mathrm{M}$ are compared graphically with the modified theory in Figure 75. In some test load conditions shown in the figure, two different modes of fallure are indicated by the F/S test data. Where this occurs both test data points are shown on the figure. Failure modes are identified for all test data points so that they can be compared with the failure loads predicted by the modified theory.

The F/S data for bead web crippling of panel 2A-2-P-3M agree reasonably well with the failure surface predicted by modified theory for most test load conditions. However, the actual failure of the panel by bead web crippling in pure axial compression (load condition 1) occurred at only 69 percent of the load predicted by the modified theory. This can be explained by the fact that F/S plots for local buckling are extrapolated to a limiting strain line (see reference 8 ). The limiting strain line is determined from the local buckling analysis as substantiated by local buckling test results. Therefore, F/S indications of panel local buckling behavior are valid only if the local buckling specimen behavior is identical to the panel local buckling behavior. This is apparently not true in the case of the fluted tubular configurations. Complex distortional modes, which are prevented from occurring in the local buckling specimens by their short length and by the stabilizing effect of the potted ends, are only partially restrained by the tube stabilizer inserts in the full size panels. Therefore, the correlations indicated in Figure 75 between F/S test data and the modified bead web crippling theory is probably not reliable and actual panel failures at substantially smaller load levels inight be expected in some load conditions if panels were tested to destruction.

The F/S indications of flat buckling in Figure 75 are premature compared to the modified flat buckling theory. This fact indicates that stresses in the flats are higher than they should be according to the panel stress analysis. lhis phenomenon is apparently due to inadequate load transfer from the pane1 ands into the tubes, which in turn can be attributed to: (1) transition sections at the panel ends are too short, and (2) the distortional flexibility of the fluted tube cross section apparently prevents the tubes from carrying their allotted portion of the panel loads. Because of this distortional 


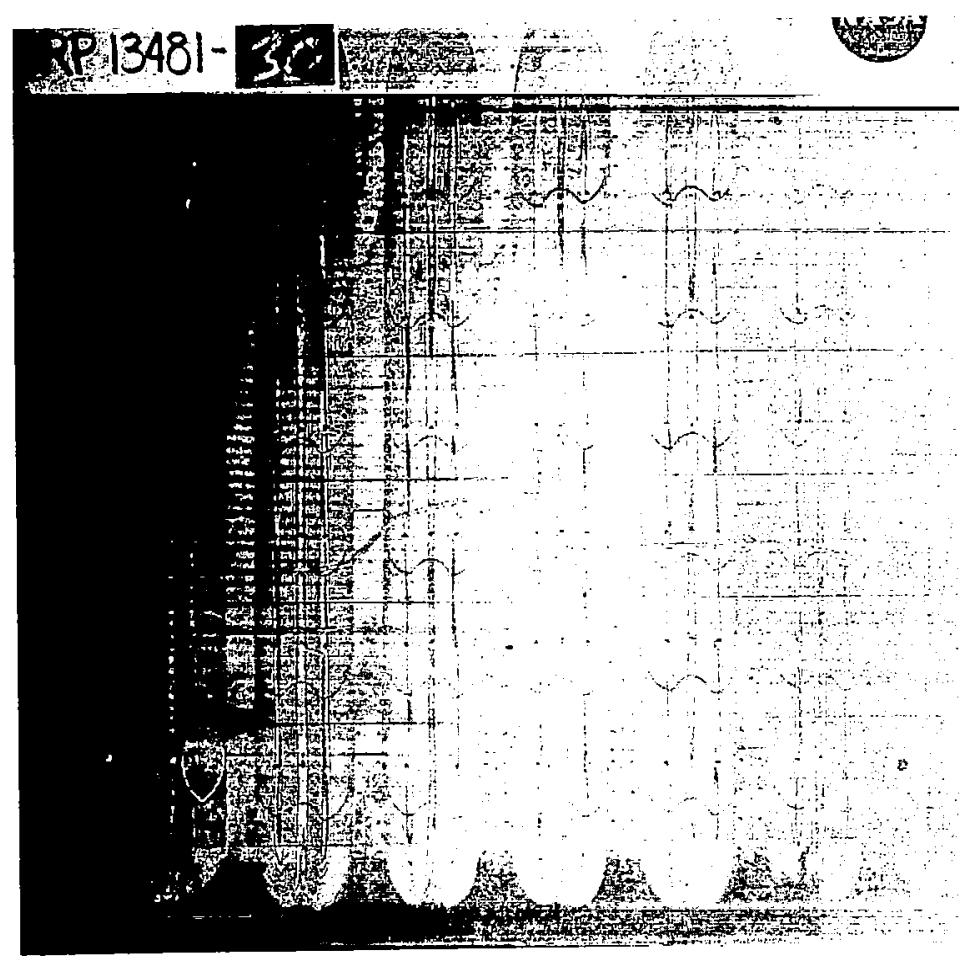

Figure 73: PANEL 2A-2-P-2MAT 88\% $N_{X Y}$

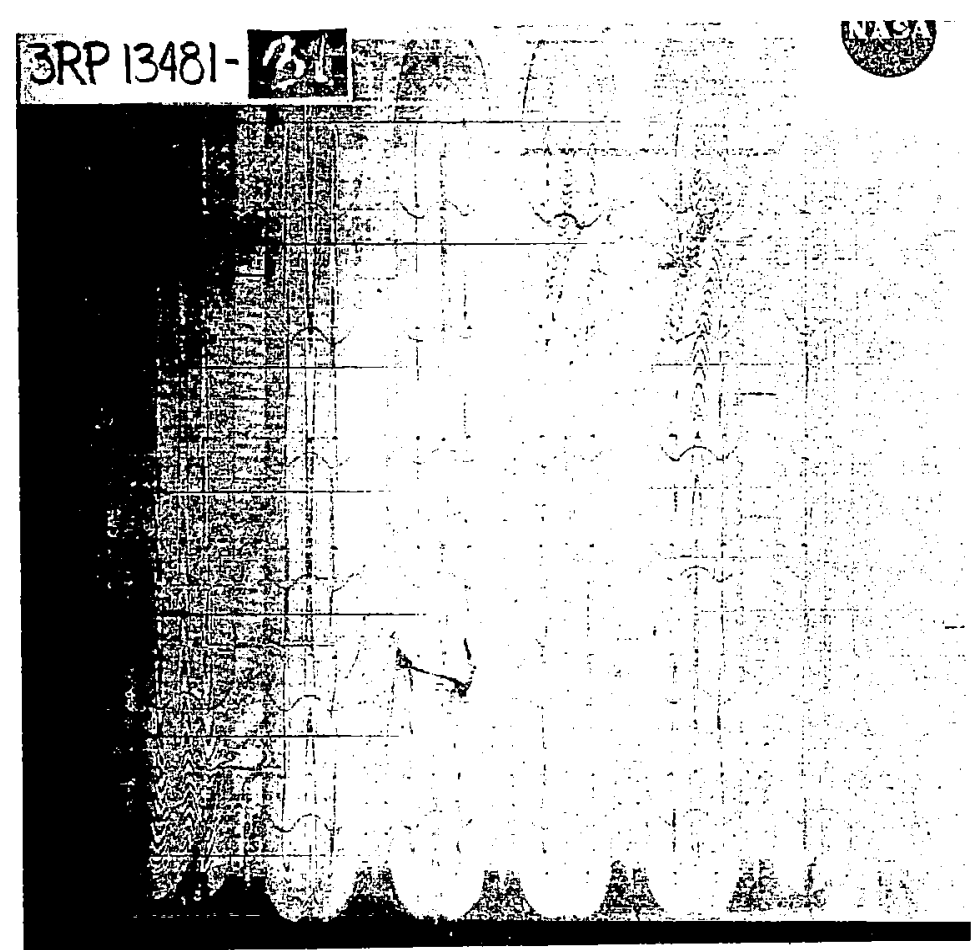

Figure 74: PANEL 2A-2-P-2M FAILED AT 92\% $N_{X Y}$ 


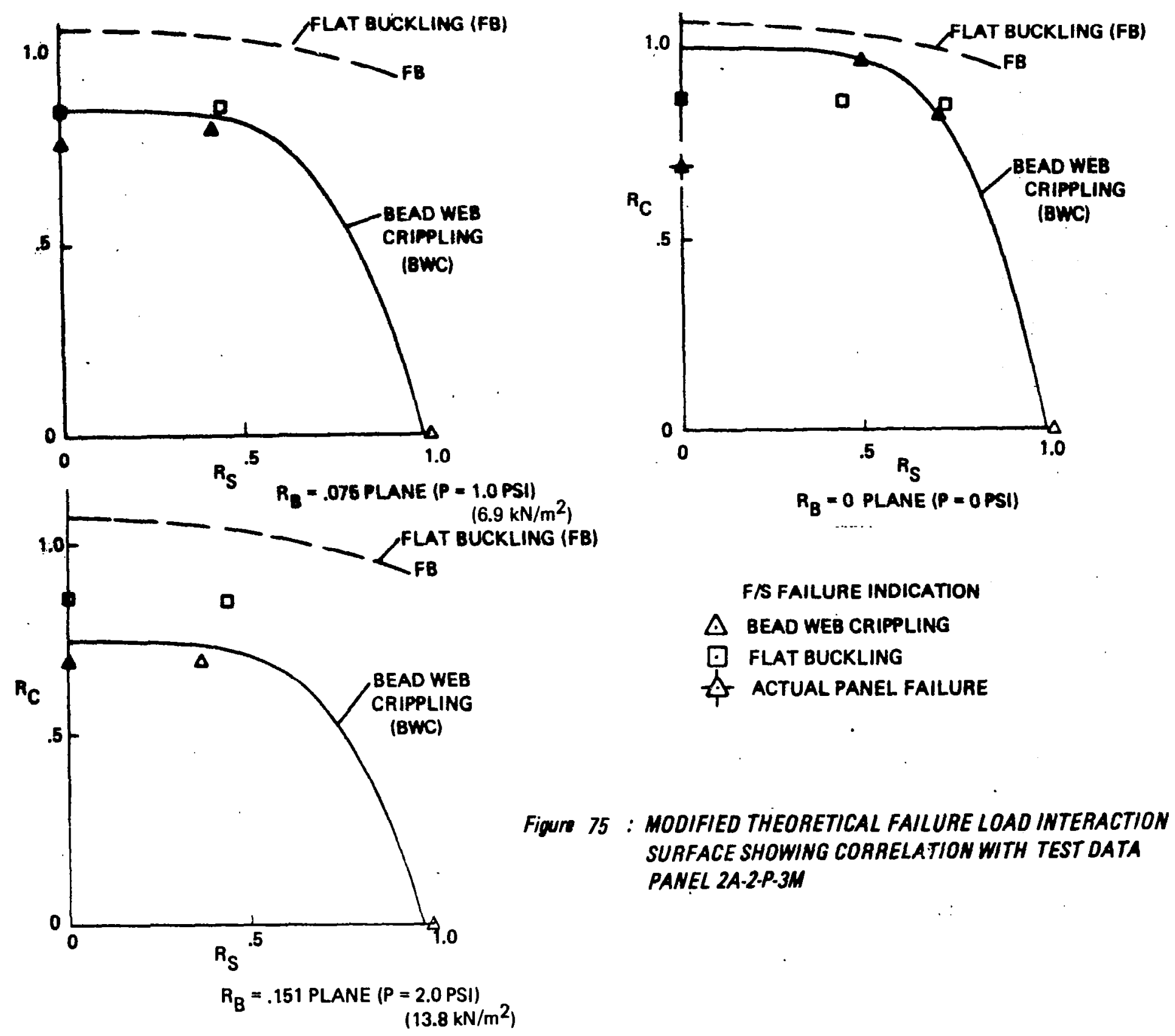


flexibility, adequate correlation cannot be obtained by simple modification of the flat buckling coefficient.

Summary of results for high load fluted tubular specimen. - The use of internal stiffening to prevent large deformations appeared to control tube flattening and raised panel strengths significantly, but at a loss in mass efficiency. However, large deformations which were not completely suppressed by the internal stiffening prevented reliable correlation of test data with theory and resulted in failure of the fluted tubular concept to achieve the high efficiency originally predicted. 


\section{FAILURE CRITERIA AND DESIGN DATA}

The static strength equations used in the initial strength analysis of the various beaded and tubular panel designs are basically those ayailable from the literature. They are expressed in general form In the Appendix, and the detailed equations are presented in Reference 9. The modifications necessary to provide the final analysis and correlations shown in the previous section are given herein and in Reference 9.

Curves to support the design of minimum mass circular tube panels of 7075-T6 aluminum were generated as described in Reference 9 and are presented in Figure 76. The curves in Figure 76 were generated from the modified equations to produce optimum designs for the specific flat width ratio, material, and the two loading ratios indicated. It would be necessary to develop other curves, of a similar nature, to support the optimum design of panels for other flat width ratio, materials, or loading ratios.

Approximate solutions in the elastic range for designs with other materials but the same loading ratios can be obtained by multiplying the indicated $\mathrm{Nx}$ scale by $\mathrm{E} / \mathrm{E}_{\mathrm{A}}$ where $\mathrm{E}_{\mathrm{A}}$ is the indicated modulus of aluminum. Beyond the elastic range the conversion becomes much more complex and requires the use of the reduced modulus terms described in Reference 9. 


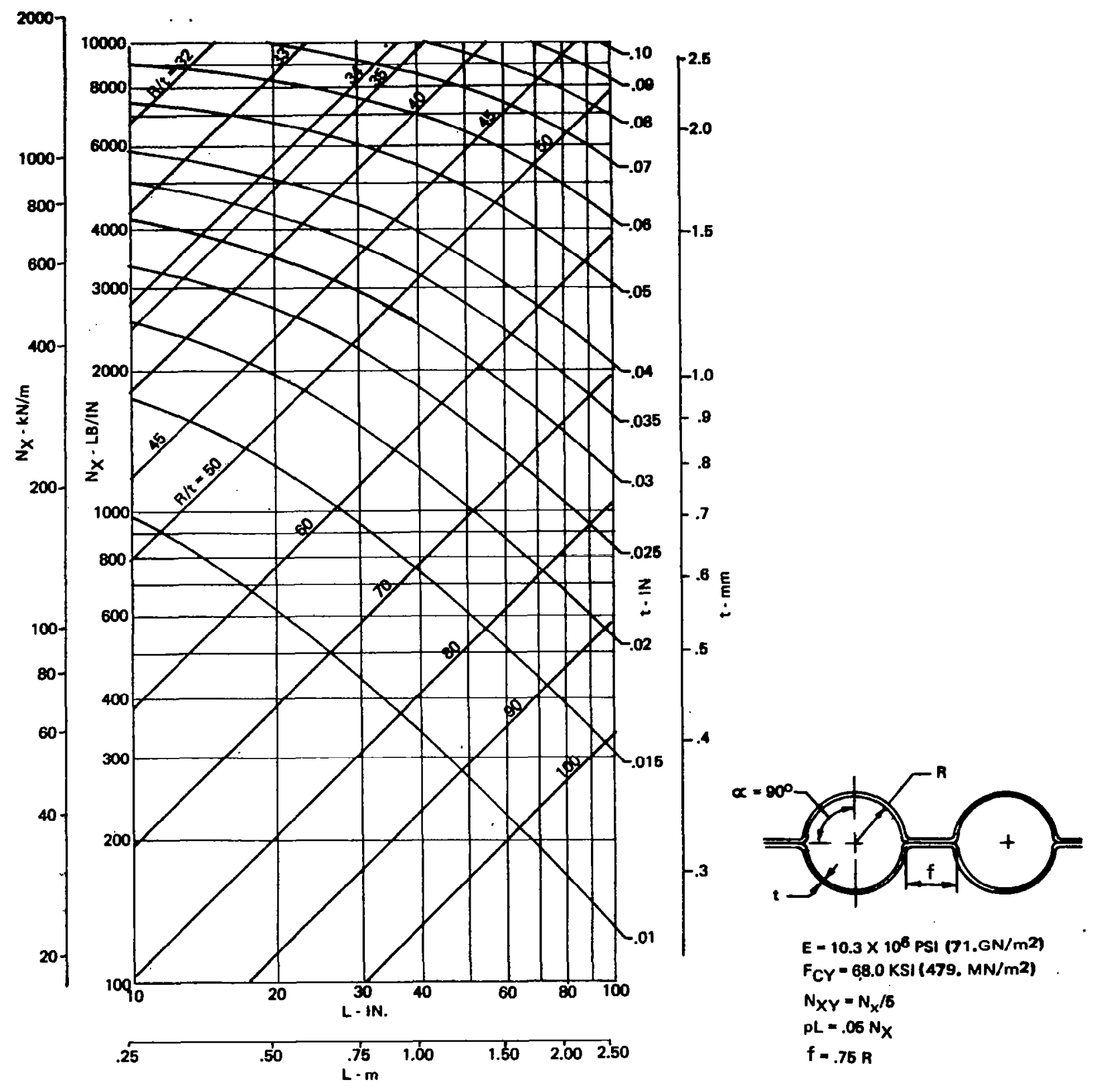

Figure 76: CIRCULAR TUBE PANEL OPTIMUM DESIGN CURVES 


\section{CONCLUDING REMARKS}

A study was conducted to exploit the efficiency of curved elements in the design of structural panels. Beaded and tubular panel concepts studied herein offer more efficiency than conventional stiffened sheet construction and appear to be compatible with efficient fabrication methods. The brake forming technique developed under this program permits much greater freedom of configuration selection and better thickness and geometry control than is available with conventional stretch forming. This method permits fabrication of more efficient designs and appears to offer a potential for significant fabrication cost reductions compared to the costs for stretch forming beaded panels.

The combined load test fixture produced relatively uniformly distributed loads in the test panels. Although complex failure modes were encountered, the Moire' grid monitoring technique permitted identification of the various modes in sufficient detail to support the mathematical modeling. The Force/Stiffness nondestructive test technique was used very successfully in obtaining a large amount of test data for various load combinations from a limited number of test pane1s.

Test data produced under combined loading on local buckling specimens and on large panels of the circular tube configuration show excellent agreement with theory and show 25 to 30 percent mass reduction over optimized stringerstiffened panels. The consistent structural performance of the circular tube panel has indicated a level of confidence which warrants the use of this concept in the design load range investigated.

The fluted single sheet beaded panel concept offers a highly efficient design in the very low load range although significant out of plane deflections occur in the end closures when the panel is loaded in shear. It appears that these out of plane deflections can be avoided by an attachment method which does not reduce the panel cross section shape to a flat sheet at the panel ends. Nevertheless, it appears that achievement of the potential advantages of the fluted single sheet configuration requires further analytical effort to derive an analysis modification which would be suitable for design.

Tests of the fluted tube panels, revealed unanticipated tube flattening under bending load and tube distortions under shear load. The tests demonstrated lower panel strengths than those predicted from local buckling tests. The use of internal stiffening appeared to control tube flattening and raised panel strengths significantly, but at a loss in mass efficiency. However, large deformations which were not completely suppressed prevented reliable correlation of test data with theory and resulted in failure of the fluted tube concept to achieve the predicted superiority to the circular tube concept in the load range investigated.

Kecause of the potential mass savings demonstrated in this program, application of the tubular panel concept should result in increased structural efficiency in many types of future aerospace structures such as advanced space vehicles, ifisslle interstages, and high speed cruise vehicles. 


\section{APPENDIX \\ STATIC STRENGTH EQUATIONS}

1. Critical Failure Loads and Stresses

\subsection{Compression}

1.1.1 panel wide column Euler buckling:

$$
\mathrm{N}_{\mathrm{xcr}}=\pi^{2} \mathrm{D}_{1} / \mathrm{L}^{2}
$$

1.1.2 bead crippling, axial compression and bending:

(Reference 13, pp. 4-7)

$$
\begin{aligned}
& F_{c c}=0.82 \mathrm{E}(\mathrm{t} / \mathrm{R})^{1.19} \quad \begin{array}{c}
\text { (See modified theory in TEST RESULTS } \\
\text { section, } p \cdot 46 .)
\end{array} \\
& \mathrm{F}_{\mathrm{cb}}=0.77 \mathrm{E}(\mathrm{t} / \mathrm{R})^{1.15}
\end{aligned}
$$

1.1.3 buckling of flats: (Reference 12, pp. 353)

$$
F_{f c}=\pi^{2} E t^{2} /\left[3 f^{2}\left(1-\nu^{2}\right)\right]
$$

where $f$ is the flat width

1.1.4 diagonal buckling of single sheet configurations:

(Reference 12, pp. 404)

$$
\begin{aligned}
& \mathrm{N}_{\text {xder }}^{\prime}=\left(2 \pi^{2} / \mathrm{d}^{2}\right)\left(\sqrt{\mathrm{D}_{1}^{\prime} \mathrm{D}_{2}^{\prime}}+\mathrm{D}_{3}^{\prime}\right) \\
& \mathrm{N}_{\text {xdcr }}=\mathrm{N}_{\text {xder }}^{\prime}\left(\mathrm{ds} / \mathrm{bs}_{\mathrm{d}}\right)
\end{aligned}
$$

where $s$ and $s d$ are developed lengths of the cross section over widths $b$ and $d$, respectively, and $\theta$ is selected to give the minimum value of $\mathrm{N}_{\mathrm{xdcr}}$ from the range

$$
0 \leq \theta \leq \alpha / 2
$$

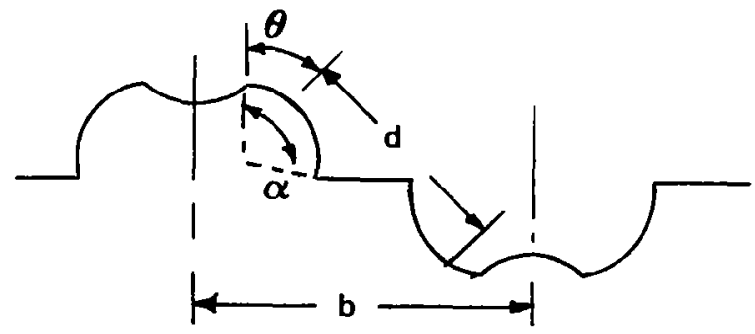




\subsection{Shear}

1.2.1 general instability:

(Reference 12, p. 407)

$$
\mathrm{N}_{\text {xycr }}=\left(4 \mathrm{k} / \mathrm{L}^{2}\right)\left(\mathrm{D}_{2} \mathrm{D}_{1}^{3}\right)^{\frac{1}{4}}
$$

where $k$ is a function of

$$
\begin{aligned}
& \beta=(\mathrm{L} / \mathrm{B})\left(\mathrm{D}_{2} / \mathrm{D}_{1}\right)^{\frac{1}{4}} \\
& 1 / \theta=\mathrm{D}_{3} /\left(\mathrm{D}_{1} \mathrm{D}_{2}\right)^{\frac{1}{2}}
\end{aligned}
$$

1.2.2 bead crippling: (Reference 14)

$$
F_{c s}=G k_{s}\left(t / S_{c}\right)^{2}
$$

where:

$$
\begin{aligned}
& \mathrm{k}_{\mathrm{s}}=4 \mathrm{z}^{.514}\left(\mathrm{Z}>10, \mathrm{~L} / \mathrm{s}_{\mathrm{c}} \geq 10\right) \quad \begin{array}{l}
\text { (See modified theory in TEST } \\
\text { RESULTS Section, } \mathrm{p} \cdot 46 .)
\end{array} \\
& \mathrm{z}=\left(\mathrm{s}_{\mathrm{c}}{ }^{2} / \mathrm{Rt}\right)\left(1-v^{2}\right)^{\frac{1}{2}} \\
& \mathrm{~s}_{\mathrm{c}} \text { is the length of the circular arc }
\end{aligned}
$$

1.2.3 shear buckling of flats: (Reference 12, p. 383)

$$
F_{f s}=5.35 \pi^{2} E t^{2} /\left[12 f^{2}\left(1-\nu^{2}\right)\right]
$$

1.2.4 diagonal buckling of single sheet configurations: (Reference 12, p. 407; sketch 1.1.4)

$$
\mathrm{N}_{\mathrm{xydcr}}=\left(4 \mathrm{k} / \mathrm{d}^{2}\right)\left[\mathrm{D}_{1}^{-}\left(\mathrm{D}_{2}^{\prime}\right)^{3}\right]^{\frac{1}{4}}
$$

where $k$ is a function of

$$
\begin{aligned}
& B=(\mathrm{d} / \mathrm{L})\left(\mathrm{D}_{1}^{-} / \mathrm{D}_{2}^{\prime}\right)^{\frac{1}{4}} \\
& 1 / \theta=\mathrm{D}_{3}^{\prime} /\left(\mathrm{D}_{1}^{-} \mathrm{D}_{2}^{-}\right)^{\frac{1}{2}}
\end{aligned}
$$


2. Stresses in Bead and Flat

\subsection{Axial Compression}

$$
f_{c}=N_{x} / \bar{t}
$$

\subsection{Bending}

$$
\text { f } \begin{aligned}
f_{\mathrm{b}}=\mathrm{M}_{\mathrm{x}} & \operatorname{cE} / \mathrm{D}_{1} \\
\text { where: } \mathrm{M}_{\mathrm{x}} & =\mathrm{pL}^{2} / 8+\mathrm{N}_{\mathrm{x}} \mathrm{y}_{\mathrm{o}} /\left(1-\mathrm{N}_{\mathrm{x}} / \mathrm{N}_{\mathrm{xcr}}\right) \\
\mathrm{y}_{\mathrm{o}} & =5 \mathrm{pL}^{4} / 384 \mathrm{D}_{1}+.001 \mathrm{~L}
\end{aligned}
$$

\subsection{Shear}

2.3.1 single sheet configurations:

$$
f_{s}=N_{x y} / t
$$

2.3.2 double sheet configurations:

$$
f_{s}=N_{x y} / 2 t
$$

2.3.3 maximum shear stress in flat due to bending (single sheet configurations only):

$$
\mathrm{f}_{\mathrm{s}_{\mathrm{flat}}}=\mathrm{f}_{\mathrm{s}}+\pi \mathrm{M}_{\mathrm{x}}^{\mathrm{EQ} / 2 \mathrm{D}_{1} \mathrm{Lt}}
$$

where $Q$ is the statical moment of one bead about the panel midplane axis.

\subsection{Stress Intensity (Reference 15)}

for determining material yield and plasticity correction factors:

$$
f_{i_{\max }}=\left[\left(f_{c}+f_{b}\right)^{2}+3 f_{s}^{2}\right]^{1 / 2}
$$


3. Failure Mode Constraint Equations

3.1 Material Yield

$$
\mathrm{f}_{\mathrm{i}_{\text {max }}} \leq \mathrm{F}_{\text {cy }}
$$

3.2 Bead Crippling

$$
f_{c} / F_{c c}+f_{b} / F_{c b}+\left(f_{s} / F_{c s}\right)^{2} \leq 1
$$

\subsection{Flat Buckling}

$$
f_{c} / F_{f c}+\left(f_{s_{f l a t}} / F_{f s}\right)^{2} \leq 1
$$

3.4 Diagonal Buckling

(single sheet configurations only):

$$
\mathrm{N}_{\mathrm{x}} / \mathrm{N}_{\mathrm{xdcr}}+\left(\mathrm{N}_{\mathrm{xy}} / \mathrm{N}_{\mathrm{xydcr}}\right)^{2} \leq 1
$$

\subsection{General Instability}

$$
N_{x} / N_{x c r}+\left(N_{x y} / N_{x y c r}\right)^{2} \leq 1
$$


(1) Shideler, John L,; and Jackson, L. Robert,: Fuselage and Tank Structures for Hypersonic Aircraft. Conference on Hypersonic Aircraft Technology, Ames Research Center, Moffett Field, CA, NASA SP-148, May 1967.

(2) Anderson, Melvin S.; Robinson, James C.; and Klich, George F.: Analysis of Wing Structures for Hypersonic Aircraft. Conference on Hypersonic Aircraft Technology, Ames Research Center, Moffett Field, CA, NASA SP-148, May 1967.

(3) Plank, P. P.; Sakata, I. F.; Davis, G. W.; and Richie, C. C.: Hypersonic Cruise Vehicle Wing Structure Evaluation. NASA CR-1568, May 1970.

(4) Card, M. F.; Davis, J. G.; and Shideler, J. L.: Advanced Design Concepts for Shuttle Airframe Structures. NASA Space Shuttle Technology Conference, San Antonio, TX, April 12-14, 1972, NASA TM X-2570, July 1972.

(5) Shideler, John L.; Anderson, Melvin S.; and Jackson, L. Robert: Optimum Mass-Strength Analysis for Orthotropic Ring-Stiffened Cylinders under Axis Compression. NASA TN D-6772, July 1972.

(6) Musgrove, M. D.; Greene, B. E.; Shideler, J. L.; and Bohon, H. L.: Advanced Beaded and Tubular Structural Panels. J. of Aircraft, Vol. 11 No. 2, February 1974.

(7) Laakso, John R.: Design Synthesis of a Boron/Epoxy Reinforced Meta1 Shear Web. AIAA/ASME/SAE 13th Structures, Structural Dynamics, and Material Conference, San Antonio, TX, April 10-12, 1972.

(8) Jones, Robert E.; and Greene, Bruce E.: The Force/Stiffness Technique for Nondestructive Buckling Testing. AIAA/ASME/SAE 15th Structures, Structura1 Dynamics, and Materials Conference, Las Vegas, Nevada, Apri1 17-19, 1974 .

(9) Greene, Bruce E.: Design and Analysis of Advanced Beaded and Tubular Structura1 Panels. NASA CR-132460.

(10) Musgrove, Max D.; and Northrop, Russel: Fabrication of Advanced Beaded and Tubular Structural Panels. NASA CR-132482.

(11) Hedges, Philip C.; and Greene, Bruce E.: Testing of Advanced Beaded and Tubular Structural Panels. NASA CR-132515.

(12) Musgrove, Max D.; and Mortensen, Robert E.: Development of Titanium Structural Element Allowables for the Boeing SST. AIAA/ASME 11th Structures, Structural Dynamics and Materials Conference, April 22-24, 1970, Denver, Colorado. 


\section{REFERENCES (Continued)}

(13) Timoshenko, S. P.; and Gere, J. M.: Theory of Elastic Stability. Second Edition, McGraw-Hill Book Co., Inc., 1961.

(14) Buckling of Thin-Walled Circular Cylinders. NASA SP-8007, September 1965, Revised August, 1968.

(15) Gerard, G.; and H. Becker: Handbook of Structural Stability, Part IIIBuckling of Curved Plates and She11s. NASA TN-3783, 1957.

(16) Nadai, A.: Theory of Flow and Fracture of Solids. Vol. I, Second Edition, McGraw-Hil1 Book Co., Inc., 1950.

(17) Dykes, B. C.: Analysis of Displacements in Large Plates by the GridShadow Moire' Technique. Fourth International Conference on Stress Analysis, April, 1970, Cambridge, England.

(18) Me11o, Raymond M.; Sherrer, Kobert E.; and Musgrove, Max D.: Intermediate Diagonal Tension Field Shear Beam Development for the Boeing SST. AIAA/ ASME 12th Structures, Structural Dynamics and Materials Conference, April 19-21, 1971, Anaheim, California. 